\title{
Assessment of Factors Affecting Boiler Tube Lifetime in Waste- Fired Steam Generators: New Opportunities for Research and Technology Development
}

Ian Wright

H.H. Krause

Battelle

Columbus, Ohio

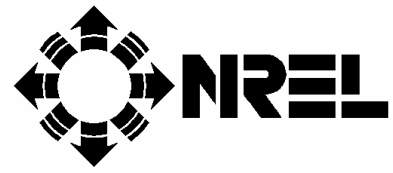

National Renewable Energy Laboratory 1617 Cole Boulevard Golden, Colorado 80401-3393

A national laboratory of the U.S. Department of Energy Managed by Midwest Research Institute for the U.S. Department of Energy under contract No. DE-AC36-83CH10093 


\section{Assessment of Factors Affecting Boiler Tube Lifetime in Waste- Fired Steam Generators: New Opportunities for Research and Technology Development}

Ian Wright

H.H. Krause

Battelle

Columbus, Ohio

NREL Technical Monitor:

Phil Shepherd

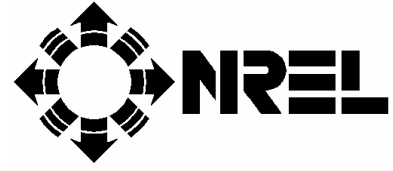

National Renewable Energy Laboratory 1617 Cole Boulevard Golden, Colorado 80401-3393

A national laboratory of the U.S. Department of Energy Managed by Midwest Research Institute for the U.S. Department of Energy under contract No. DE-AC36-83CH10093

Prepared under Subcontract No. AD-2-11143-1

July 1996 
This publicution was reproduced from the best available camera-ready copy submitted by the subcontractor and received no editorial review at NREL.

\section{NOTICE}

This report was prepared as an account of work sponsored by an agency of the United States government. Neither the United States govemment nor any agency thereof, nor any of their employees, makes any warranty, express or implied, or assumes any legal liability or responsibility for the accuracy, completeness, or usefulness of any information, apparatus, product, or process disclosed, or represents that its use would not infringe privately owned rights. Reference herein to any specific commercial product, process, or service by trade name, trademark, manufacturer, or otherwise does not necessarily constitute or imply its endorsement, recommendation, or favoring by the United States govemment or any agency thereof. The views and opinions of authors expressed herein do not necessarily state or reflect those of the United States government or any agency thereof.

Available to DOE and DOE contractors from:

Office of Scientific and Technical Information (OSTI)

P.O. Box 62

Oak Ridge, TN 37831

Prices available by calling (423) 576-8401

Available to the public from:

National Technical Information Service (NTIS)

U.S. Department of Commerce

5285 Port Royal Road

Springfield, VA 22161

(703) 487-4650 


\title{
Final Report
}

\author{
on \\ Assessment of Factors Affecting Boiler Tube Lifetime \\ in Waste-Fired Steam Generators: \\ New Opportunities for Research and \\ Technology Development
}

to

ASME

April 1994

by

Ian G. Wright \& H. H. Krause

Battelle 505 King Avenue

Columbus, Ohio 43201 
This report is a work prepared for the United States Government by Battelle. In no event shall either the United States Government or Battelle have any responsibility or liability for any consequences of any use, misuse, inability to use, or reliance upon the information contained herein, nor does either warrant or otherwise represent in any way the accuracy, adequacy, efficacy, or applicability of the contents hereof. 


\section{Contents}

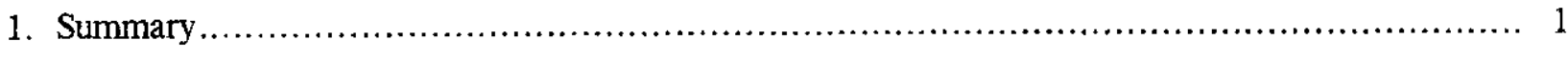

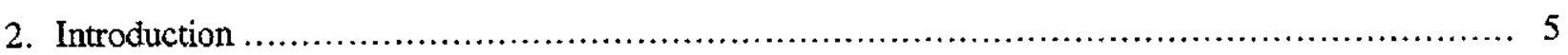

3. Sources of Information and Methodology Used ............................................ 9

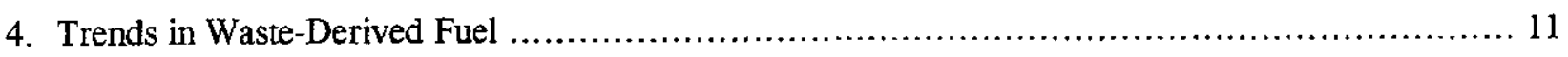

5. Summary of Current Understanding of the Causes

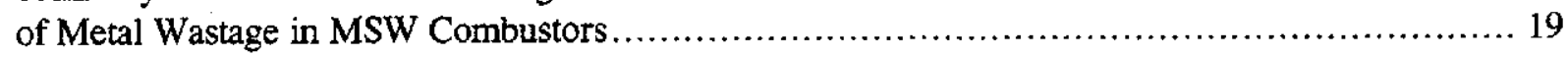

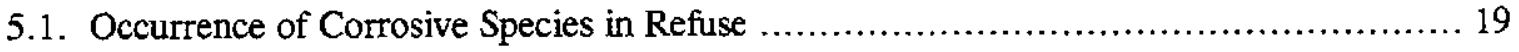

5.2. Behavior of Corrosive Species During Combustion................................. 20

5.3 Mechanisms of Corrosion ............................................................. 26

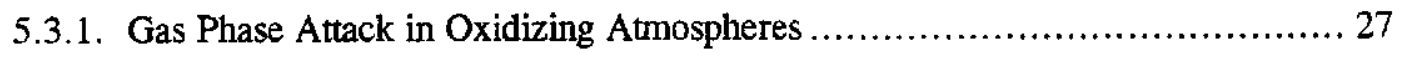

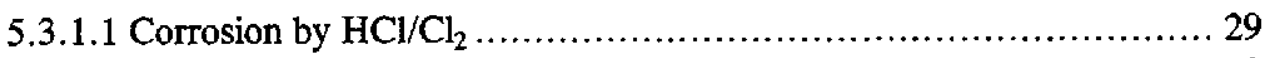

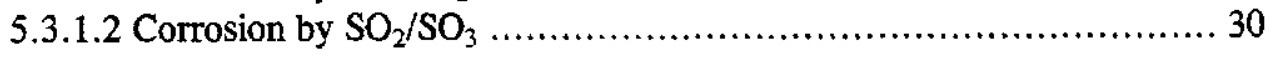

5.3.2. Gas Phase Attack in Reducing Atmospheres............................... 32

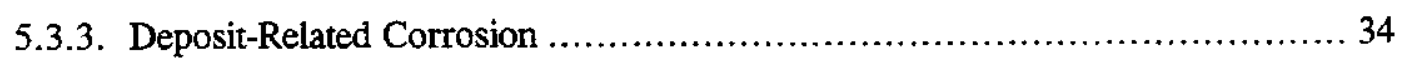

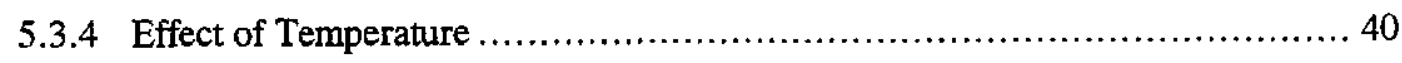

5.3.5. Condensed Acid Attack ................................................ 41

5.4. Overall Summary of Understanding of Factors Affecting Tube Life ................... 43

6. Overview of Metal Wastage Experienced in Waste-Fired Steam Generators ....................... 46

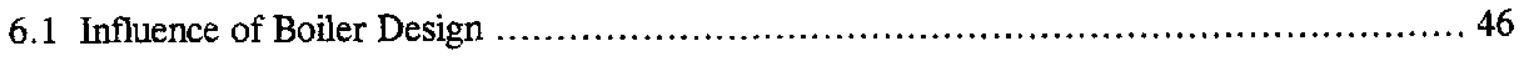

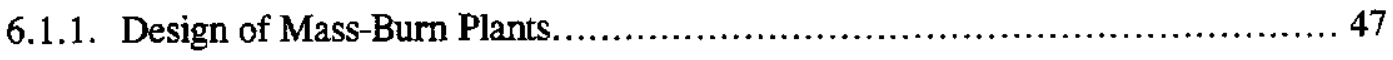

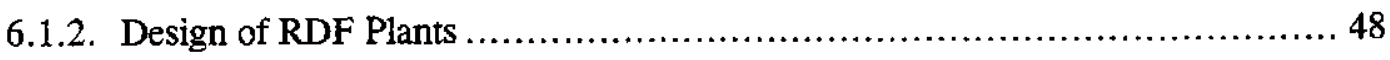

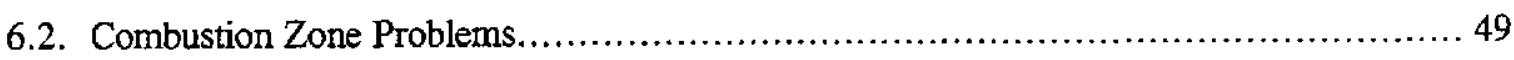

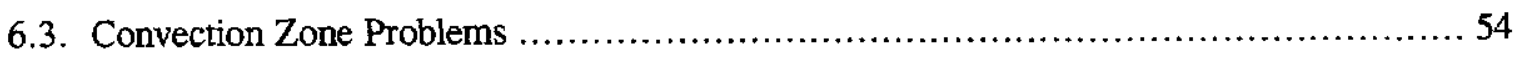

6.4. Summary of Main Categories of Boiler Tube Problems ............................... 57

6.5. Best Available Fixes for Types of Boiler Tube Problems Encountered ...................6 60

6.6. Summary of Causes of Metal Wastage and Remedial Measures Practiced .................. 63 


\section{Contents \\ (continued)}

7. Economic Impact of Boiler Tube Problems in Waste-Fired Boilers .............................6 66

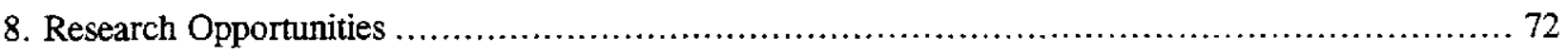

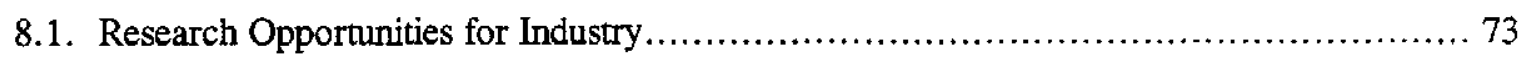

8.1.1 Improved Documentation............................................. 73

8.1.2 Control of the Combustion Process.......................................... 74

8.1.3 Definition of Conditions at Tube Surfaces ................................... 75

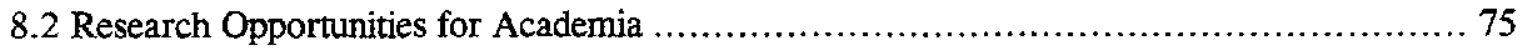

8.2.1 Definition of the Corrosive Environment..................................... 76

8.2.2. Alloy Development ........................................................ 76

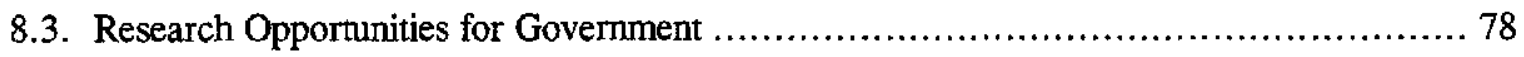

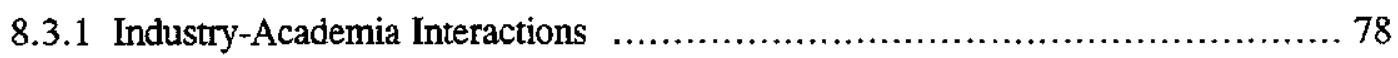

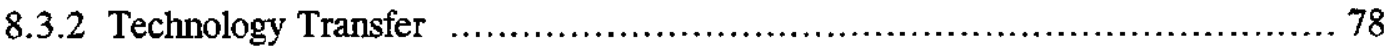

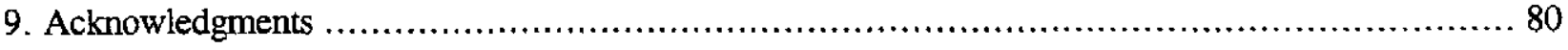

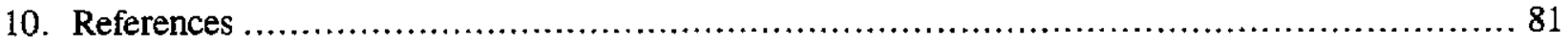

Appendix A. Questionnaire Used in Assembling Information for Individual

Waste-to-Energy Units and Summary of Data Obtained ............................A A-1

Appendix B. Listing of Waste-to-Energy Units in Operation and Planned in the United States.................................................... 


\section{Summary}

This study was conducted to assess the overall significance of the major factors that affect boiler tube lifetime-corrosion and erosion problems—in waste-fired steam generators, and to identify the research needs and technology development opportunities that could have the greatest impact on the metal wastage problem. The study was conducted by compiling data for specific facilities from the open literature and from available reports, which were then supplemented by soliciting information on operating experience and corrosion/erosion problems encountered from owners, operators, and manufacturers. In addition, the state of understanding of the applicable mechanisms of corrosion in waste-fired boilers was developed from the literature, and from expert experience.

A major difficulty was encountered in the data collection activity because the major manufacturers, owners, and operators consider fireside problems to be part of the competitive edge in this business and, as a result, specific and general information on the type, location, frequency, and cost of corrosion tends to be considered proprietary. Smaller organizations do not always have useful records, since they do not have the means to retain the expertise required to diagnose and develop details or to document corrosion problems and determine the root causes. The best available information indicates that the operational record of modern waste-to-energy (WTE) units is good, but that there are occasional unexpected outages, and that the major fireside problems usually are handled during scheduled outages. While there is some documentation in the open literature, it is incomplete because the basic cause of the major failure is not fully understood and the corrective actions to remedy or prevent the failure are not completely reported.

There are 92 waste-to-energy (WTE) facilities in operation in the U.S. with a capacity of 200 tons per day or greater, and 24 facilities are in the planning stages. Sixty-five percent of these new plants will be privately owned, and 35 percent will be municipality-owned; all will be privately operated. For economic reasons, there is a desire to improve plant efficiency, which will require raising the steam pressure and temperature. Seventeen new plants will be built at steam temperatures exceeding $400^{\circ} \mathrm{C}\left(750^{\circ} \mathrm{F}\right)$, which was previously considered a threshold limit for controlling corrosion. However, continued expansion will require implementation of all the design and operating improvements available, as well as a full understanding of the corrosion mechanisms, so that major corrosion problems that were experienced in the early stages of development of such plants in Europe can be avoided. 
The minimum cost of an outage to handle a manageable corrosion problem is estimated to range from $\$ 15 \mathrm{~K}$ to $\$ 19 \mathrm{~K}$ (not including the cost of materials) or $\$ 0.36$ to $\$ 0.45$ per ton of waste processed (not including the cost of materials). This cost compares with an average operating and maintenance cost of $\$ 33.58$ per ton of waste processed. Therefore, the cost of not understanding the real causes of the corrosion problems may be equivalent to at least 1.1 percent of the operating and maintenance costs.

The basic causes of reduction in boiler tube lifetime in waste combustors are well known in general terms: they are the presence of chlorine, alkali, and heavy metals in the fuel that combine to produce low-melting, highly-corrosive deposits on the tubes, and the heterogeneous nature of the fuel that makes it difficult to handle and results in hard to control combustion conditions. In practice, corrosion in WTE plants is primarily associated with the fact that the fuel is very heterogeneous, and gives rise to severe problems in maintaining the uniform combustion conditions desired in a steam boiler. The poor combustion characteristics of the fuel result in regions of incomplete combustion, which may include localized reducing conditions (high $\mathrm{CO}$ levels), high heat flux from flame impingement, and possibly the presence of aggressive species and deposits. The fuel also introduces chlorine-containing compounds, alkali metal compounds [especially sodium ( $\mathrm{Na}$ ) and potassium (K)], and heavy metals such as lead $(\mathrm{Pb})$, tin $(\mathrm{Sn})$, and zinc $(\mathrm{Zn})$, all of which may combine in the flame to form potential corrodants. Low-melting point chlorides of these metals, or mixtures of chlorides, deposited on the heat transfer surfaces remove protective oxide scale from the tube surfaces, allowing rapid dissolution into the molten salts, or rapid oxidation. Solid chloride deposits also can cause corrosion in the presence of sulfur dioxide in the combustion gas. Although sulfates form in deposits on tube surfaces, they typically have melting points above the temperatures that are encountered on the heat transfer surfaces in current WTE plants, and so are not particularly corrosive. Corrosion occurs on furnace walls at metal temperatures in excess of $232^{\circ} \mathrm{C}\left(450^{\circ} \mathrm{F}\right)$, under constant or cycling reducing conditions. These surfaces also are vulnerable to corrosion when in contact with combustion gas at temperatures in excess of $954^{\circ} \mathrm{C}\left(1750^{\circ} \mathrm{F}\right)$.

To avoid corrosion in the furnace zone, the design and operation of the combustion zone should be optimized so that combustion of the fuel is completed in the lower furnace. Significant improvements often can be gained through relocation or redirection of overfire air ports to improve turbulence and minimize gas stratification. Since the nature of the fuel precludes complete control of 
the combustion process, the lower furnace wall should be protected by silicon carbide tiles, or the tube surfaces should be protected by a $\mathrm{Ni} \mathrm{Cr}$ alloy applied as a cladding or as a weld overlay, up to a height at which the gas temperature has fallen to $954^{\circ} \mathrm{C}\left(1750^{\circ} \mathrm{F}\right)$, or less. Above this level, carbon steel tubes are expected to give satisfactory life, and sufficient surface should be available to cool the gas to $760^{\circ} \mathrm{C}\left(1400^{\circ} \mathrm{F}\right)$ or less, before it enters the convection bank.

Molten chloride deposits are not expected in the convective tube bank, but can occur in conditions where combustion is not completed in the lower furnace. Where combustion is relatively uniform and is completed before the gas exits the radiant zone, the deposits in the convective zone are expected to be predominantly silicates or sulfates with relatively high melting points. Reducing conditions need not exist in the convective zone for corrosion to occur: the convective heat transfer surfaces also are vulnerable to attack by chlorine $(\mathrm{HCl})$ present in the gas phase. The apparent role of $\mathrm{HCl}$ is to compromise the protective nature of the oxide scale by causing cracking or porosity, thereby increasing the oxidation rate. Until recently, the maximum steam temperature in WTE units was limited to $400^{\circ} \mathrm{C}\left(750^{\circ} \mathrm{F}\right)$ to control corrosion. A strategy for minimizing the potential for corrosion with higher steam temperatures is to arrange the steam flow so that the tubes carrying the highest temperature steam are exposed to the lowest temperature flue gas.

Where alloys with increased corrosion resistance are required, Alloy 625 and Alloy 825 appear to offer the best high-temperature service life for furnace wall and superheat applications, respectively.

The convective heat transfer surfaces could be cleaned by mechanical rapping to prevent fouling which has the claimed advantage over soot blowing that it removes only deposits and not protective oxide scale, and does not cause localized erosion. The tubes should be vertically oriented to facilitate removal of deposits, and the tube bundle configuration should be sufficiently robust to allow high-intensity rapping. For modern WTE plant designs which incorporate the features described, experience with convection sections producing steam at 443 to $454^{\circ} \mathrm{C}\left(830\right.$ to $\left.850^{\circ} \mathrm{F}\right)$ is satisfactory.

There is a need to verify and apply the available knowledge of fundamental corrosion mechanisms to operating plants. There also is a need to accurately document and diagnose boiler tube failures to be certain of their origin (fuel, operation, or design), to be certain that proper measures are taken to correct them, and to ensure that they do not become misleading evidence for future design and operating decisions. A helpful approach in the short term should be directed to a means for in situ monitoring to detect high-temperature furnace exit temperatures (or other parameters), to avoid 
subjecting the convective pass to a corrosive environment, and to understanding the conditions that cause accelerated corrosion immediately above Si C linings and high-alloy overlays on the upper furnace wall. In addition, research is needed to identify the alloying requirements for improved corrosion resistance to the specific conditions experienced at the furnace wall and in the convection zone, which will benefit not only materials selection for current units but also indicate the requirements for higher-temperature operation. Increasing the outlet steam temperature also is the goal of a program being conducted by the New Energy Development Organization (NEDO) in Japan; that program is actively developing high alloys for use in the final stages of the superheaters. Such alloys with improved corrosion resistance could be used to increase the tube lifetimes in current boiler designs, provided they prove cost-effective. 


\section{Introduction}

The disposal of municipal solid waste (MSW) is a major problem in numerous communities in the United States. In this country, approximately 195.7 million tons of MSW were produced in 1990 (EPA, 1992), of which 17 percent was recovered for recycling or composting, 16 percent was combusted, and about 67 percent was disposed of in landfills. In major urban areas, space may either be no longer available or the cost of land is rapidly increasing. Nevertheless, in some parts of the country modern landfill permits are being awarded, so that landfills continue to be an available option for the foreseable future.

Landfill design and construction emphasizes containment of the wastes to protect public health and many improvements have come about in recent years. A modern landfill is well lined to contain liquid. Liquid that may be contained is frequently pumped out and treated for safe disposal. Methane gas created in the landfill is also frequently collected by a system of wells. The gas may be burned in air using a torch-like device called a flare. More than 212 landfills use the collected gas to generate energy. The energy is usually electricity generated and used on-site. Some landfill gas is cleaned to make pipe line quality gas.

Combustion of waste can reduce the volume of material requiring disposal by about 90 percent. In addition, combustion of MSW can result in the generation of significant amounts of energy; the net generation capacity of all currently operating plants in the U. S. is 2,962 MWe (Berenyi and Gould, 1993). Reduction in availability of local landfill sites may increasingly focus attention on alternative means for MSW disposal, so that there is potential for the capacity for combustion of MSW in the U. S. to grow in the future. Nevertheless, decisions concerning the disposal of MSW by landfill or by combustion will be based on the relative costs of the available options, which will involve the haulage, tipping, maintenance, and monitoring costs (possibly offset by income from gas recovery) associated with landfill use, compared with the haulage, tipping, plant maintenance, pollution control, and ash disposal costs (offset by revenue from electricity and steam sales) associated with combustion.

Waste combustion has been practiced for more than thirty years in Germany, and experience there has formed the basis for the practices adopted elsewhere. Combustion of waste in Germany 
increased rapidly from 1965 through 1987 (Reichel, 1989); in 1987 there were 47 plants burning approximately 9 million tons/year of refuse, and it was projected that in 1995, approximately 67 plants would be in operation burning about 12 million tons/year. Based on 1980 figures, about 28 percent of the refuse in Germany was burned, compared to 23 percent for the European Economic Community, 65 percent for Japan, and 10 percent for the U.S. Of these refuse combustion plants in Germany, 27.4 percent were practicing heat recovery, and that heat recovery represented 0.46 percent of the total energy consumption in Germany (Reichel, 1989).

In 1993, there were approximately 92 waste-to-energy (WTE) facilities with capacities of 200 tons/day or greater in operation in the United States, capable of processing 96,227 tons/day of municipal waste (Berenyi and Gould, 1993). The existing waste combustion facilities in the U.S. tend to be more numerous on the East Coast ( 37.4 percent of the total), where land availability is increasingly limited. However, of the 24 facilities that are in the planning stages, 44.4 percent are in the south.

The four principal types of combustor used for the combustion of MSW are categorized by the EPA as:

(1) Mass-burn systems, in which the waste is combusted without any pre-processing other than the removal of items too large to navigate the feed system. Refuse is typically placed on a grate that moves the waste through the combustor. Combustion air in excess of stoichiometric amounts is supplied both from below the grates and above the grates. Such combustors vary in size from 50 to 1000 tons per day of refuse throughput per unit, and often use multiple combustors to achieve high site capacities. The largest mass burn combustion facility in the U.S. has a capacity of 3,150 tons per day (using 3 units). The major features of a modern mass-burn unit are illustrated schematically in Figure 6.1

(2) Modular mass-burn combustors, in which the waste is usually burned without preprocessing, often in a staged-combustion process. Combustion air at sub-stoichiometric levels is supplied to a primary chamber, and the incompletely-combusted products that pass into the secondary chamber are then mixed with excess air to complete the combustion process. This mode of operation successfully minimizes both the particle and 
toxic gas emission from these units. Modular combustors are typically made in a size range from 5 to 150 tons per day of refuse throughput.

(3) Rotary, mass-burn combustors, in which unprocessed waste is combusted in a refractorylined rotary kiln, which replaces the grate. This design is intended to provide sufficient mixing and residence time to achieve complete burnout of the fuel before the flue gas leaves the kiln and passes through the heat recovery sections of the boiler. The capacity of these combustors is in the range 100 to 450 tons per day; the average total capacity of the 8 facilities operating in the U.S. is 871 tons per day.

(4) Refuse-derived fuel (RDF) systems, in which MSW that has been processed to various extents is burned. RDF processing typically includes some sorting and removal of components that can be recycled (such as metals, glass, paper) or which have no heating value (stones, gravel), so that the calorific value of RDF typically is 20 percent or so higher than that of unprocessed waste. In addition, the waste is shredded, and subjected to mechanical and air-classification, so that the size of the fuel fed to the boiler is smaller and more uniform than unprocessed MSW. RDF may be burned as the sole fuel, or co-fired with other fuels, such as coal. The largest RDF combustion facility in the U.S. has a capacity of 4,000 tons per day (using 3 units) The type of combustor usually employed is based on stoker-fired coal-fueled boilers; an example of the design of a modern RDF-fired boiler is illustrated in Figure 6.3 .

In 1993 , some 73 percent ( 74 facilities of capacity $>200$ tons/day) of the U.S. waste combustion capacity was mass-burn units, while RDF facilities represented 27 percent of capacity (19 facilities, including 3 fluidized-bed combustors). Of the mass burn facilities, 8 employed rotary combustors, and 12 employed modular combustors, these two types accounting for about 15 percent of the capacity of the mass burn facilities. Also, some 24 dedicated waste-firing units with capacities of greater than 200 tons per day were planned or under construction, representing about 26,673 tons/day capacity and $672 \mathrm{MWe}$ net generation capacity. 
In boilers combusting MSW or RDF, corrosion, slagging, or fouling problems can occur. Numerous incidents of corrosion and erosion-corrosion of waterwall tubes, superheater tubes, and other pressure parts have been reported. The major causes of serious high-temperature corrosion in refusefired boilers are the presence in the fuel of chlorine-containing species and metallic species capable of forming low-melting point chloride compounds. Corrosion results from either gas-phase attack by $\mathrm{HCl}$ (and $\mathrm{Cl}_{2}$ formed beneath boiler-tube deposits), or by molten salt attack by metal chlorides and their eutectic mixtures that melt at temperatures in the same ranges as those typical of the boiler metal surfaces. Corrosion by sulfur-containing species also is possible in boilers.

In contrast, furnace wall corrosion in coal-fired boilers usually involves sulfur species, and takes the form of direct gas-phase corrosion by $\mathrm{H}_{2} \mathrm{~S}$ of water walls that experience exposure to conditions of incomplete combustion, or by pyrosulfates from complex deposits. Molten salt corrosion of the superheater tubes can occur which involves complex alkaline-iron sulfates formed beneath deposits. Because the root-cause mechanisms of these various forms of attack in coal-fired boilers are reasonably well understood, a methodology for identifying, recording, and selecting permanent solutions has been devised and implemented by a number of power companies. As a result, the availability loss of the participating boilers has dropped to 1.7 percent (with the best units reporting 1.4 percent), compared to previous experience of 2.7 percent (Dooley, 1992). The two major ways in which the implementation of this methodology has been effective have been the virtual elimination of repeat failures, and an increase in the accuracy with which failure types, and causes, have been identified by maintenance engineers.

Sulfur-related corrosion also can occur in refuse-fired boilers. However, because of the high levels in refuse-derived fuels of species capable of forming low-melting point sulfates and chlorides, additional sources of corrosion not encountered in coal-fired boilers often are present in refuse-fired boilers. Factors which accelerate these corrosion processes are tube wall temperatures exceeding $350^{\circ} \mathrm{C}\left(662^{\circ} \mathrm{F}\right)$, and large quantities of vaporized chlorides reaching the tubes. Corrosion in refusefired units may also be aggravated by erosion from soot blowing, particularly when steam is used as the soot blowing medium, since erosion by liquid droplets can occur. Soot blowing can remove the existing scale and deposit, thus stripping the tube of a potential barrier to the corrosive action and exposing fresh metal to attack at higher rates. 


\section{Sources of Information and Methodology Used}

The data used in this report were compiled from a comprehensive search of the technical literature, conference proceedings, and technical reports, and from discussions with representatives of boilers manufacturers, owners, and operators of waste-fired boilers. The data collection activities were coordinated with similar activities for a project conducted for the Electric Power Research Institute (Wright, et al., 1994), which was aimed at determining the types of boiler tube failures experienced in WTE units. A questionnaire was developed to guide data collection; a copy is presented in Appendix A. Questionnaires were completed to the extent possible using data gathered from the literature or from other available sources, and then approaches were made to the operators, owners, or designers in an attempt to complete the picture. Units were targeted that had reported corrosion problems, or that were known to have experienced failures. In addition, individuals were contacted who were actively involved in committees of technical societies, such as the ASME, that had interest in all aspects of waste combustion; other sources were individuals involved in the examination of tube failures, who were identified from published articles and from prior contacts. A summary of the information obtained in this way concerning the factors affecting boiler tube lifetime in WTE boilers is shown in Table A.1.

The basic technical information gathered from all sources for all of the operating combustors in the U.S., is shown in Table B.1 in Appendix B, and lists details of the type of unit, its developer, owner, and operator, together with the equipment manufacturers, the waste capacity and steam and power production specifications. Also listed in Table B.1 are the citations in the main reference section that deal with a specific unit. Information on MSW combustors planned in the U.S. is included in Appendix B, Table B.2, to the extent that it was available.

Information that was concerned with actual operating conditions, with economic aspects of operation and, in some cases, with specific materials problems and the solutions used was considered to be proprietary by some manufacturers. In fact, no information at all was available from some manufacturers and, in those cases, we were unable to supplement the available published data. There is, at present, no centralized repository of information or expertise in the areas of interest to this 
program, so that the data collection process often involved a different approach for each organization considered. 


\section{Trends in Waste-Derived Fuel}

The amount of MSW generated in the U.S. has increased at a steady rate from approximately 90 million tons in 1960 to approximately 196 million tons in 1990, and is expected to reach 225 million tons by the year 2000 (EPA, 1992). This trend is illustrated in Figure 4.1, which also compares the amounts of MSW disposed of in landfills, by collection for recycling and composting, and by combustion.

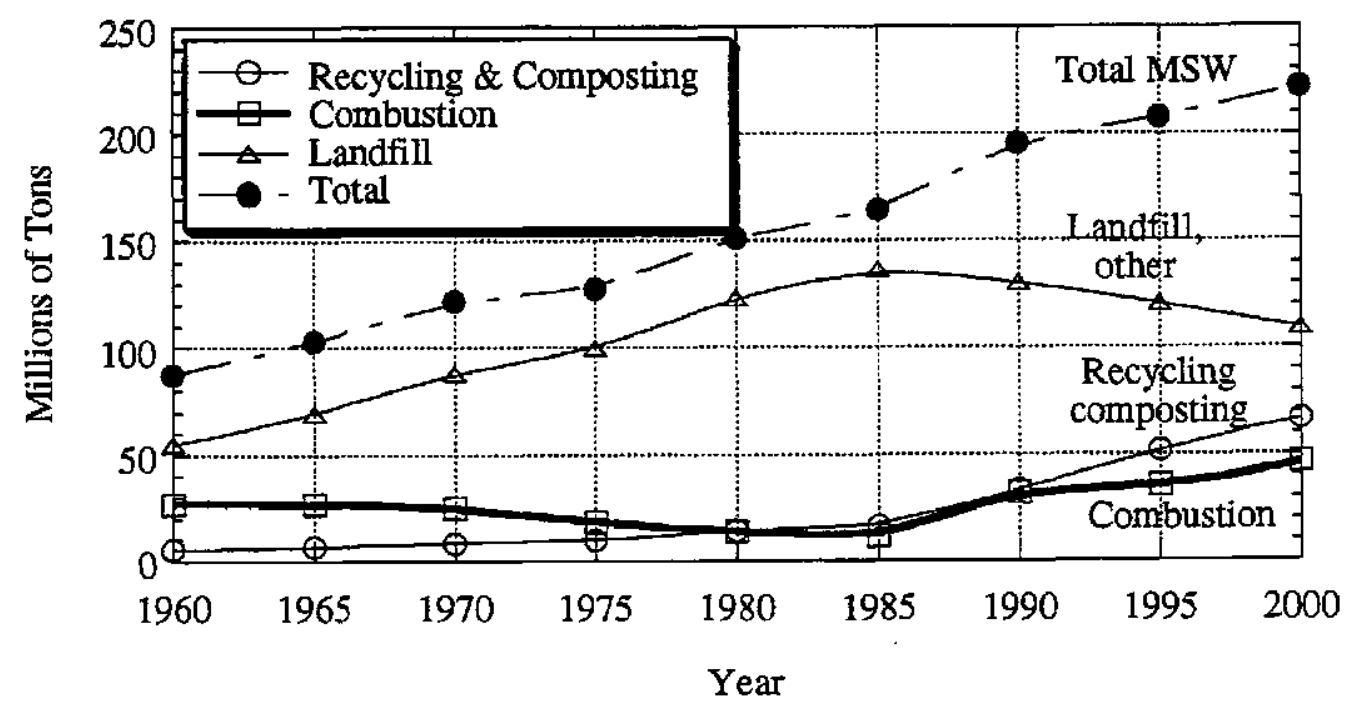

Figure 4.1 Trends in the disposal of MSW in the U.S. (EPA, 1992).

In 1960, an estimated 31 percent of the MSW in the U.S. was disposed of by combustion, mostly with no energy recovery (and no air pollution controls). In the 1960's and 1970's, combustion of MSW dropped steadily as old incinerators were shut down, reaching a minimum of 7 percent in 1985, as is shown in Figure 4.2. In recent years, the combustion of MSW has increased steadily, reaching 16 percent in 1992. All of the major new facilities are designed for energy recovery, and to meet air pollution standards. Based on surveys of new MSW combustors that are scheduled to come 
into operation in the 1990's, the U.S. Environmental Protection Agency (EPA, 1992) projected that the percentage of the MSW combusted will increase to 21 percent by the year 2000 .

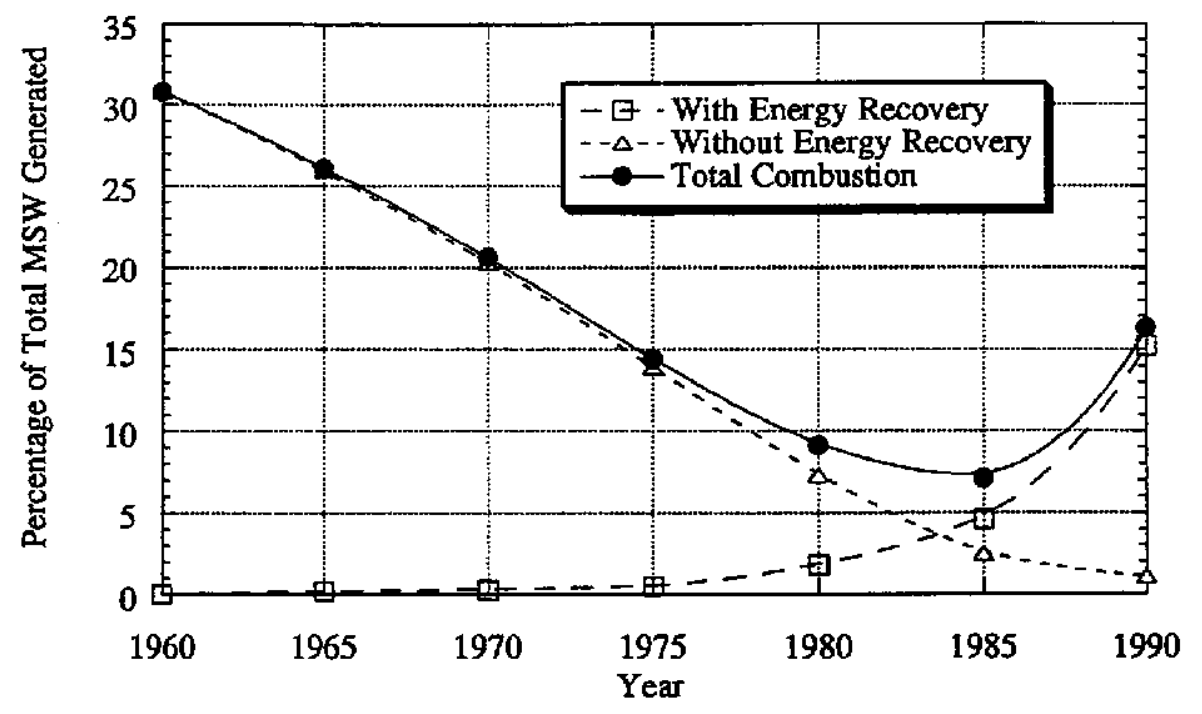

Figure 4.2 Trends in combustion of MSW in the U.S. (U.S. EPA, 1992).

The EPA also reported that, in 1990, the throughput in refuse-fired boilers over a year of operation was, on average, approximately 80 percent of rated capacity. New facilities are reporting operation at very high utilization rates, whereas older combustors do not meet the same levels of annual throughput compared to rated capacity.

The types of materials that are discarded into the U.S. MSW stream are indicated in Figure 4.3, as a function of time (Anon, 1988). These estimates were made in 1988; comparison of the data for the year 1990 from two sources indicate good agreement, except for paper products and cardboard for which the two estimates disagreed by 4.2 percent, as illustrated in Table 4.1.

Using known heat values of each constituent, an ash content of 22.4 percent and a moisture content of 25.2 percent, a calorific value for the actual $1990 \mathrm{MSW}$ of 4,860 Btu/lb was obtained (Herrmann, 1991). This is close to the value of 5,000 Btu/lb currently used for planning purposes by the major MSW combustor suppliers. On a dry basis ( 29.5 percent ash), the calorific value is 6,500 Btu/lb.

Taking the average composition shown in the right hand column in Table 4.1 (Franklin Associates, Ltd., 1988) as the baseline, the effects of removal of various proportions of the components 
under various recycling scenarios was examined. The amounts of the MSW involved in these scenarios are as shown in Table 4.2.

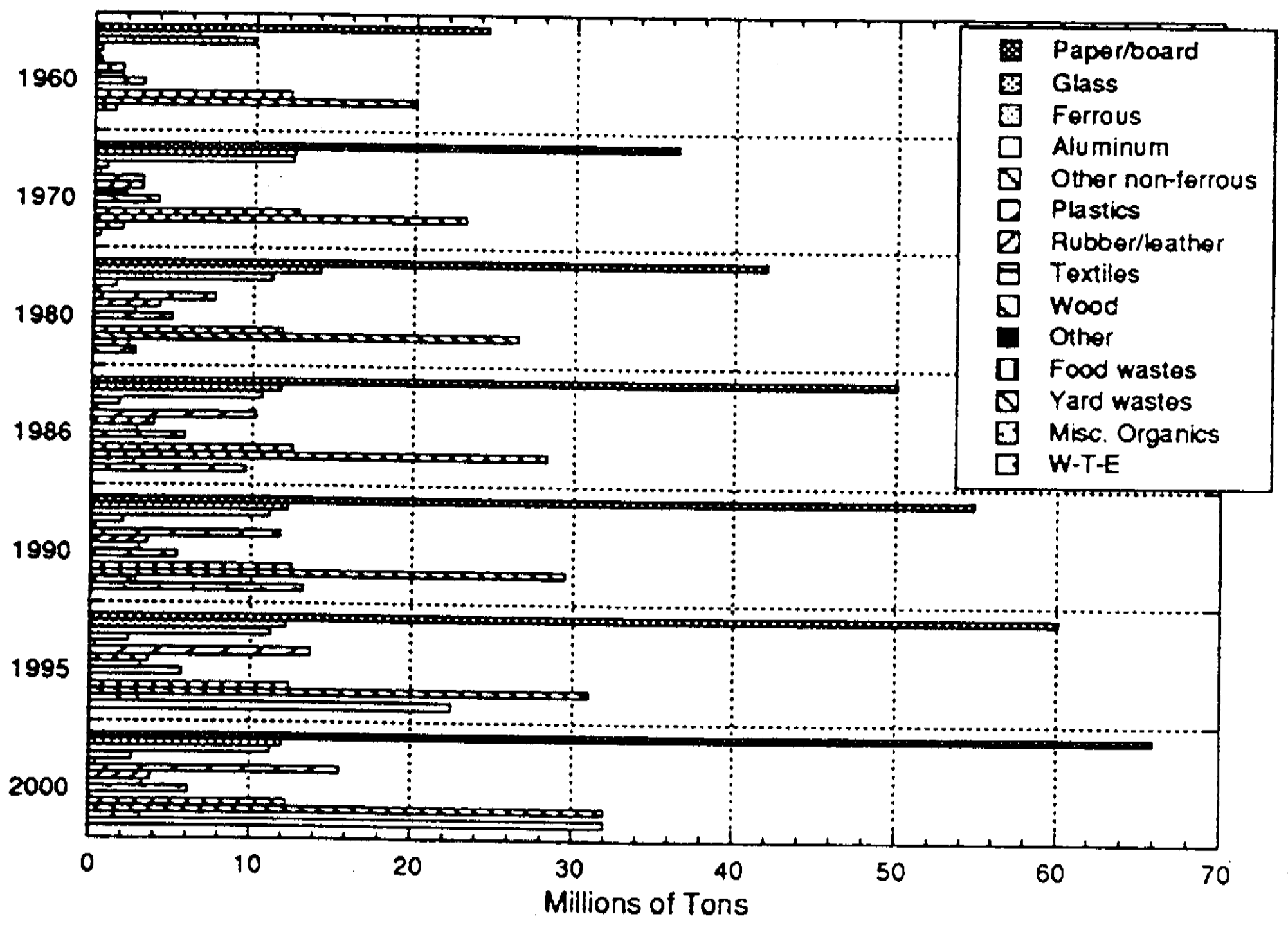

Figure 4.3 Types of materials discarded into U.S. MSW stream (1988 estimate). 
Table 4.1 Makeup of U.S. municipal solid waste.

\begin{tabular}{||l|c|c||}
\hline \multicolumn{1}{|c|}{ Component } & \% of MSW (EPA, 1992) & \% of MSW (Anon, 1988) \\
\hline Paper products & & 30.0 \\
\hline Cardboard & 36.8 (total) & 11.0 \\
\hline Yard waste & 19.7 & 17.9 \\
\hline Plastics & 7.9 & 6.5 \\
\hline Food, rubber, textile, wood & 16.3 & 16.0 \\
\hline Ferrous metal & 7.5 & 6.8 \\
\hline Aluminum & 1.3 & 1.2 \\
\hline Other non-ferrous metal & 0.2 & 0.7 \\
\hline Glass & 8.3 & 8.2 \\
\hline Stone, ceramics & & 0.6 \\
\hline 1/4 in. fines & 2.0 (total) & 1.1 \\
\hline
\end{tabular}

Table 4.2 Levels of components removed in assumed recycling scenarios.

\begin{tabular}{|ll|c|l|}
\hline Component Recycled & $\begin{array}{c}\text { Wt.\% of } \\
\text { MSW Recycled }\end{array}$ & \multicolumn{1}{c|}{$\begin{array}{c}\text { Components Removed } \\
\text { (wt. \%) }\end{array}$} \\
\hline (a) $\quad$ Combustibles only & 4.9 & $\begin{array}{l}5 \% \text { of paper, 25\% of cardboard, } \\
10 \% \text { of plastics }\end{array}$ \\
\hline (b) $\quad$ Inerts only & 6.7 & $\begin{array}{l}50 \% \text { of Al, 50\% of glass, } \\
30 \% \text { of ferrous metal }\end{array}$ \\
\hline (c) & Yard waste only & 9.0 & $50 \%$ of yard waste \\
\hline (d) $\quad$ Inerts and yard waste & 15.7 & (b) + (c) \\
\hline (e) $\quad \begin{array}{l}\text { Combustibles, inerts, } \\
\text { \& yard waste }\end{array}$ & 20.6 & (a) + (b) + (c) \\
\hline (f) $\quad \begin{array}{l}\text { Maximum combustibles, } \\
\text { inerts, \& yard waste }\end{array}$ & 36.6 & $\begin{array}{l}30 \% \text { of paper, } 40 \% \text { of cardboard, } \\
60 \% \text { of yard wastes, } 50 \% \text { of plastics, } \\
40 \% \text { of ferrous metal, 60\% of Al, 70\% of glass }\end{array}$ \\
\hline
\end{tabular}


Some of the results of these considerations are illustrated in Figure 4.4 for both MSW and RDF. In this figure, the calorific values of the MSW after recycling has removed the stated components is represented by the bars labelled 'MB', or mass burn, whereas the bars labelled 'RDF' indicate the calorific value of RDF made from the same MSW stream. Recycling 4.9 percent of the MSW in the form of combustibles, for example, resulted in a reduction in calorific value of the MSW and RDF of only 1.7 and 0.5 percent, respectively. Perhaps surprisingly, the maximum change in the calorific value of MSW was an increase from 6,500 to $7,100 \mathrm{Btu} / \mathrm{lb}$, which suggests that the effects on the thermal design aspects of MSW combustors of any of the recycling schemes suggested will be relatively small. The maximum changes in calorific value of RDF from the various recycling scenarios were even smaller, from 7,920 to $8,160 \mathrm{Btu} / \mathrm{lb}$ (dry basis).

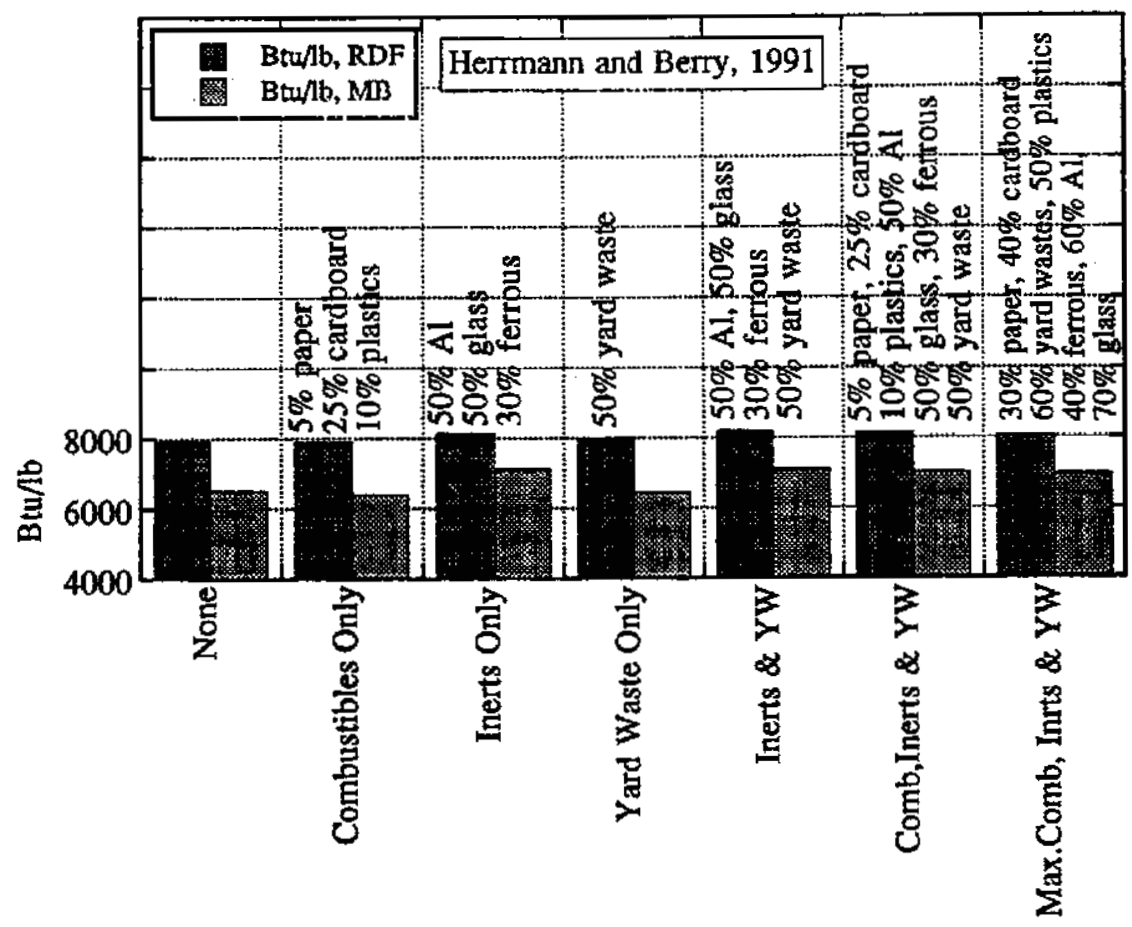

Figure 4.4 Effects of recycling of various components of the waste stream on the calorific value of MSW and RDF.

The plastics content of MSW in the U.S. has increased rapidly since 1960, when it comprised less than 1 percent $\left(0.4 \times 10^{6}\right.$ tons), to 8.3 percent $\left(16.2 \times 10^{6}\right.$ tons $)$ in 1990 , and is projected to 
increase to $24.8 \times 10^{6}$ tons (>11 percent) in the year 2000, as is indicated in Figure 4.5 (EPA, 1992). Plastics are found in containers and packaging, in durable and in non-durable goods.

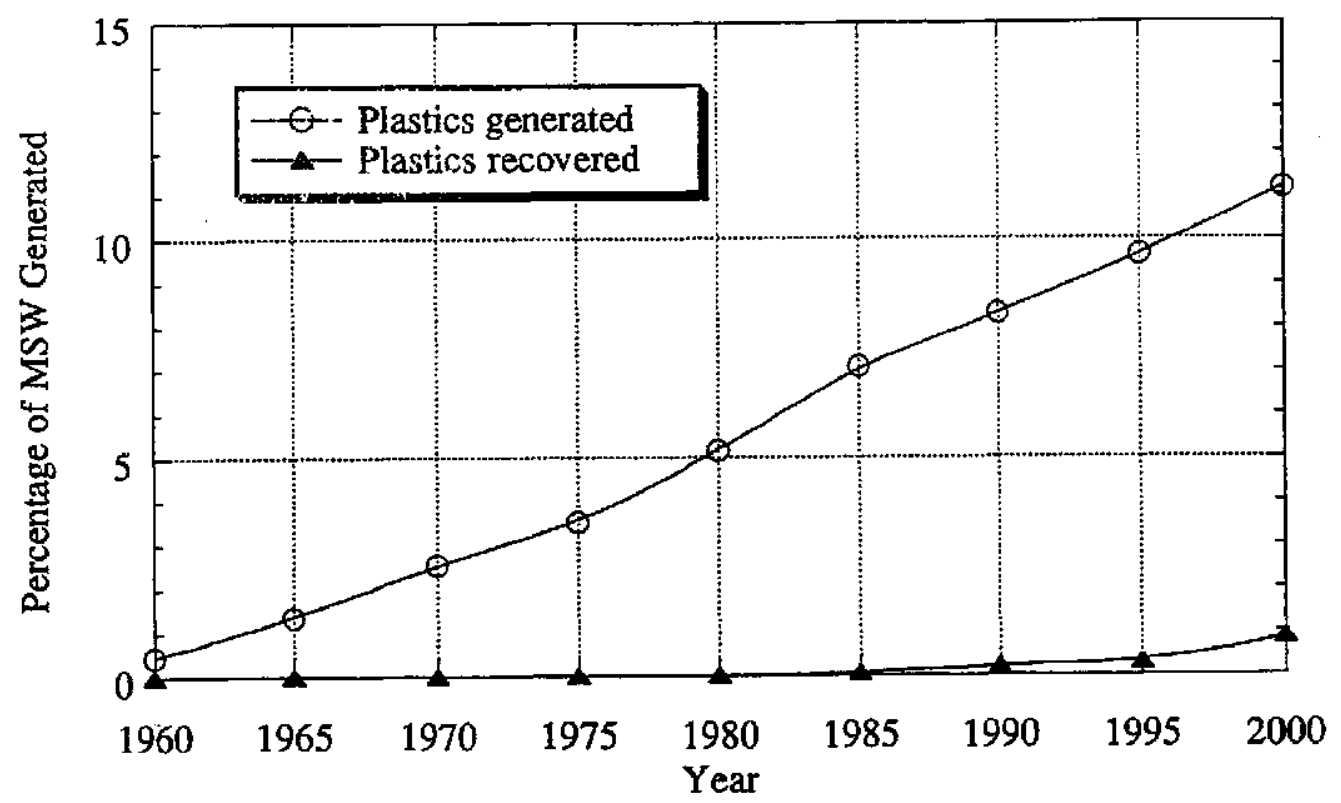

Figure 4.5 Trend in plastics content of U.S. MSW (EPA, 1992).

The amounts of plastics in MSW from the various sources are itemized (for 1990) in Figure 4.6. Packaging contains plastics in the form of beverage and condiment containers, bags and sacks, wrapping, and other products. In durable goods, plastics are found in appliances, household furnishings such as furniture, carpets, and in items such as the cases of lead-acid batteries, and other products. In non-durable goods, plastics are found in eating utensils, clothing, disposable diapers, and miscellaneous products.

Vaughan, et al. (1974) estimated that PVC accounted for approximately 24 percent of the plastics in MSW. Using this value, and the chlorine content of PVC (57.7 wt. percent), the chlorine content of MSW derived from PVC can be estimated as indicated in Figure 4.7. Also incorporated in the data used in that figure are values for the chlorine content derived from the actual total U.S.

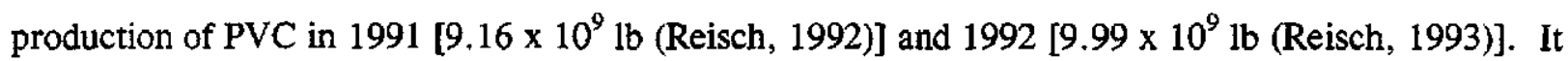
is evident that the curve suggests that the PVC-derived chlorine content of plastics in MSW will approach 1.6 percent by the year 2000 . 


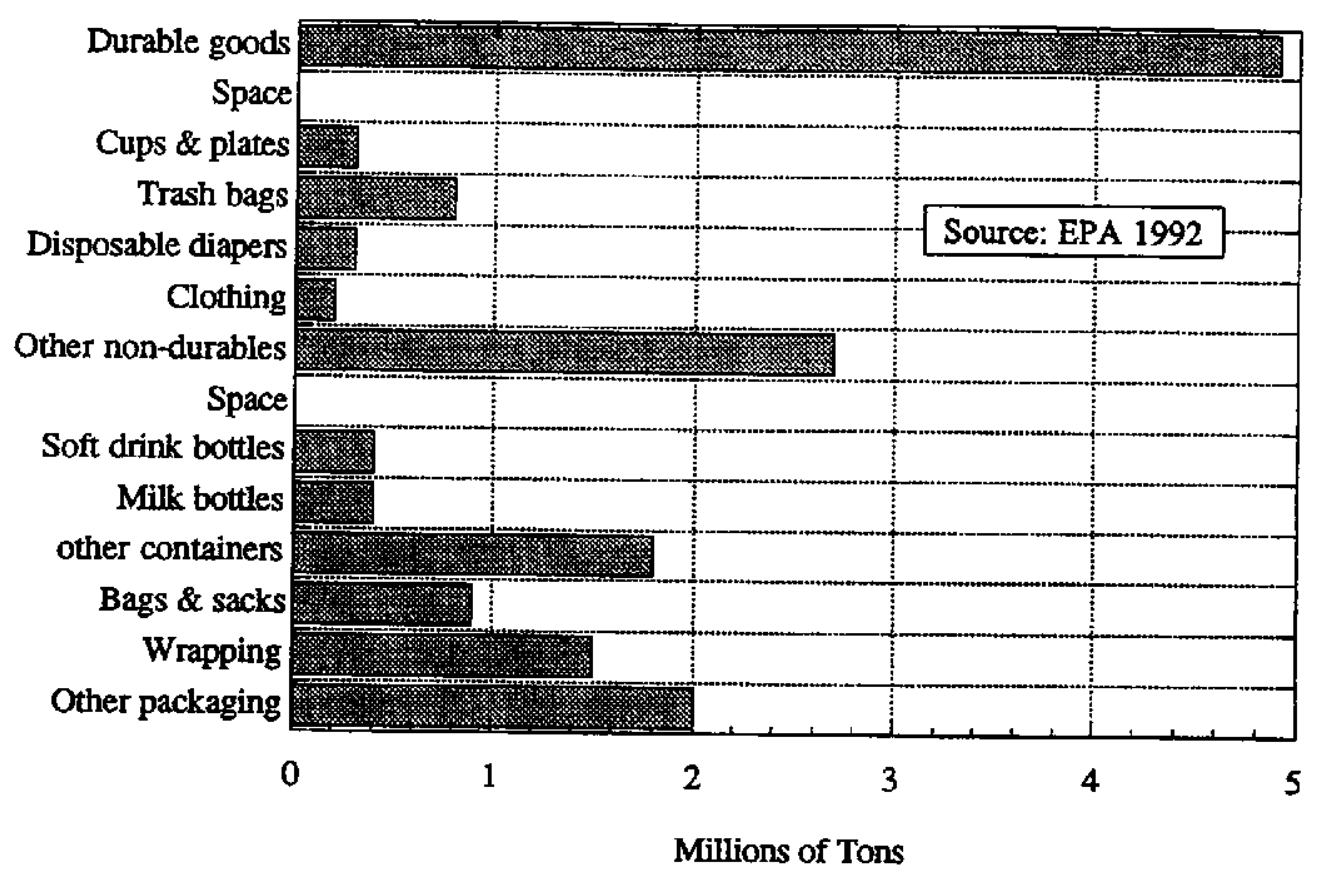

Figure 4.6 Sources of plastics in the U.S. MSW stream in 1990 (EPA, 1992).

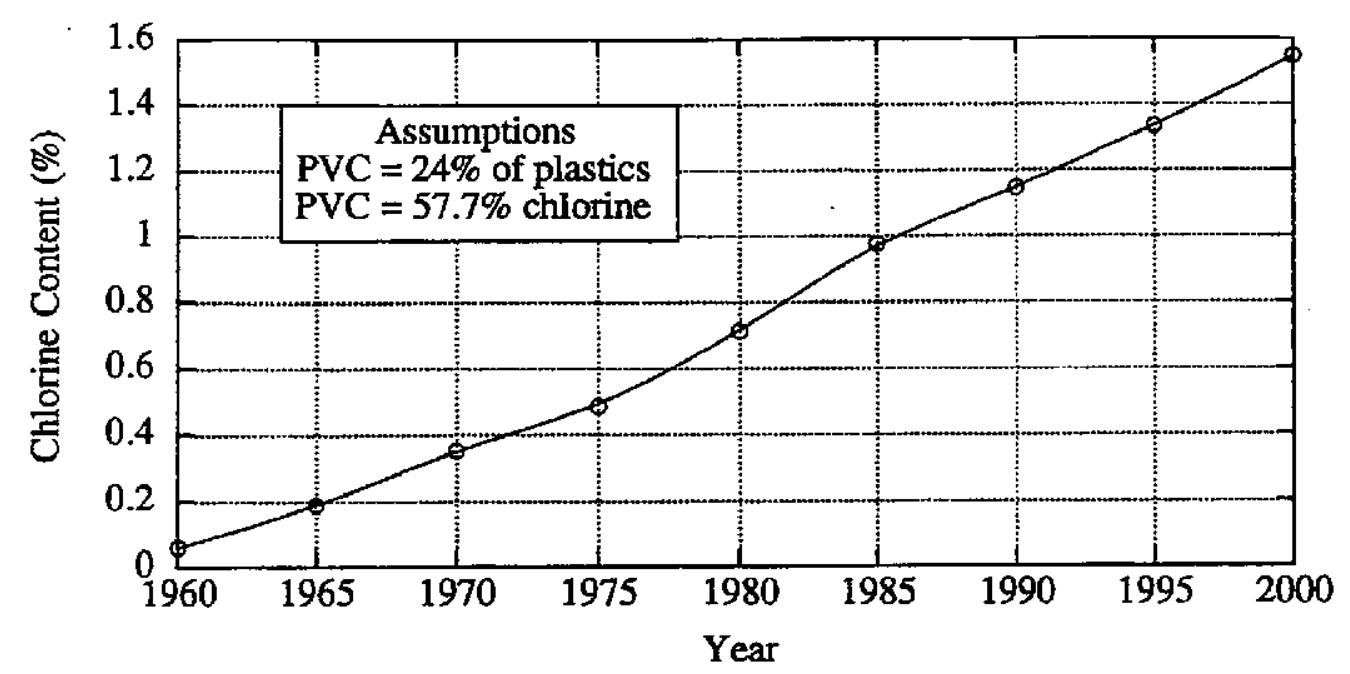

Figure 4.7 Estimated PVC-derived chlorine content of U.S. MSW. 
Overall, it appears that the amount of MSW generated will continue to increase at a rate of approximately three million tons per year for the foreseeable future. In the event that the decreased trend of disposal in landfills continues, combustion will represent an increasingly important option. The projected effects of increased recycling of components in the waste on the calorific value of the fuel are relatively small; it is unlikely that the combustion characteristics will be improved as a result of recycling procedures, but any increased removal of items such as glass and aluminum could help to improve the operability of the combustor grates. If the removal of heavy metals such as lead, tin, and zinc could be improved along with the glass, some of the potential for forming corrosive, low-melting compounds might be reduced. The possibility of removing and recycling a significant fraction of the plastics could lead to some reduction in the chlorine content of the waste. The chlorine derived from PVC is projected to increase at a steady rate of approximately 0.4 percent every 10 years. However, since the other sources of chlorine in the waste are diverse, it may not be viable to reduce chlorine levels via recycling to a point where corrosion is reduced significantly. 


\section{Summary of Current Understanding of the Causes of Metal Wastage in MSW Combustors}

Corrosion in refuse-fired boilers is caused primarily by interaction among chlorine, alkali metals ( $\mathrm{Na}$ and $\mathrm{K}$ ), and by heavy metals such as $\mathrm{Pb}, \mathrm{Sn}$ and $\mathrm{Zn}$ from the fuel. Attack can result from the action of low-melting chlorides deposited on the tube surfaces, and from gas-phase corrosion, and the type and rate of corrosion can be greatly increased under conditions of incomplete combustion. Where the flue gas is persistently sub-stiochiometric ${ }^{1}$ (reducing), that is, contains high levels of $\mathrm{C} \mathrm{O}$, the sulfur may be present predominantly as $\mathrm{H}_{2} \mathrm{~S}$. Measurements by Johnson, et al. (1970), albeit in a propane/liquefied petroleum gas flame, showed a rapid increase in $\mathrm{H}_{2} \mathrm{~S}$ and $\mathrm{COS}$ in the flame, and a decrease in $\mathrm{SO}_{2}$ and $\mathrm{SO}_{3}$ levels as the equivalence ratio (ratio of actual combustion air level to that required for stoichiometric combustion) fell below about 0.8 . Sulfur may play an important role by promoting chlorine corrosion and by acting directly as $\mathrm{H}_{2} \mathrm{~S}$ under reducing conditions.

\subsection{Occurrence of Corrosive Species in Refuse.}

The chlorine in municipal refuse is of both organic and inorganic origin. Polyvinyl chloride (PVC) plastics are the principal source of the organic portion. The U.S. production of PVC amounted to $9.99 \times 10^{9} \mathrm{lb}$. in 1992 (Reisch, 1993), and a significant amount of this material finds its way into the waste stream each year. Sorting of bulk refuse at four different times at a municipal combustor (Vaughan, et al., 1974) gave values for the plastics content of the refuse of 3 to 6 percent. Of this, about 24 percent was estimated to be PVC. Eight analyses of typical refuse samples from the combustor showed that the chlorine content of the waste, on a dry basis, ranged from 0.32 to 0.79 weight percent, with an average of 0.49 percent. The remaining chlorine in the waste was determined to be of inorganic origin, present primarily as $\mathrm{NaCl}$.

\footnotetext{
${ }^{1}$ Stiochiometric is defined as the relative amount of compounds required for a completion of a chemical reaction. In combustion systems stoichiiometric conditions refer to the amount of oxygen required to complete the conversion process. Therefore substoichiometric is a condition where insufficent oxygen exits for complete combustion.
} 
Shredded refuse samples on 5 different days at the Baltimore County, MD facility contained 0.41 to 0.61 weight percent chlorine. Similar testing of bulk refuse at the Greenpoint combustor, Brooklyn, NY gave values ranging from 0.63 to 2.06 weight percent chlorine. Large amounts of plastic and food products in the waste during the sampling time were responsible for the very high chlorine content in Brooklyn wastes (Domalski, 1986).

Sulfur is present in municipal refuse in materials such as rubber (sulfur cross links), detergents (sulfonates), paper products $\left(\mathrm{Na}_{2} \mathrm{SO}_{4}\right)$, and occasionally as gypsum board $\left(\mathrm{CaSO}_{4} \cdot 6 \mathrm{H}_{2} \mathrm{O}\right)$. Vaughan, et al., (1974) reported analyses for sulfur in refuse, which gave values ranging from 0.1 to 0.4 percent, with an average of 0.2 percent.

\subsection{Behavior of Corrosive Species During Combustion.}

Probably the most extensive work on the behavior of chlorine during combustion in boilers is the work of the Central Electricity Generating Board relating to high-chlorine British coals. However, the composition and combustion properties of coal are significantly different from those of MSW or RDF, so that ash formation and deposit behavior, hence, the predominant mechanisms of corrosion, are quite different in coal-fired boilers than in WTE units. Nevertheless, the general reactions in the flame are expected to be similar. Because it is associated with organic matter, chlorine appears in the combustion products primarily as $\mathrm{HCl}$. Gibb (1983) indicated that the amount of $\mathrm{HCl}$ found in boiler flue gases was about $80 \mathrm{ppm}$ for each 0.1 percent of chlorine in the coal. Since the combustion temperature in MSW-fired units easily exceeds that at which chlorine evolution occurs, the same rule can be applied to refuse. Other measurements in the furnace of a 120 MWe boiler fired with coals containing high-chlorine contents (Clarke and Morris, 1983) indicated $\mathrm{HCl}$ values ranging from 150 to $470 \mathrm{ppm}$, close to those calculated on the assumption that all the coal chlorine was converted to $\mathrm{HCl}$ in the flame.

Analyses of the bottom ash and fly ash from refuse-firing by Vaughan, et al. (1974), showed that only 0.01 to 0.02 weight percent chlorine remained in the ash. Hence, it appears that practically all of the chlorine in refuse also is volatilized during combustion. 
Some of the $\mathrm{HCl}$ in the combustion products can be oxidized to elemental $\mathrm{Cl}_{2}$ in the presence of metal oxide catalysts, which would be possible on the surfaces of oxidized tubes or beneath boiler deposits, by the classic Deacon reaction:

$$
2 \mathrm{HCl}+1 / 2 \mathrm{O}_{2}=\mathrm{Cl}_{2}+\mathrm{H}_{2} \mathrm{O}
$$

Chlorine can even be formed in the flame, as demonstrated by Mal'tseva, et al., (1983), who showed that several percent of $\mathrm{Cl}_{2}$ were formed when organic compounds containing chlorine were burned.

In the flame, the majority of the sulfur is oxidized to $\mathrm{SO}_{2}$, and a proportion is further oxidized to $\mathrm{SO}_{3}$, the reaction being promoted in the presence of catalytically-active surfaces such as those on oxidized tubes. The maximum amount of $\mathrm{SO}_{3}$ that can be formed from the oxidation of $\mathrm{SO}_{2}$ is dependent mainly on temperature. The equilibrium level of $\mathrm{SO}_{3}$ increases as the temperature decreases: below $427^{\circ} \mathrm{C}\left(800^{\circ} \mathrm{F}\right)$, essentially all the sulfur in the system $\mathrm{SO}_{2}-\mathrm{SO}_{3}$ will be $\mathrm{SO}_{3}$ at equilibrium whereas, above $1093^{\circ} \mathrm{C}\left(2000^{\circ} \mathrm{F}\right)$, it will be mainly $\mathrm{SO}_{2}$. These equilibrium values also are affected by the oxygen partial pressure such that very low oxygen partial pressures will lead to a smaller conversion to $\mathrm{SO}_{3}$. In boilers, however, equilibrium is rarely attained in the flame, so that the levels of $\mathrm{SO}_{3}$ formed are typically lower than predicted, and only about 1 percent of the $\mathrm{SO}_{2}$ is converted to $\mathrm{SO}_{3}$.

Not all the chlorine and sulfur appear in the flame as $\mathrm{HCl}$ or $\mathrm{SO}_{2}$ when $\mathrm{Na}$ also is present. From thermodynamic data, Boll and Patel (1961) calculated relationships between the various Nacompounds that could exist in boiler flue gases. The results for a high-chlorine ( 0.66 percent), 4.5 percent sulfur coal are shown in Figure 5.1. It is significant that $\mathrm{NaCl}$ predominates under reducing conditions (90 percent theoretical air) and at very high temperatures, whereas $\mathrm{Na}_{2} \mathrm{SO}_{4}$ has the highest vapor pressures under oxidizing conditions and lower temperatures.

In view of such data and from a knowledge of the composition of deposits formed in coal-fired boilers, Jackson (1963) deduced a series of reactions that probably occur in the flue gas and in deposits at various temperatures. As shown in Figure 5.2, chlorides participated throughout the deposit in the case of a high-chlorine fuel, whereas chlorides were converted to hydroxides for a low-chlorine fuel. This conversion would result in formation of $\mathrm{HCl}$ as well:

$$
\mathrm{NaCl} \text { (vapor) }+\mathrm{H}_{2} \mathrm{O}=\mathrm{NaOH} \text { (vapor) }+\mathrm{Hcl} \text {. }
$$



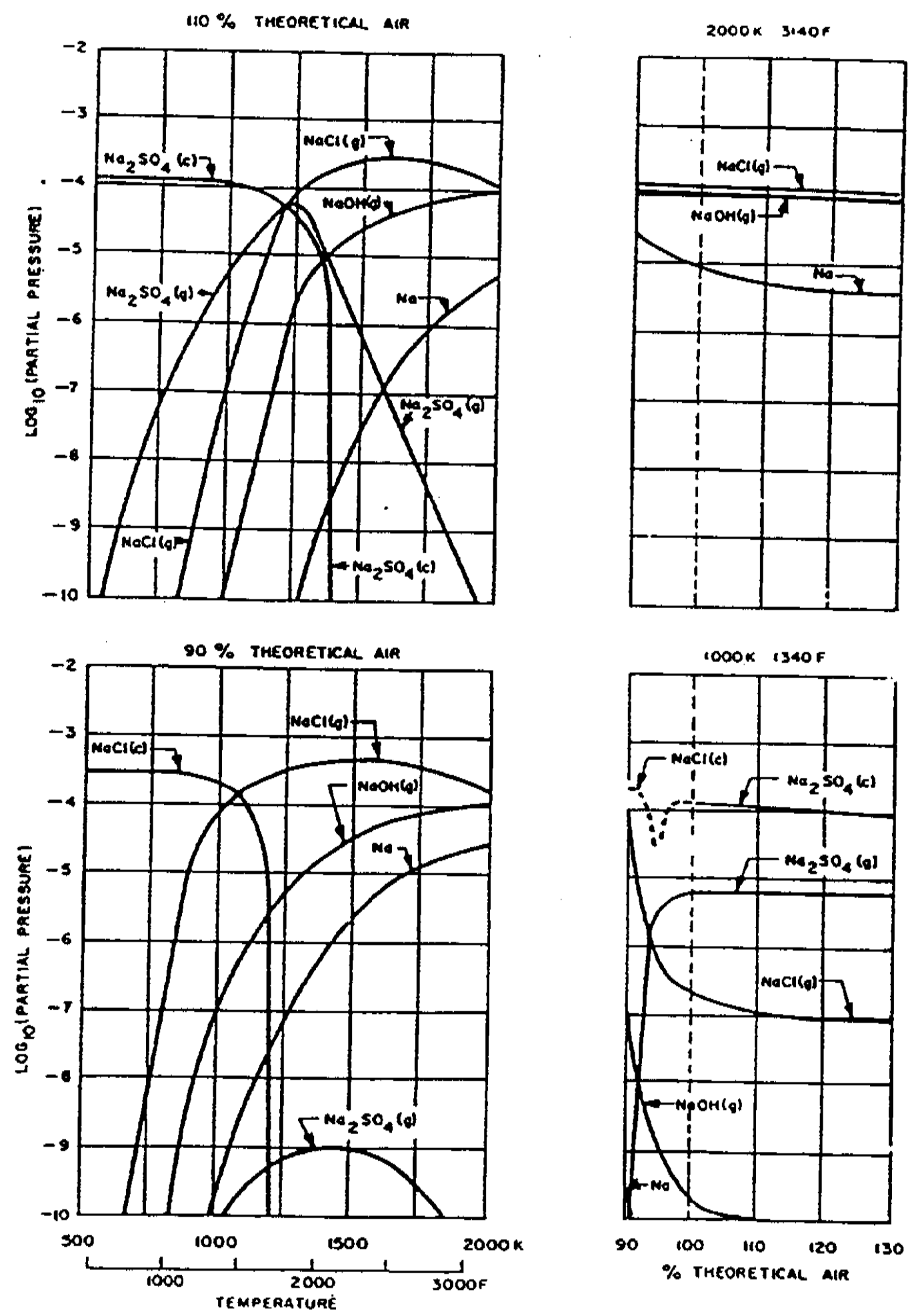

Figure 5.1. Calculated partial pressures of sodium compounds under combustion conditions (Boll \& Patel, 1961) 
Cutler, et al., (1971) calculated that, at equilibrium in the flue gases of a boiler fired with coal containing 0.8 weight percent chlorine at $1627^{\circ} \mathrm{C}\left(2960^{\circ} \mathrm{F}\right)$ flame temperature, 25 percent conversion to $\mathrm{NaOH}$ would take place. However, the extent of conversion would decrease to 10 percent at $1227^{\circ} \mathrm{C}$ $\left(2240^{\circ} \mathrm{F}\right)$ and 5 percent $1027^{\circ} \mathrm{C}\left(1880^{\circ} \mathrm{F}\right)$.

Bishop (1968) identified $\mathrm{NaCl}$ by $\mathrm{X}$-ray diffraction in the fly ash deposited downstream of the flame from combustion of a British (Thoresby) coal, containing 0.86 to 0.90 percent chlorine and 0.9 percent sulfur, in a combustion rig which simulated superheater tube conditions. The initial deposits, formed during the first hour, contained 10 to 25 percent chloride. As the exposure time increased, the $\mathrm{NaCl}$ was converted to an equivalent amount of $\mathrm{Na}_{2} \mathrm{SO}_{4}$, and the chlorine content of the deposit leveled off at about 5 percent after 3 hours. These results, showing the decrease in chlorine accompanied by the increase in sulfur content, are shown in Figure 5.3. Bishop also found that the critical metal temperature for $\mathrm{NaCl}$ deposition was $730^{\circ} \mathrm{C}\left(1346^{\circ} \mathrm{F}\right)$. Above this temperature no $\mathrm{NaCl}$ was found in the deposits.
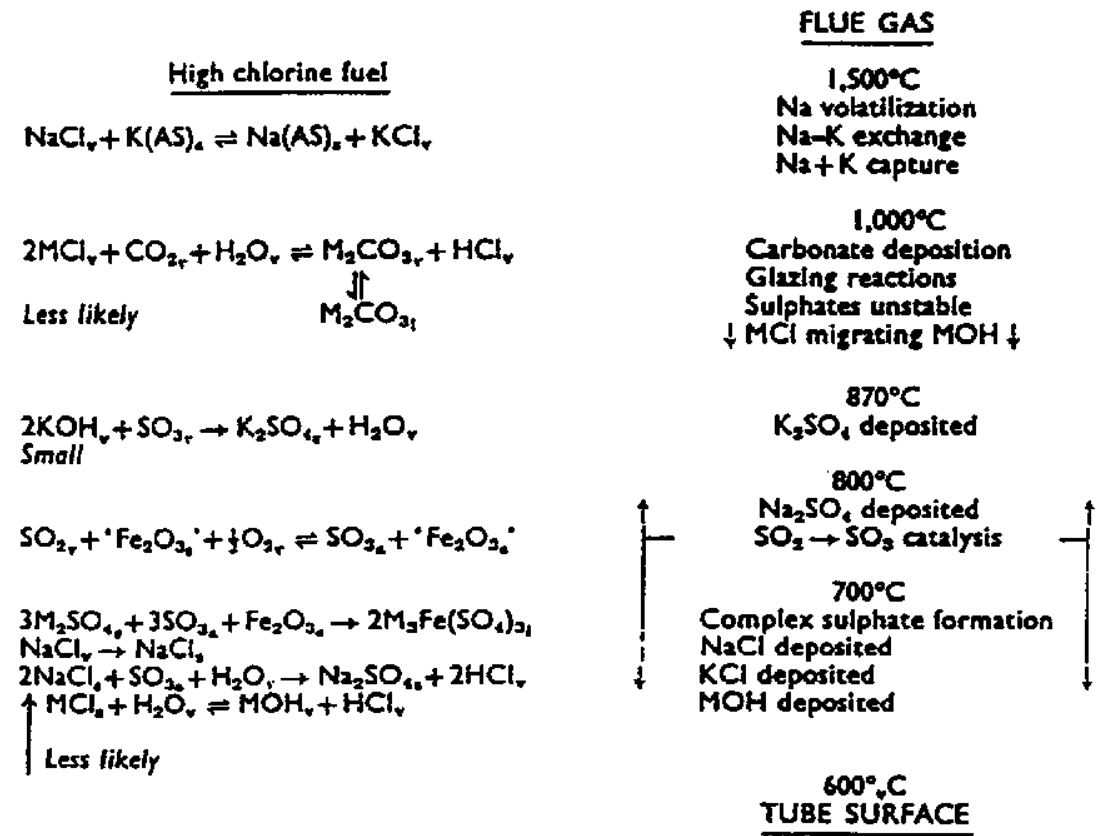

Figure 5.2 Sequence of reactions with temperature gradient in deposit. (AS) - aluminosilicate. Subscripts: $a=$ adsorbed, 1 = liquid, $\mathrm{s}=$ solid, $\mathrm{v}=$ vapor (Jackson, 1963).

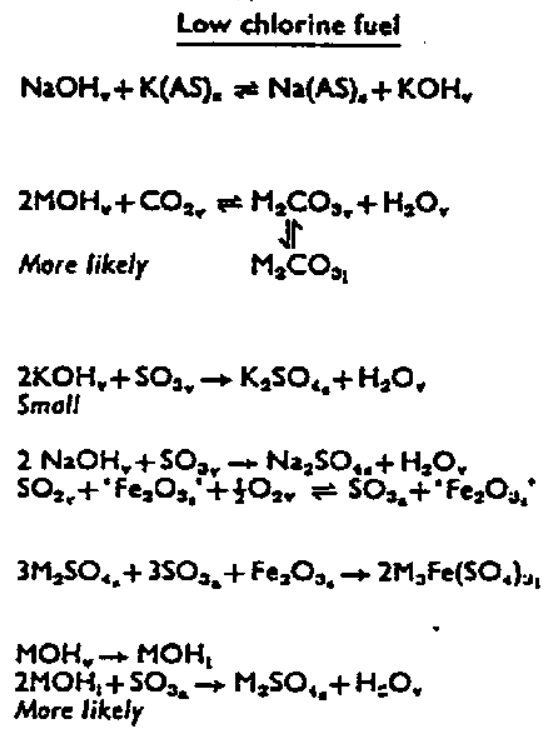

TUBE SURFACE 


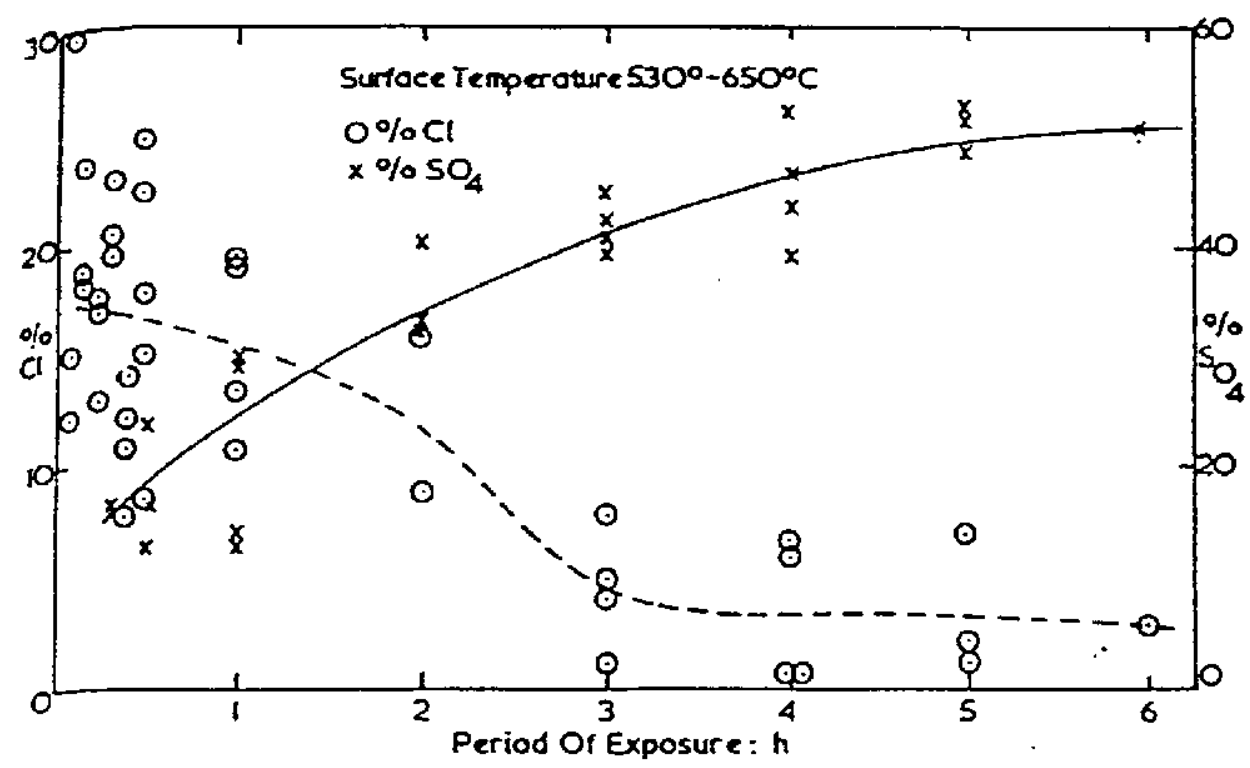

Figure 5.3 Chlorine and sulfate content of deposits from burning a high-chlorine coal (Bishop, 1968).

Both $\mathrm{NaCl}$ and $\mathrm{KCl}$ were identified by $\mathrm{X}$-ray diffraction analysis of probe deposits collected at the Miami County, OH waste combustor (Krause, 1986). These chlorides were found on the lower temperature probe specimens, exposed at about $260^{\circ} \mathrm{C}\left(500^{\circ} \mathrm{F}\right)$ and, in some short-term tests (24-hour), chloride concentrations of 21 to 27 weight percent were measured.

The transport of $\mathrm{NaCl}$ downstream of a flame also was investigated by Jackson and Duffin (1963), using a combustion rig that provided flue gas temperatures, composition, and residence time approximating that of a full-scale plant. When $\mathrm{NaCl}$ was added to the fuel, it was possible to condense it onto cooled probes and, by varying the temperature of the collecting surface, vapor pressure data were obtained. The maximum metal temperature for $\mathrm{NaCl}$ deposition of about $732^{\circ} \mathrm{C}\left(1350^{\circ} \mathrm{F}\right)$ noted by Bishop was confirmed in this work. The vapor pressure plot for $\mathrm{NaCl}$ in the presence of water vapor is shown with those for $\mathrm{NaOH}$ and $\mathrm{Na}_{2} \mathrm{SO}_{4}$ in Figure 5.4. Under combustion conditions, the maximum partial pressure of $\mathrm{NaCl}$ vapor which could be obtained from the coal used would be 0.24 torr. This corresponds to the $\mathrm{NaCl}$ vapor pressure at a temperature of $740^{\circ} \mathrm{C}\left(1364^{\circ} \mathrm{F}\right)$, which is in agreement with Bishop's results.

Daniel (1991) estimated the chemical compositions of the flue gas and deposits on the furnace wall and superheaters from the combustion of a refuse-derived fuel containing 0.62 percent chlorine, 


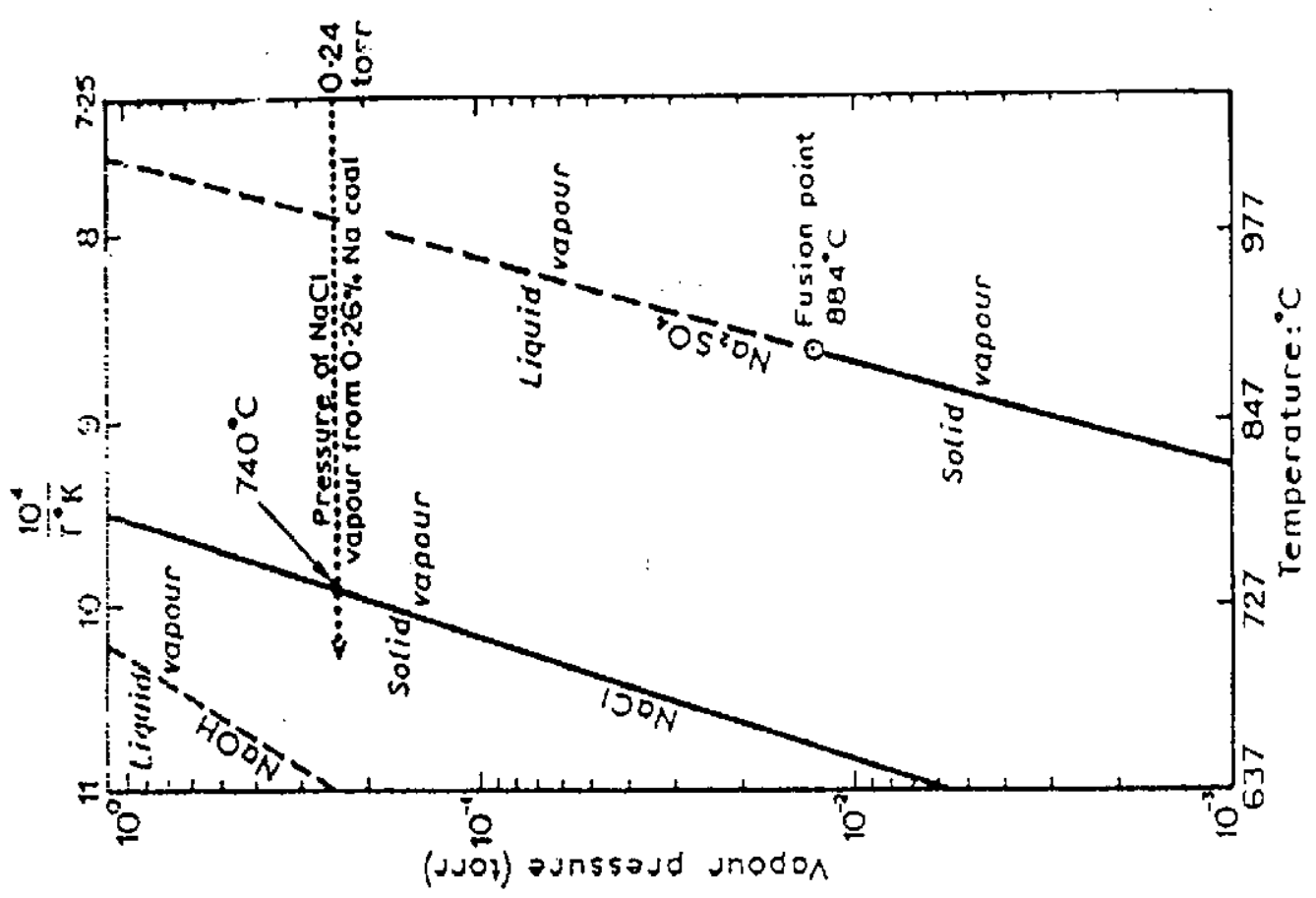

Figure 5.4 Vapor pressures of $\mathrm{NaOH}, \mathrm{NaCl}$, and $\mathrm{Na}_{2} \mathrm{SO}_{4}$ under combustion conditions (Jackson and Duffin, 1963).

0.29 percent sulfur together with, in weight percent, $1.08 \mathrm{Na} ; 0.77 \mathrm{~K} ; 3.88 \mathrm{Ca} ; 0.28 \mathrm{Mg} ; 0.77 \mathrm{Fe}$;

$6.40 \mathrm{Si} ; 0.72 \mathrm{Al} ; 0.05 \mathrm{~Pb}$ and $0.02 \mathrm{Zn}$. The concentration of the chlorine, sulfur, and alkali species in the flue gas as it passes through the boiler are illustrated in Figure 5.5. In the furnace and superheater regions, the calculated (equilibrium) concentrations of $\mathrm{HCl}$ (70 to $270 \mathrm{ppm}$ ) and $\mathrm{SO}_{2}$ (90 to $300 \mathrm{ppm}$ ) were in good agreement with values measured in refuse-burners. Beyond the superheater, as the flue gas is cooled below about $527^{\circ} \mathrm{C}\left(981^{\circ} \mathrm{F}\right)$, the reaction between $\mathrm{HCl}$ and alkali silicates is thermodynamically favored, and the calculated $\mathrm{HCl}$ concentration generally approached zero. In practice, because these gas-solid reactions generally are slow at the lower temperatures, most of the chlorine remains in the flue gas as $\mathrm{HCl}$, and there is little chloride (as $\mathrm{NaCl}$ or $\mathrm{KCl}$ ) in the fly ash. At the concentrations present in the flue gas, $\mathrm{NaCl}, \mathrm{NaOH}, \mathrm{KCl}$ and $\mathrm{KOH}$ are expected to condense on bare furnace walls, roughly in proportion to their concentration in the flue gas. Further equilibration at the furnace wall temperature will result in conversion of the hydroxides to chlorides and sulfates. 


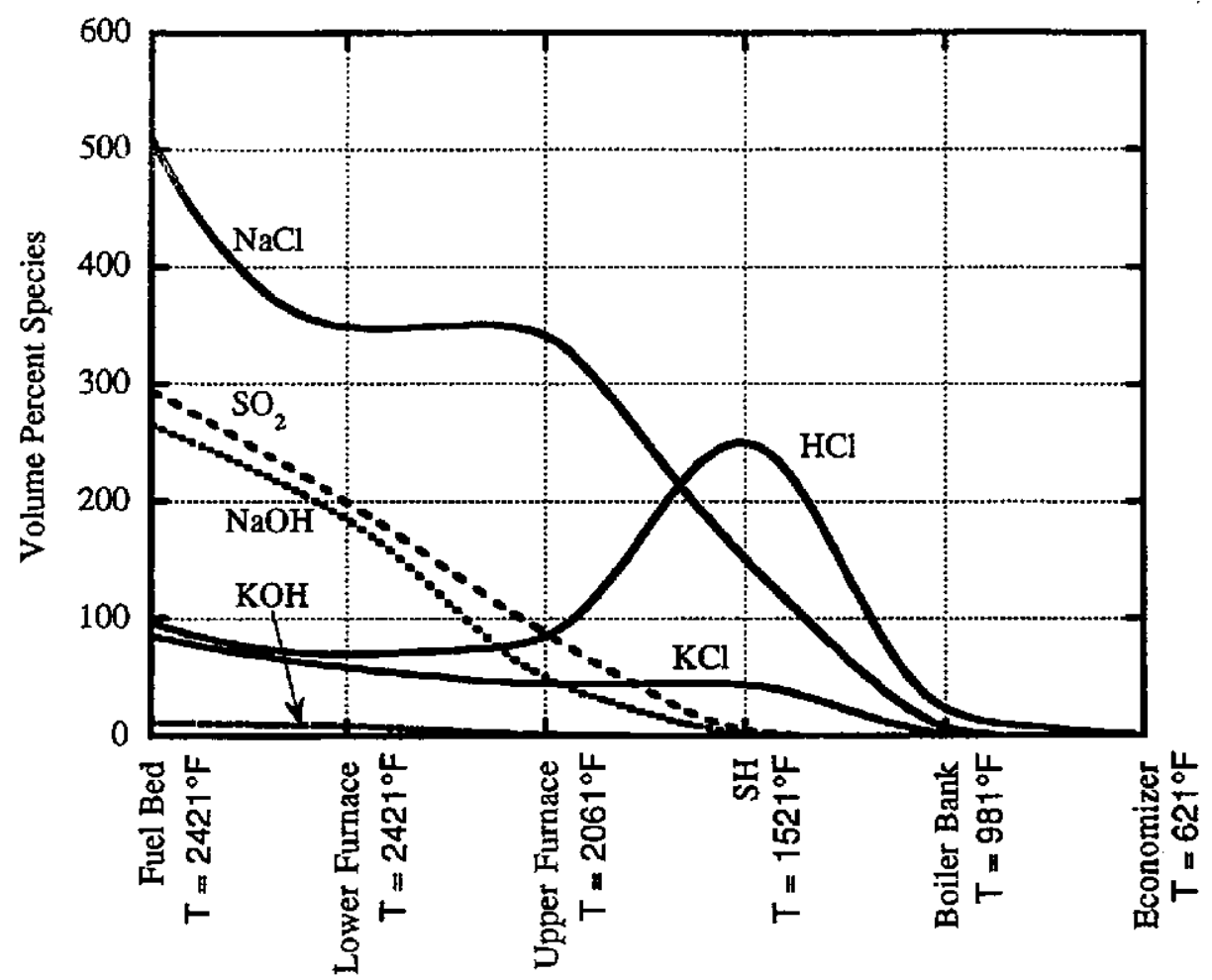

Figure 5.5 Concentration of corrosive species in flue gas of an RDF-fired boiler as a function of location (and gas temperature) (Daniel, 1991).

Heavy metal species, such as zinc, lead, and tin, which are present in refuse are subject to oxidation in the flame, and the oxides which are formed during combustion can react with $\mathrm{HCl}$ to form metal chlorides. These compounds have low melting points [ $\mathrm{SnCl}_{2}: 246^{\circ} \mathrm{C}\left(475^{\circ} \mathrm{F}\right) ; \mathrm{ZnCl}_{2}: 283^{\circ} \mathrm{C}$ $\left.\left(541^{\circ} \mathrm{F}\right) ; \mathrm{PbCl}_{2}: 501^{\circ} \mathrm{C}\left(934^{\circ} \mathrm{F}\right)\right]$ and, when mixed with $\mathrm{NaCl}, \mathrm{KCl}$ or other metal chlorides, can form eutectic mixtures that melt at temperatures as low as $179^{\circ} \mathrm{C}\left(350^{\circ} \mathrm{F}\right)$. These mixtures are discussed in detail under deposit-related attack in Section 5.3.3.

\subsection{Mechanisms of Corrosion}

Chlorine and sulfur can be involved in both high-and low-temperature corrosion of boiler components. High-temperature corrosion may result from: 
(1) Gas-phase attack by $\mathrm{HCl} / \mathrm{Cl}_{2}-$ or $\mathrm{SO}_{2} / \mathrm{SO}_{3}$ - containing gas under locally oxidizing conditions,

(2) Gas-phase attack by $\mathrm{HCl}$ or $\mathrm{H}_{2} \mathrm{~S}$ under conditions where the local oxygen partial pressure of the gas is sufficiently low that $\mathrm{H}_{2} \mathrm{~S}$ forms a significant proportion of the sulfur species present,

(3) Liquid-phase attack by direct deposition of molten sulfates or chlorides and their eutectic mixtures that melt at boiler metal temperatures, and

(4) Liquid phase attack beneath mostly solid deposits on superheater tubes.

Low-temperature corrosion in the back end of the boiler, usually in the form of pitting, can result from condensation of $\mathrm{H}_{2} \mathrm{SO}_{4}, \mathrm{H}_{2} \mathrm{SO}_{3}$, or $\mathrm{HCl}$.

\subsubsection{Gas Phase Attack in Oxidizing Atmospheres.}

Iron forms two sulfides, $\mathrm{FeS}_{2}$ and $\mathrm{FeS}$, which melt at 1171 and $1193^{\circ} \mathrm{C}\left(2140\right.$ and $\left.2179^{\circ} \mathrm{F}\right)$, respectively, two sulfates, $\mathrm{FeSO}_{4}$ and $\mathrm{Fe}_{2}\left(\mathrm{SO}_{4}\right)_{3}$, which decompose at 90 and $480^{\circ} \mathrm{C}\left(194\right.$ and $\left.896^{\circ} \mathrm{F}\right)$, respectively, and two chlorides: $\mathrm{FeCl}_{2}$ and $\mathrm{FeCl}_{3}$. These chlorides melt at about $675^{\circ} \mathrm{C}\left(1247^{\circ} \mathrm{F}\right)$ and $305^{\circ} \mathrm{C}\left(581^{\circ} \mathrm{F}\right)$, respectively, and attain significant vapor pressures at relatively low temperatures: $536^{\circ} \mathrm{C}\left(997^{\circ} \mathrm{F}\right)$ and $167^{\circ} \mathrm{C}\left(332^{\circ} \mathrm{F}\right)$, respectively. The ranges of stability of the iron sulfides, sulfates, and chlorides, in terms of the prevailing sulfur or chlorine and oxygen partial pressures in the environment at 400 and $850^{\circ} \mathrm{C}\left(752\right.$ and $\left.1562^{\circ} \mathrm{F}\right)$, are shown in simplified Ellingham-Pourbaix diagrams in Figure 5.6. The respective partial pressures of $\mathrm{O}_{2}, \mathrm{~S}_{2}$ and $\mathrm{Cl}_{2}$ in the environment of interest can provide information on the corrosion products expected under equilibrium conditions, and, therefore, give some indication of the possible corrosion reactions. The vertical dotted lines in the diagrams indicate the oxygen partial pressure (in atm.) in oxidizing flue gas ( $\left.\log \mathrm{PO}_{2}=-3\right)$, in flue gas from stoichiometric combustion (-13), and fully substoichiometric combustion (-20). An example of the use of equilibrium calculations to explore the variation of oxygen and chlorine partial pressures with oxidant to chlorine-containing fuel ratio has been given by McNallan and Liang (1985).

A knowledge of the equilibrium oxygen and chlorine partial pressure, or oxygen and sulfur partial pressures in the gas can be used to indicate the expected stable corrosion products for those 
conditions at a given temperature. For example, the expected corrosion product on a furnace wall tube at $752^{\circ} \mathrm{F}$ subjected to a gas with $\log \mathrm{PO}_{2}=-20$ and $\log \mathrm{PCl}_{2} \geq-10$ would be $\mathrm{FeCl}_{2}$. While this compound is solid at $752^{\circ} \mathrm{F}$, it has a significant vapor pressure which could lead to relatively rapid loss from the surface. In order to form the more desirable oxide, $\mathrm{Fe}_{2} \mathrm{O}_{3}$, the local oxygen partial pressure must be increased, or the chlorine partial pressure decreased to move the gas composition into the zone of stability of the oxide.

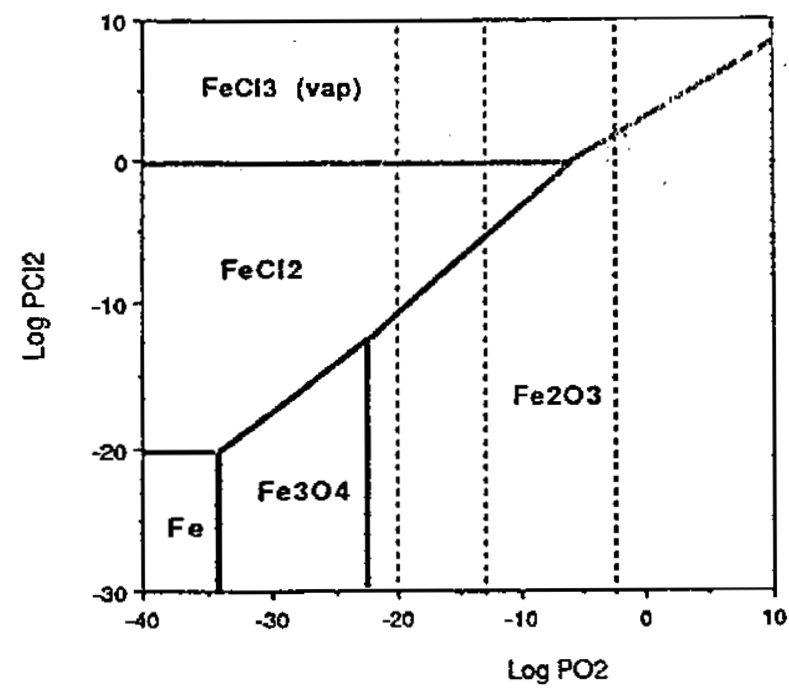

(a) $\mathrm{Fe}-\mathrm{O}-\mathrm{Cl}, 400^{\circ} \mathrm{C}\left(752^{\circ} \mathrm{F}\right)$

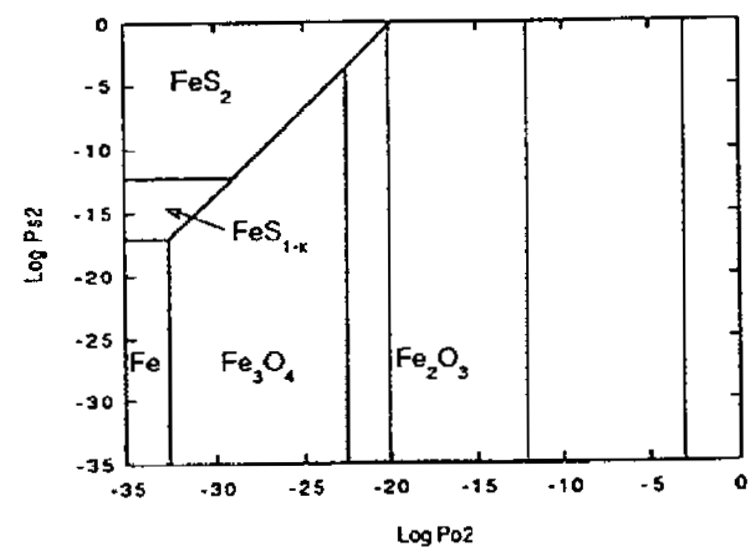

(c) $\mathrm{Fe}-\mathrm{O}-\mathrm{S}, 400^{\circ} \mathrm{C}\left(752^{\circ} \mathrm{F}\right)$

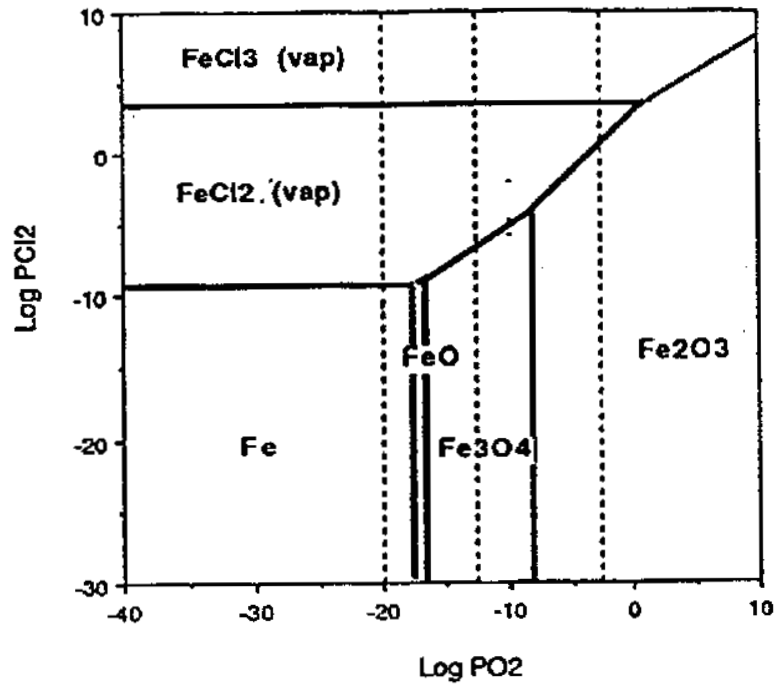

(b) $\mathrm{Fe}-\mathrm{O}-\mathrm{Cl}, 850^{\circ} \mathrm{C}\left(1562^{\circ} \mathrm{F}\right)$

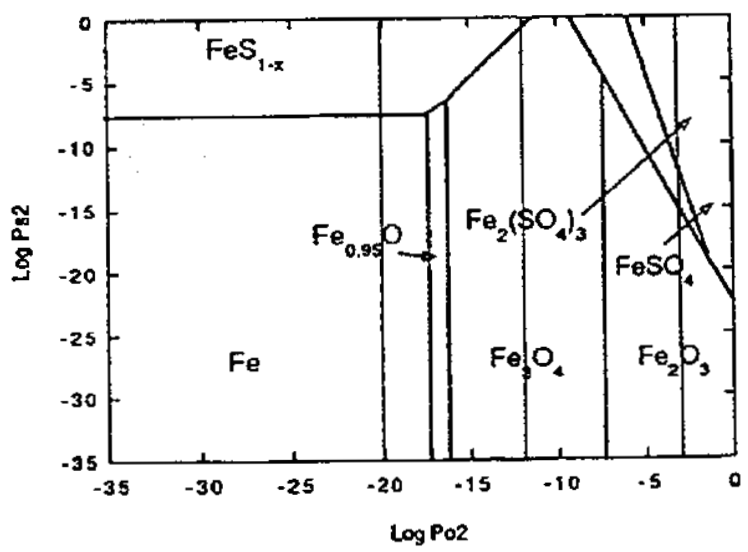

(d) $\mathrm{Fe}-\mathrm{O}-\mathrm{S}, 850^{\circ} \mathrm{C}\left(1562^{\circ} \mathrm{F}\right)$

Figure 5.6 Simplified Ellingham-Pourbaix diagrams showing corrosion products expected at equilibrium conditions. 
Obviously, such diagrams are only useful as an indication of what corrosion products would be expected if equilibrium conditions existed. However, since the equilibration of gas mixtures is catalyzed by oxidized surfaces, it is possible that equilibrium may be attained locally on corroding tube surfaces.

\subsubsection{Corrosion by $\mathrm{HCl} / \mathrm{Cl}_{2}$}

The corrosion of a bare iron or mild steel surface in pure gaseous $\mathrm{HCl}$ typically occurs at a relatively low parabolic reaction rate up to $593^{\circ} \mathrm{C}\left(1100^{\circ} \mathrm{F}\right)$ because the $\mathrm{FeCl}_{2}$ reaction product forms a stable surface layer:

$$
\mathrm{Fe}+2 \mathrm{HCl}=\mathrm{FeCl}_{2}+\mathrm{H}_{2} \text {. }
$$

The presence of chlorine-containing compounds in the corrosion scale at the metal-deposit interface has been identified by electron microprobe analyses of failed superheater tubes from municipal combustors (Krause, 1974; Kautz, 1977). Krause (1986) demonstrated by X-ray diffraction analysis of similar corrosion products on combustor probes that the chlorine was present as $\mathrm{FeCl}_{2}$ over the temperature range 149 to $593^{\circ} \mathrm{C}\left(300\right.$ to $\left.1100^{\circ} \mathrm{F}\right)$.

Although $\mathrm{FeCl}_{2}$ has a vapor pressure of $10^{-4}$ atm. at $536^{\circ} \mathrm{C}\left(997^{\circ} \mathrm{F}\right)$, catastrophic corrosion in 100 percent $\mathrm{HCl}$ does not occur until the melting temperature is reached at $675^{\circ} \mathrm{C}\left(1247^{\circ} \mathrm{F}\right)$. However, when oxygen is present, oxidation to $\mathrm{FeCl}_{3}$ begins at $400^{\circ} \mathrm{C}\left(752^{\circ} \mathrm{F}\right)$, as demonstrated by Ihara and his colleagues (Ihara, 1981) by:

$$
\mathrm{FeCl}_{2}+\mathrm{HCl}+1 / 4 \mathrm{O}_{2}=\mathrm{FeCl}_{3}+1 / 2 \mathrm{H}_{2} \mathrm{O}
$$

The $\mathrm{FeCl}_{3}$ is very volatile $\left[10^{-4}\right.$ atm. vapor pressure at $\left.167^{\circ} \mathrm{C}\left(332^{\circ} \mathrm{F}\right)\right]$, and its evaporation leaves the metal surface exposed to further attack by $\mathrm{HCl}$.

Note that the simplified Ellingham-Pourbaix diagrams in Figure 5.6 suggest that attack of iron by chlorine is not expected to occur in an oxidizing environment (i.e., $\log \mathrm{P}_{\mathrm{O} 2}>-3$ ) because of the formation of the thermodynamically more stable oxides unless, of course, the partial pressure of 
chlorine is very high, or chlorine can directly contact the metal by transporting through the oxide scale via cracks, fissures, or bulk diffusion.

A detailed study of the disruption of the oxide layer on steel by $\mathrm{HCl}$ in flue gas was reported by Mayer (1980). Experiments were conducted at a metal temperature of $538^{\circ} \mathrm{C}\left(1000^{\circ} \mathrm{F}\right)$ and a flue gas temperature of $1060^{\circ} \mathrm{C}\left(1940^{\circ} \mathrm{F}\right)$. Without $\mathrm{HCl}$ in the flue gas, a continuous non-porous scale consisting of $\mathrm{FeO}, \mathrm{Fe}_{3} \mathrm{O}_{4}$, and $\mathrm{Fe}_{3} \mathrm{O}_{4}$ was formed. With 0.1 vol. percent $\mathrm{HCl}$ in the gas, the inner scale layers were continuous, but the outer $\mathrm{Fe}_{2} \mathrm{O}_{3}$ layer became blistered and cracked. This $\mathrm{Fe}_{2} \mathrm{O}_{3}$ layer in turn became porous and discontinuous when the $\mathrm{HCl}$ concentration was increased to 0.2 vol. percent. A further increase of $\mathrm{HCl}$ content to $0.8 \mathrm{vol}$. percent caused complete disintegration of the $\mathrm{Fe}_{2} \mathrm{O}_{3}$ layer, and the $\mathrm{Fe}_{3} \mathrm{O}_{4}$ layer became irregular and porous. The maximum content of $\mathrm{HCl}$ that was investigated ( 2 vol. \%) destroyed the continuity of both outer layers, exposing the underlying $\mathrm{FeO}$ to attack by oxygen and $\mathrm{HCl}$.

Inasmuch as $\mathrm{FeCl}_{2}$ has been found as a corrosion product in the metal temperature range 149 to $260^{\circ} \mathrm{C}\left(300\right.$ to $\left.500^{\circ} \mathrm{F}\right)$, where $\mathrm{HCl}$ has little activity, the corrosive agent in this zone must be elemental chlorine formed by oxidation of $\mathrm{HCl}$. As shown by Brown, et al., (1947), chlorine attacks steel rapidly in this lower temperature range. In addition to formation from $\mathrm{HCl}$, the elemental chlorine can result from oxidation of $\mathrm{FeCl}_{3}$ in the scale layer:

$$
2 / 3 \mathrm{FeCl}_{3}+1 / 2 \mathrm{O}_{2}=1 / 3 \mathrm{Fe}_{2} \mathrm{O}_{3}+\mathrm{Cl}_{2}
$$

A cyclic reaction can then occur beneath the scale, with the chlorine attacking the tube metal to form more $\mathrm{FeCl}_{3}$. The $\mathrm{FeCl}_{2}$ scale also can be involved in the same type of cyclic system, because it is subject to oxidation to $\mathrm{Cl}_{2}$, as demonstrated by Fassler and his associates (1968):

$$
4 \mathrm{FeCl}_{2}+3 \mathrm{O}_{2}=2 \mathrm{Fe}_{2} \mathrm{O}_{3}+4 \mathrm{Cl}_{2}
$$

\subsubsection{Corrosion by $\mathrm{SO}_{2} / \mathrm{SO}_{3}$}

As shown in Figure 5.6, the iron sulfides have narrower stability ranges than the iron chlorides and form at very low oxygen partial pressures. Experimental results (Ross, 1965) have shown that a $S_{2}$ 
partial pressure of $10^{-13} \mathrm{~atm}$. was sufficient to produce $\mathrm{FeS}$ when the partial pressures of $\mathrm{SO}_{2}$ and $\mathrm{O}_{2}$ were below $10^{-14} \mathrm{~atm}$., whereas at higher $\mathrm{SO}_{2}$ partial pressures, iron oxides formed. When oxides were present on the iron surface, higher $S_{2}$ partial pressures and perhaps moisture (Kubaschewski, 1953) were needed to form FeS.

One of the most likely scenarios for sulfidation attack under oxidizing combustion conditions in boilers is through alkali sulfates or pyrosulfates that are formed in the flame and are deposited on the furnace walls. The type of reaction involved, at temperatures near $260^{\circ} \mathrm{C}\left(500^{\circ} \mathrm{F}\right)$ and higher, is that proposed many years ago by Corey, et al., (1945 and 1949) and by Coates (1968), which involve fluxing of the protective oxide layer by the reaction:

$$
\mathrm{Fe}_{2} \mathrm{O}_{3}+3 \mathrm{~K}_{2} \mathrm{~S}_{2} \mathrm{O}_{7} \rightarrow 2 \mathrm{~K}_{3} \mathrm{Fe}\left(\mathrm{SO}_{4}\right)_{3}
$$

Direct attack of the tube metal by pyrosulfate and bisulfate would then occur via:

$$
\mathrm{K}_{2} \mathrm{~S}_{2} \mathrm{O}_{7}+3 \mathrm{Fe} \rightarrow \mathrm{Fe}_{2} \mathrm{O}_{3}+\mathrm{FeS}+\mathrm{K}_{2} \mathrm{SO}_{4}
$$

and

$$
2 \mathrm{KHSO}_{4}+3 \mathrm{Fe} \rightarrow \mathrm{Fe}_{2} \mathrm{O}_{3}+\mathrm{FeS}+\mathrm{K}_{2} \mathrm{SO}_{4}+\mathrm{H}_{2} \mathrm{O}
$$

The high corrosivity of these salts is probably related to the fact that they have relatively low melting points, that is, about $302^{\circ} \mathrm{C}\left(575^{\circ} \mathrm{F}\right)$ for $\mathrm{K}_{2} \mathrm{~S}_{2} \mathrm{O}_{7}$ and $213^{\circ} \mathrm{C}\left(415^{\circ} \mathrm{F}\right)$ for $\mathrm{KHSO}_{4}$. In addition to laboratory evidence showing the corrosivity of these materials, it should be pointed out that azide and $\mathrm{pH}$ tests made on individual corrosion probe specimens typically show the presence of sulfide and the presence of acidic hydrolyzing salts (Miller, 1972).

The presence of FeS in the scale formed on tube surfaces, whether the scale is wholly sulfide or a sulfide-oxide mixture, is detrimental because the diffusion of Fe in FeS is faster than through $\mathrm{Fe}_{3} \mathrm{O}_{4}$, so that the rate of metal wastage is increased. In addition, because a larger volume of $\mathrm{FeS}$ is formed than $\mathrm{Fe}_{3} \mathrm{O}_{4}$, for a given amount of $\mathrm{Fe}$ consumed, sulfide scales are more susceptible to spallation than are oxide scales. 


\subsubsection{Gas Phase Attack in Reducing Atmospheres.}

In reducing (substoichiometric) environments (where $\log \mathrm{P}_{\mathrm{O} 2} \leq-13$ atm. at $850^{\circ} \mathrm{C} / 1562^{\circ} \mathrm{F}$ in Figure 5.6) oxide phases would be absent or discontinuous, and iron sulfide or chloride can form directly on the metal surface when $\log P_{\mathrm{C}_{12} \geq-9} \mathrm{~atm}$. or $\log \mathrm{P}_{\mathrm{S2}} \geq-8 \mathrm{~atm}$. The rate of corrosion then depends on temperature (which determines the vapor pressure of the corrosion product, and whether it is molten), on the activity of chlorine or sulfur in the environment up to some threshold level (Brooks, 1985), which determines the amount of surface coverage by chloride or sulfide, and on the gas flow rate, which controls the rate of evaporative loss. Under these conditions, direct gaseous sulfidation attack can occur to form the sulfide, by:

$$
\mathrm{Fe}+\mathrm{H}_{2} \mathrm{~S}=\mathrm{FeS}+\mathrm{H}_{2} \text {. }
$$

The presence of FeS on probe specimens in the metal-scale interface region has been confirmed by $\mathrm{X}$-ray diffraction in a number of studies.

Excessive furnace wall corrosion first noted in European combustors during the 1970's was found to be associated with high $\mathrm{CO}$ levels in the flue gas as well as chloride in the tube deposits (Thoemen, 1972). The combined effects of $\mathrm{CO}$ and $\mathrm{HCl}$ on corrosion were investigated under controlled laboratory conditions by the Central Electricity generating Board in the U.K. using gas mixtures. Initially, a $\mathrm{N}_{2}-\mathrm{O}_{2}-\mathrm{H}_{2} \mathrm{O}-\mathrm{SO}_{2}$ gas mixture was used to simulate the gas composition near the walls. The corrosion rates were parabolic (decreasing with time), and the addition of 400 or 2,000 $\mathrm{ppm} \mathrm{HCl}$ did not greatly affect the corrosion rates. A thin layer of chloride was found at the metalscale interface, and the scales formed in the presence of $\mathrm{HCl}$ were less adherent, and had a greater tendency to crack and spall (Brooks and Glover, 1981). Latham, et al. (1991) commented that "this indicated that the presence of a chloride species in a scale does not necessarily imply that rapid attack must result..."

Mayer, et al. (1983) studied the corrosion of mild steel in oxidizing or reducing conditions containing $\mathrm{HCl}$ ( or $\mathrm{Cl}_{2}$ ), and postulated that the effect of the chlorine species is to cause disruption of the normal, protective oxide scale through cracking or blistering or, at high $\mathrm{HCl}$ levels $(0.8 \mathrm{vol}$. percent), complete disintegration of the outer $\mathrm{Fe}_{2} \mathrm{O}_{3}$ layer, and the development of porosity in the inner 
$\mathrm{Fe}_{3} \mathrm{O}_{4}$ layer. These changes result in some acceleration, but not a catastrophic increase in the rate of corrosion compared to air oxidation.

When the oxygen in the gas was replaced by $\mathrm{CO}$, the corrosion rates were parabolic in the absence of $\mathrm{HCl}$, but faster than in the $\mathrm{O}_{2}$-containing gas mixare (Brooks and Meadowcroft, 1983). When $400 \mathrm{ppm} \mathrm{HCl}$ was introduced, linear oxidation kinetics were observed. Once transition to linear kinetics had occurred, there was little subsequent dependence of corrosion rate when the $\mathrm{HCl}$ content was increased to $2,000 \mathrm{ppm}$. The scales formed were loosely adherent, porous, and multilayered with bands of iron oxide and iron sulfide; there was no evidence of chloride at the metal-scale interface, nor as internal penetrations, as often was found in boiler furnace wall tubes. The effect attributed to $\mathrm{HCl}$ was the promotion of the formation of thicker, more porous, less adherent scales. Placing deposits (derived from burning high-chlorine coal) on the samples during the tests increased the corrosion rates, but did not change the form of the kinetics or the scale morphology.

Further work by Brooks and Gilroy (1984) under experimental conditions where the $\mathrm{SO}_{2}$ in the simulated flue gas was replaced with $\mathrm{H}_{2} \mathrm{~S}$ showed that the corrosion rates were linear whether or not

- $\mathrm{HCl}$ was present in the gas. The rates were similar to those measured in the $\mathrm{SO}_{2}$-containing gas when the experimental conditions were expected to have catalyzed the equilibration of the gas mixtures. Also, there was no obvious effect on the corrosion rates of an addition of $400 \mathrm{ppm} \mathrm{HCl}$. Brooks and Gilroy (1984) subsequently found by that, in the $\mathrm{N}_{2}-\mathrm{CO}-\mathrm{H}_{2} \mathrm{O}-\mathrm{SO}_{2}$ simulated flue gas under conditions where the conversion of $\mathrm{SO}_{2}$ to $\mathrm{H}_{2} \mathrm{~S}$ was weakly catalyzed, the corrosion rate of mild was lower than in the $\mathrm{H}_{2} \mathrm{~S}$-containing gas mixture.

Latham et al., (1991) concluded that the conditions for the rapid furnace wall corrosion observed in boilers burning high-chlorine coals probably require that the combustion gas is locally equilibrated at the boiler wall and, since equilibration is slow at the prevailing wall temperatures, and that the presence of thick corrosion products, deposits, or slagging also may be necessary. Although these results did not cleariy assign a role for chlorine, the action of $\mathrm{HCl}$ to promote weakly-adherent, cracked, and porous scales could provide easy access of the gas to the alloy surface, and provide a larger area of catalytic surface.

The major additions to Fe-based engineering alloys, such as $\mathrm{Ni}$ and $\mathrm{Cr}$, also form chlorides and sulfides that are less thermodynamically stable than the corresponding oxides, so that attack of these by chlorine or sulfur is also more likely in an oxygen-deficient environment. Hossain (1981) pointed out 
that the free energies of formation for oxides, chlorides, and sulfides of the elements usually found in boiler tubes are such that the sulfides would be formed preferentially to the chlorides.

\subsubsection{Deposit-Related Corrosion.}

Corrosion by molten salts containing sulfur and chlorine occurs primarily on furnace wall tubes, where low-melting compounds or eutectic mixtures are formed in deposits. The molten salts can act as a flux for protective oxides on the tubes, thus exposing the surfaces to continued oxidation and/or chlorination or sulfidation. The metal chlorides are the most likely sources of molten salt corrosion because of their low melting points and fluxing properties. In corrosion probe studies with municipal refuse (Kautz, 1977), $\mathrm{Pb}, \mathrm{Zn}$ and $\mathrm{Sn}$ often were found at the interface of the metal and corrosion products in the same region with chlorine. The chlorides of these metals are relatively low-melting compounds that would have been liquid at probe metal temperatures. Such chlorides probably formed by reaction of the metal oxides with $\mathrm{HCl}$ in the flue gas, as there was no evidence for their existence as chlorides in the unburned waste.

Daniel, et al., (1986) reported that the deposit on a badly corroded wall tube from a refusefired boiler contained $22.7 \mathrm{wt}$. percent chlorine. Analysis by $\mathrm{X}$-ray diffraction identified $\mathrm{NaCl}$ in the deposit, and electron microprobe $\mathrm{X}$-ray scans showed that $\mathrm{K}, \mathrm{Zn}$, and $\mathrm{Fe}$ also were associated with the chlorine. Compounds such as $\mathrm{NaCl}, \mathrm{KCl}$, and $\mathrm{FeCl}_{2}$, which are not low-melting compounds, can form eutectic mixtures of low-melting point with the $\mathrm{Pb}, \mathrm{Zn}$, and $\mathrm{Sn}$ chlorides. Many of these combinations of chlorides melt below $260^{\circ} \mathrm{C}\left(500^{\circ} \mathrm{F}\right)$ as shown in Figure 5.7. The two mixtures with the lowest melting points involve $\mathrm{FeCl}_{3}$ with $\mathrm{NaCl}$ or $\mathrm{PbCl}_{2}$. Thus, in the presence of either of these chlorides, $\mathrm{FeCl}_{3}$ formed as a corrosion product on steel may become part of a molten salt mixture rather than volatilize from the deposit.

The eutectic mixtures formed by $\mathrm{ZnCl}_{2}$ and $\mathrm{SnCl}_{2}$ all would be molten at wall tube temperatures and may be responsible for much of the corrosion of wall tubes by municipal refuse. As shown in Figure 5.7, all of the $\mathrm{PbCl}_{2}$ eutectics except that with $\mathrm{FeCl}_{3}$ would only melt at superheater temperatures. Chlorides of $\mathrm{K}, \mathrm{Mg}$, and $\mathrm{Ca}$ also can be part of low-melting eutectic mixtures. Consequently, boiler deposits from refuse firing can include a large number of components that have 
the potential for causing molten salt attack on the furnace wall or superheater tubes. This contrasts significantly with coal firing.

Otsuka, et al., (1993) used simulated deposits to investigate the relative effects of chlorides and sulfates on the corrosion of austenitic steels and Ni-base alloys. They found that high-Ni alloys such as $825, \mathrm{G} 3,625,690,600$, and pure Ni exhibited good corrosion resistance to chloride-based deposits at $400^{\circ} \mathrm{C}\left(752^{\circ} \mathrm{F}\right)$, whereas Fe-based alloys such as 304 and $316 \mathrm{~L}$ were severely corroded. In contrast, for predominantly sulfate deposits (containing a small amount of chloride) expected to form on superheater tubes, the corrosion behavior at $550^{\circ} \mathrm{C}\left(1022^{\circ} \mathrm{F}\right)$ appeared to be a function of alloy $\mathrm{Cr}$ content, with the higher- $\mathrm{Cr}$ alloys corroding slowest. For alloys of similar $\mathrm{Cr}$ content, increasing $\mathrm{Ni}$ content appeared to degrade the resistance to corrosion. The best-performing alloy in all the environments tested was Alloy 625.

The presence of a solid alkali chloride deposit on the metal surface increases the corrosion process if $\mathrm{SO}_{2}$ is present in the flue gas. In this case, the chloride is converted to sulfate, with the release of $\mathrm{HCl}$ in the deposit:

$2 \mathrm{NaCl}+\mathrm{SO}_{2}+1 / 2 \mathrm{O}_{2}+\mathrm{H}_{2} \mathrm{O}=\mathrm{Na}_{2} \mathrm{SO}_{4}+2 \mathrm{Hcl}$
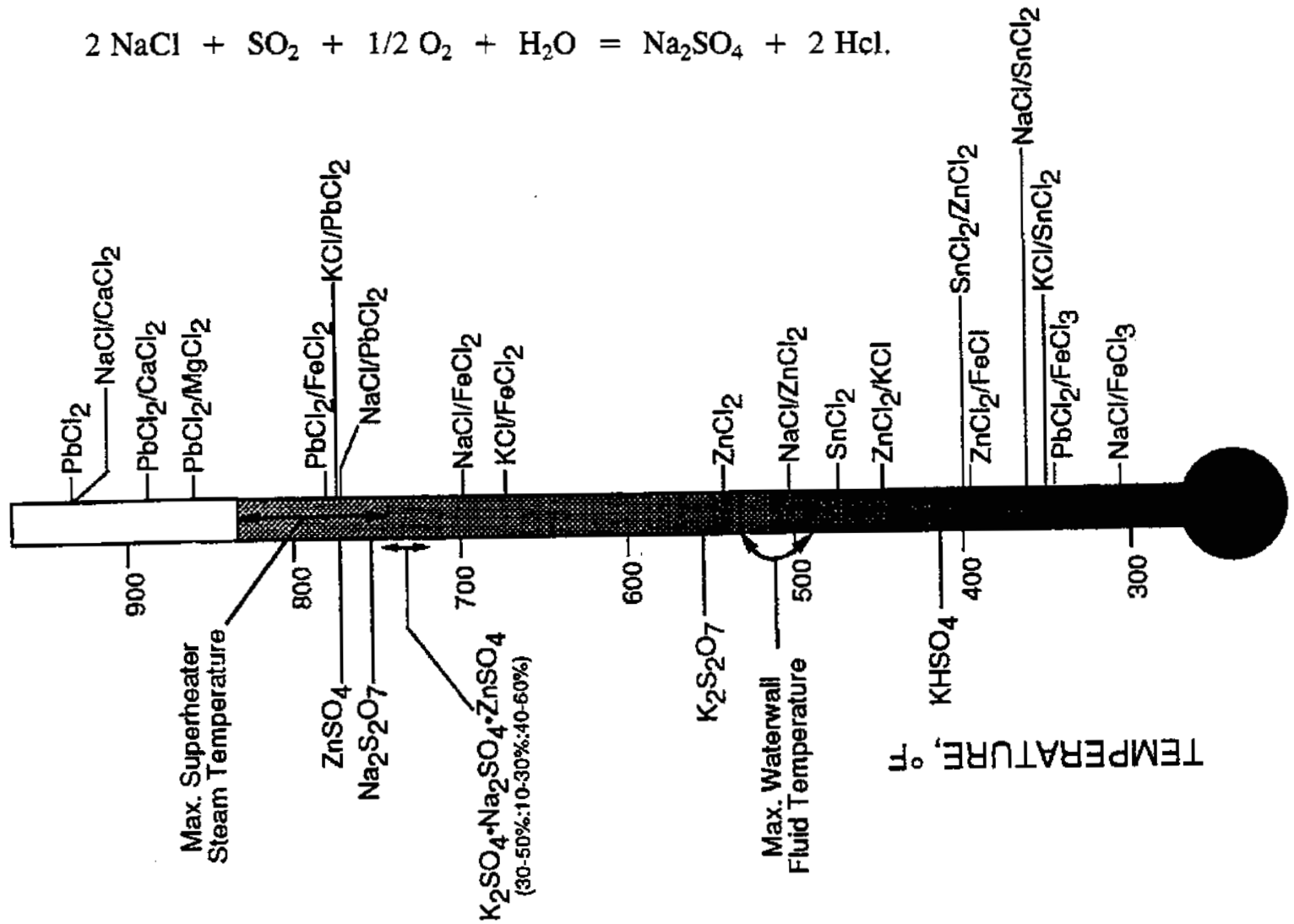

Figure 5.7 Melting temperatures of various salts found in WTE combustors. 
This role of $\mathrm{SO}_{2}$ was demonstrated in laboratory experiments (Miller, 1972) in which alloys were exposed to sulfate-chloride salt mixtures in a synthetic flue gas with and without $\mathrm{SO}_{2}$, and has been observed in simulated gas turbine conditions (Hossain, 1981). As shown in Table 5.1, introduction of only $250 \mathrm{ppm} \mathrm{SO}$, typical of refuse combustion, resulted in large increases in the corrosion rates. Increasing the $\mathrm{SO}_{2}$ concentration to $2500 \mathrm{ppm}$, typical of coal-fired boilers, caused a significant increase on the attack of C-steel, but had only a minor effect on T11. Type 321 stainless steel underwent slightly less corrosion at the higher $\mathrm{SO}_{2}$ level, which may be attributable to experimental variation. Increasing the metal temperature from 427 to $538^{\circ} \mathrm{C}\left(800\right.$ to $\left.1000^{\circ} \mathrm{F}\right)$ caused much more increase in the corrosion rate than did an increase in the amount of $\mathrm{NaCl}$ in the deposit, as shown in Table 5.2. These results indicate that only small amounts of alkali chloride in the rube deposits will cause serious corrosion. It is significant that without a deposit on the metal the gas phase attack by the synthetic flue gas containing $250 \mathrm{ppm} \mathrm{SO}_{2}$ was slight, showing that the formation of $\mathrm{HCl}$ in the deposit is the critical factor.

Table 5.1 Effects of $\mathrm{SO}_{2}$ concentration on corrosion rates in sulfate-chloride mixture at $1000^{\circ} \mathrm{F}^{\text {(a) }}$ (Miller, 1972).

\begin{tabular}{|l|c|c|c|}
\hline & & \multicolumn{2}{c|}{ Corrosion Rates, mils/month } \\
\hline \multicolumn{1}{|c|}{ Alloy } & $\mathrm{No} \mathrm{SO}_{\mathbf{2}}{ }^{\text {(b) }}$ & $\mathbf{2 5 0} \mathbf{~ p p m ~ \mathbf { S O } _ { 2 }}$ & $\mathbf{2 5 0 0} \mathbf{~ p p m ~ \mathbf { S O } _ { 2 }}$ \\
\hline Carbon steel & 20 & 74 & 99 \\
\hline T11 & 10 & 62 & 68 \\
\hline TP321 & 1 & 15 & 6 \\
\hline
\end{tabular}

(a) Synthetic flue gas: $80 \%$ air, $10 \% \mathrm{CO}_{2}, 10 \% \mathrm{H}_{2} \mathrm{O}$.

(b) Mixture consisted of $78 \mathrm{~K}_{2} \mathrm{SO}_{4}-21 \mathrm{Na}_{2}-\mathrm{SO}_{4}-1 \mathrm{NaCl}$.

The effect of $\mathrm{NaCl}$ on the surface of a metal under oxidizing conditions was investigated for various alloys by Hancock and coworkers (1972 and 1973). The experimental techniques employed were hot-stage microscopy and measurement of the natural vibration frequencies of freely-suspended bars. With Fe-based alloys, extensive blistering and cracking of the oxide scale occurred when solid $\mathrm{NaCl}$ was used to contaminate the specimen surface, the severity of the attack increasing with increasing temperature. 
Table 5.2 Effect of deposits and temperature on corrosion rates in flue gas atmospheres ${ }^{(a)}$ (Miller, 1972).

\begin{tabular}{||c|c|c|c|c|c|c||}
\hline & \multicolumn{6}{|c|}{ Corrosion Rates, mils/month } \\
\hline & \multicolumn{2}{|c|}{ No Deposit } & \multicolumn{2}{c|}{ Deposit A $^{\text {(b) }}$} & \multicolumn{2}{c|}{ Deposit B $^{\text {(c) }}$} \\
\hline Alloy & $\mathbf{8 0 0 ~ F}$ & $\mathbf{1 0 0 0 ~ F}$ & $\mathbf{8 0 0 ~ F}$ & $\mathbf{1 0 0 0 ~ F}$ & $\mathbf{8 0 0 ~ F}$ & $\mathbf{1 0 0 0 ~ F}$ \\
\hline Carbon steel & 1 & 8 & 6 & 74 & 18 & 68 \\
\hline T11 & 1 & 5 & 3 & 62 & 14 & 62 \\
\hline TP321 & 0 & 0 & $<1$ & 15 & $<1$ & 17 \\
\hline
\end{tabular}

(a) Synthetic flue gas: $80 \%$ air, $10 \% \mathrm{CO}_{2}, 10 \% \mathrm{H}_{2} \mathrm{O}, 250 \mathrm{ppm} \mathrm{SO}_{2}$.

(b) Deposit A: $78 \mathrm{~K}_{2} \mathrm{SO}_{4}-21 \mathrm{Na}_{2} \mathrm{SO}_{4}-1 \mathrm{NaCl}$.

(c) Deposit B: $75 \mathrm{~K}_{2} \mathrm{SO}_{4}-20 \mathrm{Na}_{2} \mathrm{SO}_{4}-5 \mathrm{NaCl}$.

Below the melting point of the salt, the attack was localized; while above the melting point, widespread failure of the scale occurred (Hancock, et al., 1972; Hurst, et al., 1973). Similar effects were noted for a range of Ni-base alloys. Any reaction between the oxide and the chloride had no effect on the overall oxidation rate--apparently the corrodent must have access to the metal surface before accelerated oxidation can occur (Davies, 1972). The vibration technique demonstrated that mechanical failure of the surface oxide scale occurs continually, even in isothermal conditions, on all $\mathrm{Fe}$ - and Ni-based alloys studied. Any contaminant in the gas therefore is provided with direct access to the metal surface. Concentration profiles across a section of mild steel corroded under such conditions showed a large concentration of chlorine at the metal-scale interface, with little or no chlorine present throughout the scale itself. A mechanism of scale disruption proposed by Hoare (1969) involves direct reaction between the metal and the chlorine to produce a volatile oxychloride.

As mentioned earlier, sulfur-bearing compounds play an important role with regard to molten salt attack over the range of temperatures experienced by boiler tubes. For example, the most corrosive salts found in laboratory tests intended to simulate the conditions experienced at the waterwalls of coal-fired boilers (Miller, 1972) at $316^{\circ} \mathrm{C}\left(600^{\circ} \mathrm{F}\right)$ were the pyrosulfates and the bisulfates. Since the corrosion reactions, which are electrochemical in nature, can take place more readily in liquids than in solids or gases, the presence of a liquid phase is of great importance. The 
melting points of these salts may be further lowered by the $\mathrm{Zn}$ and $\mathrm{Pb}$ salts also shown to be present on corroded specimens from probe exposures.

Overall, given the wide range of compounds that may be present in deposits formed on tubes in waste-fired boilers and that can give rise to low-melting salts, there are a number of possible scenarios available to explain the often-observed accelerated corrosion. Krause (1986) attempted to rationalize the sequence of chemical reactions that may occur in these deposits and lead to corrosion. Figure 5.8 is a schematic representation of the proposed mechanism, which explains the dimpled surface structures that are usually observed on corroded tubes by the presence of both $\mathrm{FeS}$ and $\mathrm{FeCl}_{2}$ phases at the metal/scale interface. Dimpling is a result of the variation in corrosion resulting from these phases, which coat adjacent areas on the tubes. Because of the cation vacancies in the FeS structure, there is a higher diffusion rate of iron ions through the $\mathrm{FeS}$ film than through the $\mathrm{FeCl}_{2}$ film, which is more ionic in character, has fewer cation vacancies, and thus a lower cation diffusion rate. The driving force for this diffusion in both cases is the iron concentration gradient established by the formation of the more stable iron oxides at the exterior surface of these films. The oxide formation depends upon the $\mathrm{SO}_{2}$ or $\mathrm{O}_{2}$ penetrating the mixed oxide scale and the other deposits. The presence of $\mathrm{FeCl}_{2}$ or $\mathrm{FeS}$ at the metal/scale interface suggests that the $\mathrm{O}_{2}$ partial pressure at the metal surface is reduced, and/or the $\mathrm{Cl}_{2}$ or $S_{2}$ partial pressures are elevated (see Figure 5.6) so that oxide and/or chloride or sulfide can coexist. However, the chloride and sulfide are slowly oxidized to $\mathrm{Fe}_{2} \mathrm{O}_{3}$ at the outer surface of the scale away from the metal substrate, so that the $\mathrm{Cl}_{2}$ or $\mathrm{S}_{2}$ partial pressure in the respective phase is increased and the reaction proceeds by attack of the substrate metal.

The observed low $\mathrm{pH}$-values of the deposits in refuse-fired boilers also suggest the presence of the acid sulfates or pyrosulfates. $\mathrm{ZnCl}_{2}$ and $\mathrm{FeCl}_{2}$ would also give an acidic reaction upon hydrolysis. However, the presence of bisulfates, pyrosulfates, or alkali trisulfates has not been proved by X-ray diffraction. This, of course, does not mean that they were not present, since studies (Miller, 1972) have shown that these materials are difficult to detect in amounts less than 5 percent. Dilution of these phases with normal sulfates reduces the attack on the steels by very significant amounts. 


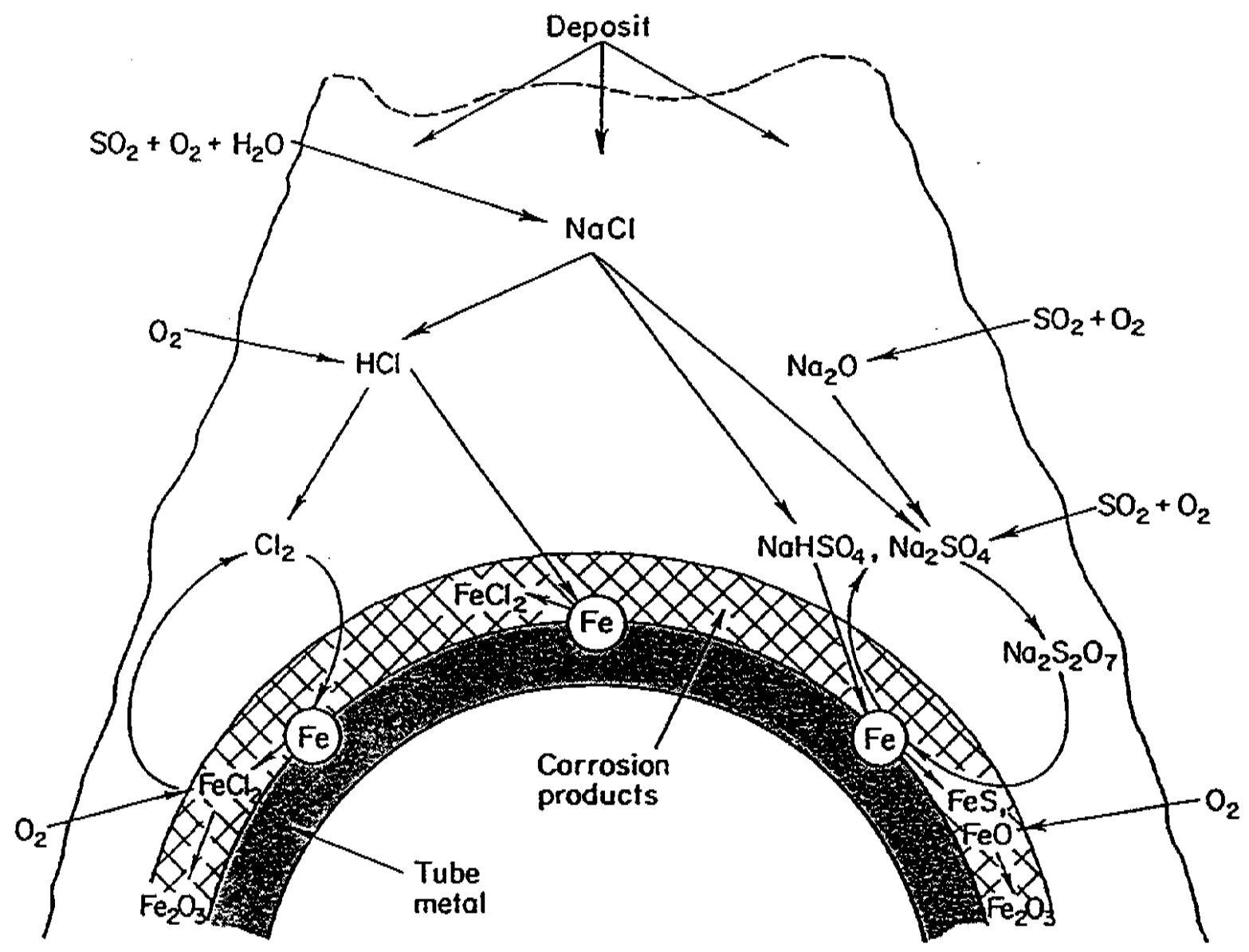

Figure 5.8 Sequence of chemical reactions explaining corrosion of combustor boiler tube (Krause, 1986). 


\subsubsection{Effect of Temperature}

Temperature has an important effect on the corrosion reactions in combustors. Early tests described by Vaughan, et al., (1974) showed that both the metal and the gas temperatures influenced the corrosion rates. Data for carbon steel are shown in Figures 5.9 and 5.10 as Arrhenius plots, which represent the corrosion rates as a function of the metal temperature and gas temperature, respectively. At gas temperatures of 760 and $593^{\circ} \mathrm{C}\left(1400\right.$ and $\left.1100^{\circ} \mathrm{F}\right)$, the corrosion rates and the temperaturedependence of corrosion were significantly lower than at the higher gas temperatures (Figure 5.9), especially at metal temperatures of $371^{\circ} \mathrm{C}\left(700^{\circ} \mathrm{F}\right)$ and higher. The activation energies determined from these plots were very low compared to that expected (approximately $35 \mathrm{kcal} / \mathrm{mole}$ ) for simple oxidation, and ranged from about 5 to $0.3 \mathrm{kcal} / \mathrm{mole}$. In addition, it should be noted that for these combustor corrosion data, no unique activation energy value could be assigned for corrosion at any given metal or gas temperature. At the lower metal (and gas) temperatures low activation energies were measured, consistent with corrosion attack by low-melting compounds. At the higher metal temperatures, when the gas temperatures were also high and corrosion was expected to proceed by gasmetal interactions such as sulfidation/oxidation (which are characterized by well-defined diffusion processes), higher activation energies were measured.

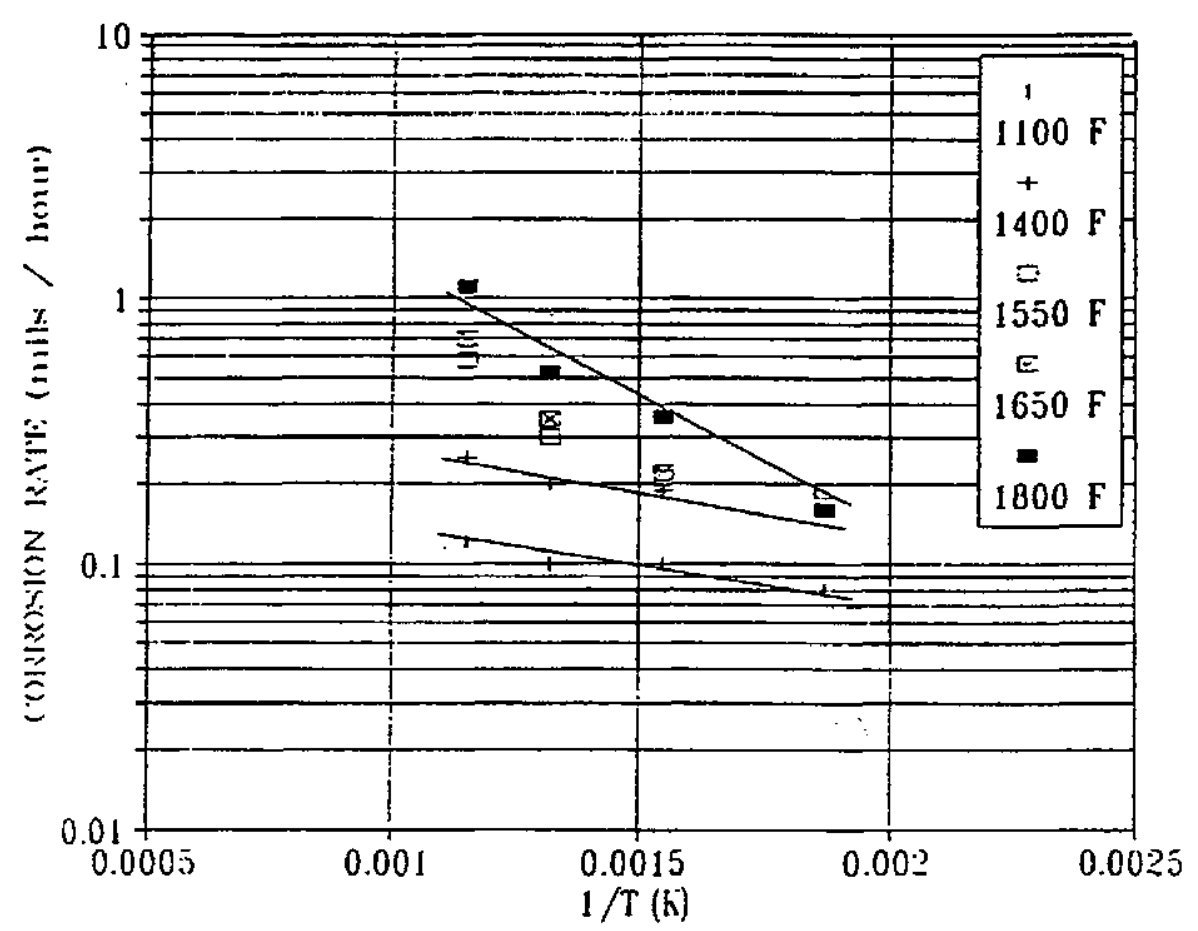

Figure 5.9 Corrosion rates of carbon steel in MSW combustors as a function of metal temperature. (The legend indicates data points for different gas temperatures.) 
41

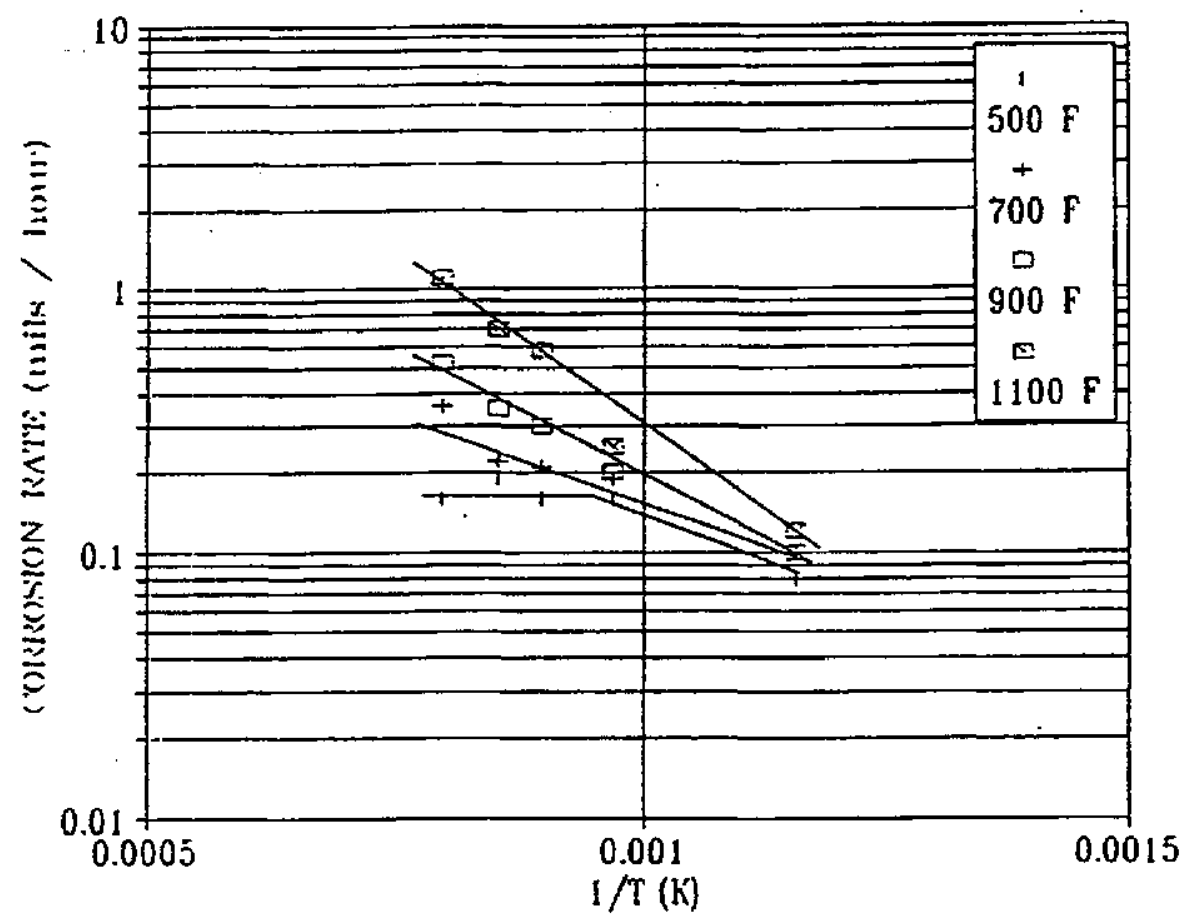

Figure 5.10 The effects of gas temperature on the corrosion rate of carbon steel in MSW combustors. (The legend indicates data points for different metal temperatures.)

Laboratory studies of simulated deposits (Otsuka, et al., 1993) have shown that, for both sulfate-based and chloride-based deposits, corrosion was only slight to negligible at temperatures below the melting point of the deposit. As soon as constituents of the deposits melted, rapid corrosion was observed. Also, in the absence of a deposit, corrosion from a simulated flue gas containing $1500 \mathrm{ppm}$ $\mathrm{HCl}$ was slight at temperatures up to $550^{\circ} \mathrm{C}\left(1022^{\circ} \mathrm{F}\right)$.

\subsubsection{Condensed Acid Attack.}

Corrosion by condensed $\mathrm{H}_{2} \mathrm{SO}_{4}, \mathrm{H}_{2} \mathrm{SO}_{3}$, or $\mathrm{HCl}$ can occur whenever the flue gas stream is cooled below the respective dewpoints of $\mathrm{SO}_{3}, \mathrm{SO}_{2}$, or $\mathrm{HCl}$. This situation is most likely to occur in the air preheater, electrostatic precipitator, ducts, and stack. Based on the nature of the fuel, refuse combustors have more $\mathrm{HCl}$ than $\mathrm{SO}_{2}$ in the flue gas. Therefore $\mathrm{HCl}$ attack would be predominant in the scrubber and in downstream components of such units. Fortunately, the dewpoint of $\mathrm{HCl}$ is low, falling in the range 27 to $60^{\circ} \mathrm{C}\left(80\right.$ to $\left.140^{\circ} \mathrm{F}\right)$ depending on the $\mathrm{HCl}$ concentration and the water content of the gas, as shown in Figure 5.11 (Krause, 1984). Consequently, attack by condensed $\mathrm{HCl}$ rarely occurred before the days of wet scrubbing of the flue gas. Condensed $\mathrm{HCl}$ contributes to the corrosion 
of scrubbers designed to remove S-oxides from coal-fired boilers because it has a synergistic action with the sulfurous and sulfuric acids generated.

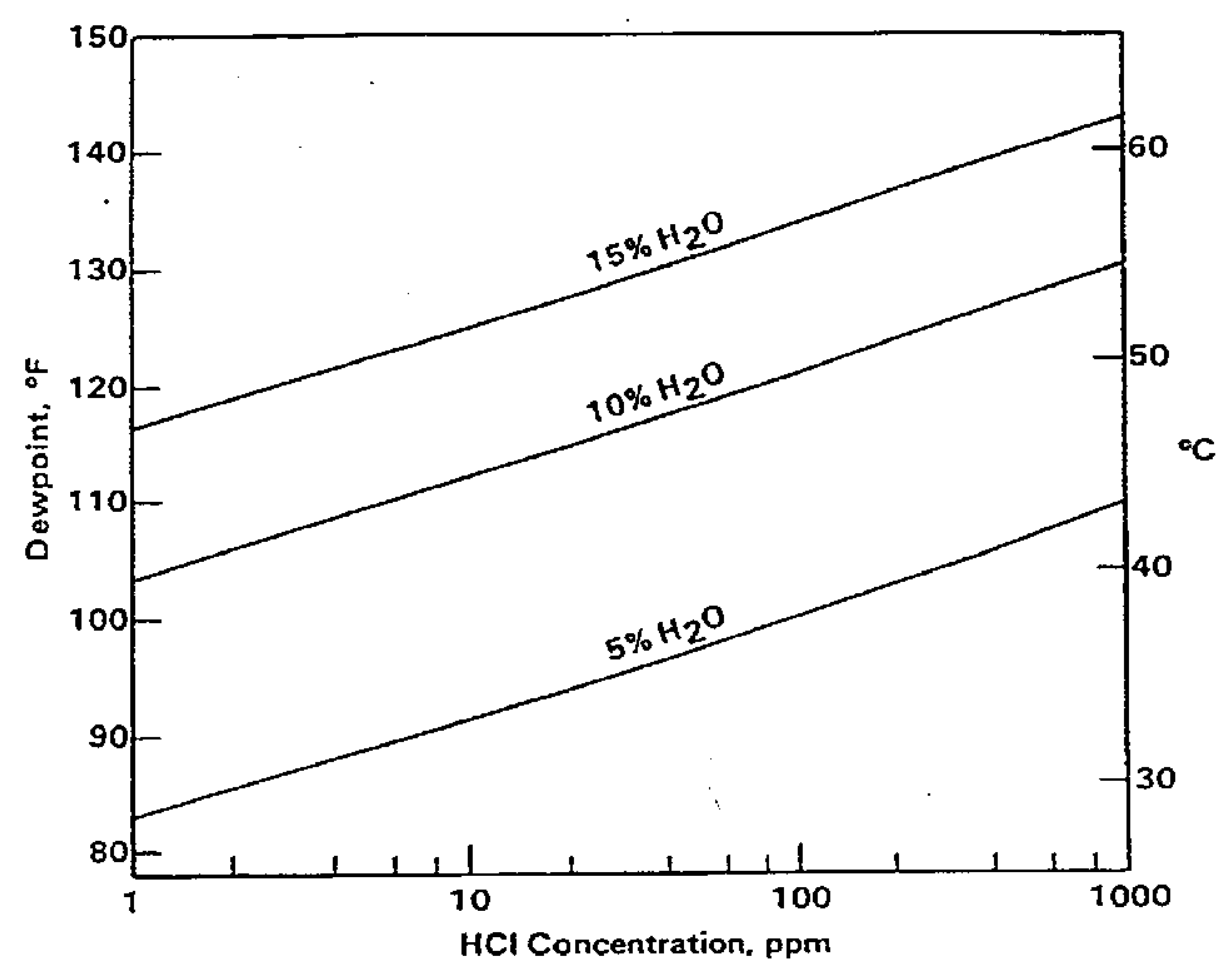

Figure 5.11 Hydrochloric acid dewpoint as a function of $\mathrm{HCl}$ and $\mathrm{H}_{2} \mathrm{O}$ concentrations (Krause, 1984).

Because the chloride corrosion products formed on steel absorb moisture readily from the air, $\mathrm{HCl}$ can form on the metal surface during periods of downtime. Corroded tubes have been observed to become "dripping wet" under such circumstances in humid summer weather, and corrosion rates are enhanced. As a result, it is recommended that auxiliary heating be used to maintain dry conditions during downtime of boilers fueled with chlorine-containing fuels. 


\subsection{Overall Summary of Understanding of Factors Affecting Tube Life}

Corrosion of the heat transfer surfaces of a WTE boiler can result from several sources:

(1) Direct attack by corrosive gas in areas of incomplete combustion, especially where the flame impinges on the metallic surfaces.

(2) Rapid dissolution of protective oxide scales and of the metal surface by low-melting point salts, (French 1991) predominantly chlorides, that condense on the furnace walls, and sometimes on the convection bank tubes. Consideration of the processes occurring in the combustion zone suggests that salts deposited in the convection bank should be sulfaterich, rather than chloride-rich, hence, higher-melting, but this is not always the case. Where chlorides can be deposited on the higher-temperature superheater tubes, the rate of attack can be rapid.

(3) Gas phase oxidation of the superheater tubes, accelerated by the effects of $\mathrm{HCl}$ and mechanical cleaning which can act to cause cracking and spalling of the otherwise relatively protective scales.

Practically all of the chlorine in refuse is volatilized during combustion; it is estimated that the amount of $\mathrm{HCl}$ found in boiler flue gases is about $80 \mathrm{ppm}$ for each 0.1 percent of chlorine in the fuel. The estimated current level of chlorine in MSW is at least 1.3 percent, suggesting that the $\mathrm{HCl}$ content of the combustion gases could exceed $1,000 \mathrm{ppm}$.

Compounds of alkali metals, $\mathrm{Na}$ and $\mathrm{K}$, in MSW are subject to oxidation in the flame, and the oxides which are formed during combustion can react with $\mathrm{HCl}$ to form metal chlorides. The concentrations of chlorine-, sulfur-, and alkali metal-species in the flue gas change as it cools on passage through the boiler. At the concentrations present in the flue gas, $\mathrm{NaCl}, \mathrm{NaOH}, \mathrm{KCl}$, and $\mathrm{KOH}$ are expected to condense on furnace walls, roughly in proportion to their concentration in the flue gas. Further equilibration at the furnace wall temperature will result in conversion of the hydroxides to chlorides and sulfates, so that furnace wall deposits are expected to be mainly chlorides, with some sulfates. $\mathrm{NaCl}$ and $\mathrm{KCl}$ have been identified by $\mathrm{X}$-ray diffraction analysis of probe deposits collected from operating WTE units. 
If the gas is cooled below about $649^{\circ} \mathrm{C}\left(1200^{\circ} \mathrm{F}\right)$ before it enters the convection zone, most of the hydroxides and chlorides can condense out on the furnace walls, so that deposits in the convection zone will be predominantly sulfate-rich. Further cooling below about $527^{\circ} \mathrm{C}\left(981^{\circ} \mathrm{F}\right) \mathrm{HCl}$ concentrations would decrease to near zero because of reaction with alkali silicates. In practice, these gas-solid reactions generally are slow at the lower temperatures. Therefore, most of the chlorine leaving the boiler remains in the flue gas as $\mathrm{HCl}$, and there is little chloride (as $\mathrm{NaCl}$ or $\mathrm{KCl}$ ) in the fly ash.

Heavy metal species, such as zinc, lead, and tin which also are present in refuse, can form metal chlorides in the flame. These compounds have relatively low melting points. However, when mixed with $\mathrm{NaCl}, \mathrm{KCl}$, or other metal chlorides, resulting compounds could be molten at furnace walltube temperatures. The two such mixtures with the lowest melting points involve $\mathrm{FeCl}_{3}$ with $\mathrm{NaCl}$ or $\mathrm{PbCl}_{2}$ (approximately $152^{\circ} \mathrm{C} / 305^{\circ} \mathrm{F}$, and $171^{\circ} \mathrm{C} / 340^{\circ} \mathrm{F}$, respectively). The eutectic mixtures formed by $\mathrm{ZnCl}_{2}$ and $\mathrm{SnCl}_{2}$ all would be molten at wall tube temperatures, whereas all of the $\mathrm{PbCl}_{2}$ eutectics (except that with $\mathrm{FeCl}_{3}$ ) would only melt at superheater temperatures. Chlorides of $\mathrm{K}, \mathrm{Mg}$, and $\mathrm{Ca}$ also can be part of low-melting eutectic mixtures.

Corrosion is only slight to negligible at temperatures below the melting point of the deposits. As soon as constituents of the deposits melt, rapid corrosion occurs. However, the presence of a solid alkali chloride deposit on the metal surface can aggravate the corrosion process if $\mathrm{SO}_{2}$ is present in the flue gas. In that case, the chloride is converted to sulfate, with the release of $\mathrm{HCl}$ in the deposit.

Low pH-values are measured for the deposits in refuse-fired boilers, which also suggest the presence of the acid sulfates or pyrosulfates. The lowest-melting pyrosulfate, $\mathrm{K}_{2} \mathrm{~S}_{2} \mathrm{O}_{7}$, melts at approximately $293^{\circ} \mathrm{C}\left(560^{\circ} \mathrm{F}\right)$.

Corrosion by direct action of $\mathrm{HCl}$ gas is slow in the metal temperature range 149 to $260^{\circ} \mathrm{C}$ ( 300 to $500^{\circ} \mathrm{F}$ ). However, chlorine attacks steel rapidly in this temperature range. At a metal temperature of $538^{\circ} \mathrm{C}\left(1000^{\circ} \mathrm{F}\right)$ and a flue gas temperature of $1060^{\circ} \mathrm{C}\left(1940^{\circ} \mathrm{F}\right)$, corrosion by combustion gas without $\mathrm{HCl}$ results in a continuous non-porous scale consisting of $\mathrm{FeO}, \mathrm{Fe}_{3} \mathrm{O}_{4}$, and $\mathrm{Fe}_{3} \mathrm{O}_{4}$ being formed. With 0.1 vol. percent $\mathrm{HCl}$ in the combustion gas, the inner scale layers are continuous, but the outer $\mathrm{Fe}_{2} \mathrm{O}_{3}$ layer becomes blistered and cracked. This $\mathrm{Fe}_{2} \mathrm{O}_{3}$ layer in turn becomes porous and discontinuous when the $\mathrm{HCl}$ concentration is increased to 0.2 vol. percent. A further increase of $\mathrm{HCl}$ content (to 0.8 vol. percent) causes complete disintegration of the $\mathrm{Fe}_{2} \mathrm{O}_{3}$ layer, 
and the $\mathrm{Fe}_{3} \mathrm{O}_{4}$ layer becomes irregular and porous. The maximum content of $\mathrm{HCl}$ that was investigated ( 2 vol. \%) destroyed the continuity of both outer layers, exposing the underlying FeO to attack by oxygen and $\mathrm{HCl}$. Nevertheless, in the absence of a deposit, corrosion from a simulated flue gas containing $1,500 \mathrm{ppm} \mathrm{HCl}$ was found to be slight at metal (and gas) temperatures up to $550^{\circ} \mathrm{C}$ $\left(1022^{\circ} \mathrm{F}\right)$.

Corrosion rates and the temperature-dependence of corrosion measured in field tests were significantly lower at gas temperatures below $760^{\circ} \mathrm{C}\left(1400^{\circ} \mathrm{F}\right)$, than at the higher gas temperatures, especially at metal temperatures of $371^{\circ} \mathrm{C}\left(700^{\circ} \mathrm{F}\right)$ and higher. At the lower metal (and gas)

temperatures, results indicated that the corrosion attack was by low-melting compounds. At the higher metal and gas temperatures, the corrosion proceeded by gas-metal interactions (which are characterized by well-defined diffusion processes), higher activation energies were measured.

In nominally reducing conditions, corrosion of low alloy steel at $400^{\circ} \mathrm{C}\left(752^{\circ} \mathrm{F}\right)$ by flue gas (at the same temperature) without $\mathrm{HCl}$ occurs at a parabolic rate. With $400 \mathrm{ppm} \mathrm{HCl}$ in the flue gas, corrosion rates of mild steel are linear with time. Increasing the $\mathrm{HCl}$ content of the gas to $2,000 \mathrm{ppm}$ almost doubled the linear corrosion rate; there is little effect of further increases above $2,000 \mathrm{ppm} \mathrm{HCl}$ on corrosion rates. The increase in the corrosion rate resulting from the presence of $\mathrm{HCl}$ in a reducing atmosphere was attributed to oxidation-sulfidation promoted by scale disruption through $\mathrm{FeCl}_{2}$ subsequent formation and volatilization. The formation of volatile $\mathrm{FeCl}_{2}$ induces scale porosity. This higher porosity promotes spalling during service.

Corrosion by condensed $\mathrm{H}_{2} \mathrm{SO}_{4}, \mathrm{H}_{2} \mathrm{SO}_{3}$, or $\mathrm{HCl}$ can occur whenever the flue gas stream is cooled below the respective dewpoints of $\mathrm{SO}_{3}, \mathrm{SO}_{2}$, or $\mathrm{HCl}$. However, the dewpoint of $\mathrm{HCl}$ is the lowest of the three, so that no extra measures are required to prevent condensation. However, if condensation does occur, $\mathrm{HCl}$ can contribute to severe pitting attack. 


\section{Overview of Metal Wastage Experienced in Waste-Fired Steam Generators}

\subsection{Influence of Boiler Design}

In a modern mass-burn boiler, the combustion chamber typically is enclosed by membrane waterwalls, the lower regions of which are protected from corrosion. The top of the radiant zone consists of bare waterwalls. The combustion gas passes from the radiant zone into a convection section containing the steam generator, superheater, and economizer tube banks. The configuration of the boiler may parallel that of a conventional coal-fired boiler, in which the superheater is situated at the top of the combustion chamber in the entrance to the convection zone as illustrated in Figure 6.1 or, alternatively, the convection zone may consist of several passes with the superheater situated a considerable distance from the combustion chamber, as is shown in Figure 6.2.

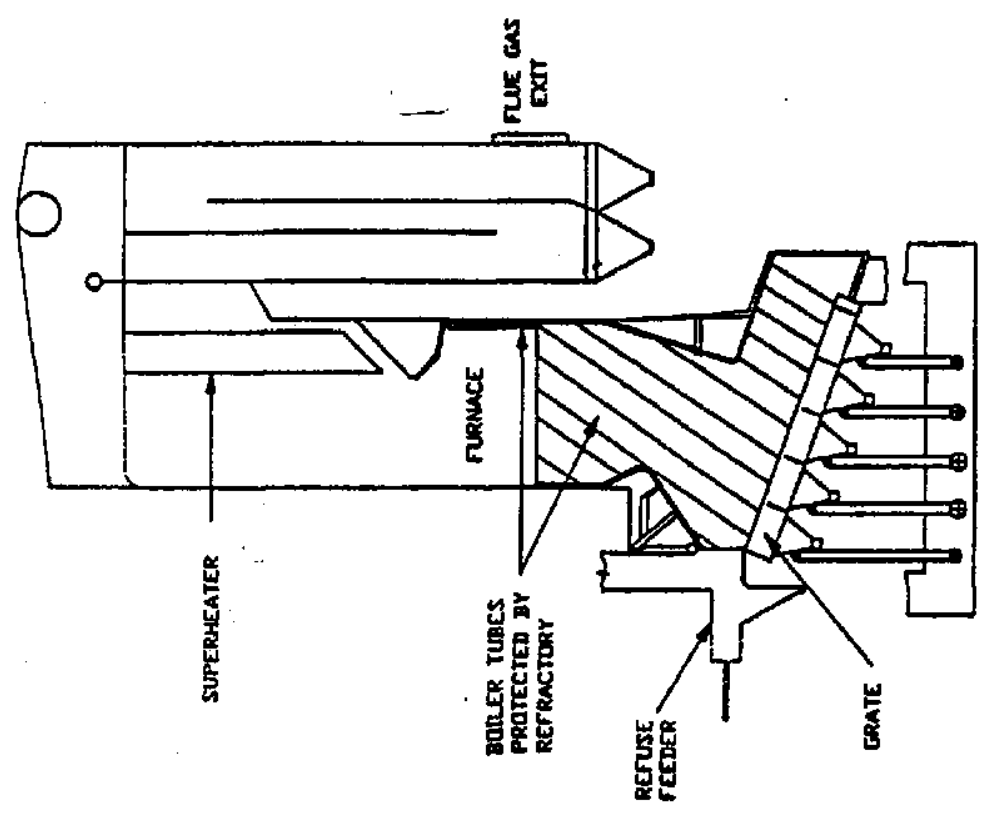

Figure 6.1 Schematic elevation of a waste-to-energy boiler with the superheater at the top of the furnace zone (Strach, 1989). 


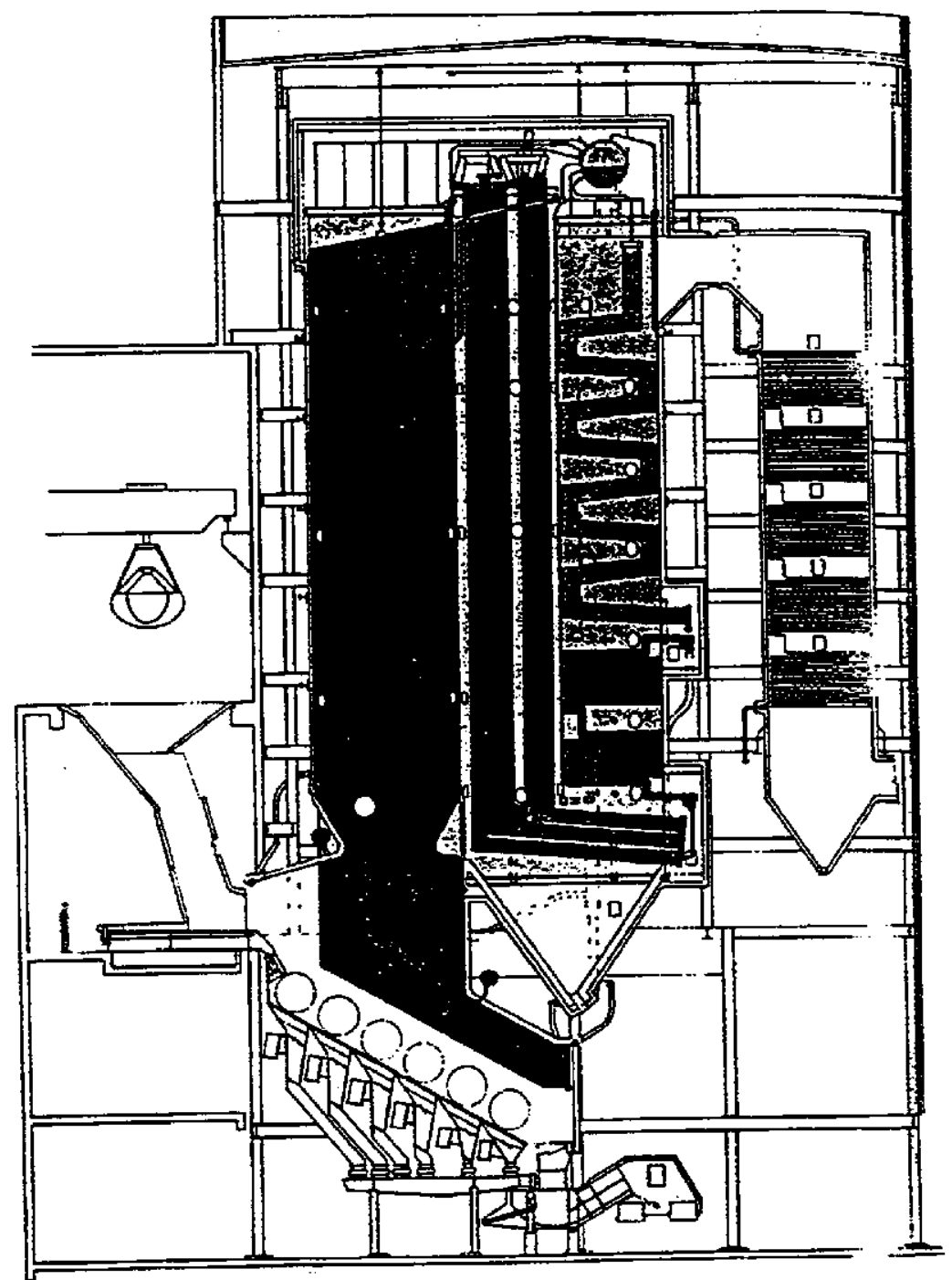

Figure 6.2 Schematic elevation of a waste-to-energy boiler with the superheater located in the back pass (Gursky, 1992). Used by permission.

\subsubsection{Design of Mass-Burn Plant}

The lower part of the combustion chamber in a multi-pass mass-burn boiler usually is lined with silicon carbide to avoid corrosion. In this zone, the combustion gas is cooled to approximately $954^{\circ} \mathrm{C}\left(1750^{\circ} \mathrm{F}\right)$ to minimize corrosion of the upper, unprotected waterwalls. Corrosion of the convection pass tubes can be minimized if the combustion gas temperature is cooled to the range 650 to 
$760^{\circ} \mathrm{C}\left(1200\right.$ to $\left.1400^{\circ} \mathrm{F}\right)$. One approach to cooling the gas is to arrange for the second gas pass to be an empty, waterwall-lined chamber (see Figure 6.2), or to contain evaporator elements. The first heat transfer tube bundle in the third pass encountered by the flue gas is the final superheater which, in modern designs, is arranged for parallel flow, and reduces the flue gas temperature from about $650^{\circ} \mathrm{C}$ $\left(1200^{\circ} \mathrm{F}\right)$ to about $600^{\circ} \mathrm{C}\left(1112^{\circ} \mathrm{F}\right)$. The tube material is mostly carbon-steel, but higher alloys may be used for the leading tubes where the gas entering the tube bank may attain temperatures higher than desired. The next heating surface is the primary superheater which also is fabricated from carbon steel, and which reduces the flue gas temperature from $600^{\circ} \mathrm{C}$ to about $450^{\circ} \mathrm{C}\left(842^{\circ} \mathrm{F}\right)$. The fourth pass contains the economizer where the flue gas temperature is reduced to about $230^{\circ} \mathrm{C}\left(446^{\circ} \mathrm{F}\right)$ before the flue gas enters the gas cleanup system.

In general, corrosion damage has been experienced in newly erected mass-burn plants after a few thousand hours of operation. Only a few cases have been reported where increased corrosion occurred after many years of damage-free operation. The most critical areas for fireside corrosion appear to be the waterwalls in the combustion chamber (especially when the SiC coating has been lost, has not been applied, or does not extend to a sufficient height), and the first convection-heated tube banks, especially superheaters exposed to the highest gas temperatures. No obvious correlation has been noted between the design steam parameters and the occurrence of corrosion. However, there does seem to be some correlation between increasing tube surface metal temperature and increasing corrosion, as expected since corrosion processes are thermally-activated. Where accelerated corrosion is observed, the corrosion rates are nearly always very high (Reichel, 1989), around 500 to 1,000 $\mathrm{nm} / \mathrm{hr}$ (172 to $345 \mathrm{mil} / \mathrm{yr})$.

\subsubsection{Design of RDF Plants}

The design of boilers used to fire RDF usually has been based on that of stoker-fired boilers used with coal; the superheater is located above the nose at the top of the combustion zone, and the steam generator and economizer are contained in a single convection pass, as indicated schematically in Figure 6.3. The use of an essentially standard boiler design may reduce the initial cost of the unit, but the relatively small size of the furnace zone (compared, for instance to units designed for mass-burning) requires that attention must be given to maintaining good heat absorption in the waterwalls, so that the flue gas temperature at the entrance to the superheater is acceptably low. For this reason, SiC lining of 
the lower waterwalls generally is not practiced. Experience with RDF-fired boilers has been that some have suffered furnace wall wastage and tube failures after very short operating times, in some cases within the initial 2,000 hours to one year of operation. Depending on the boiler and location within the furnace, corrosion rates up to 913 to $1,370 \mathrm{~nm} / \mathrm{hr}$ ( 315 to $472 \mathrm{mil} / \mathrm{yr}$ ) have been measured. In most boilers, waterwall corrosion has resulted in the application of a weld overlay of a corrosion-resistant nickel-chromium alloy, Alloy $625(61 \mathrm{Ni}-21.5 \mathrm{Cr}-9 \mathrm{Mo}-5 \mathrm{Fe}-3.6 \mathrm{Nb}-0.4 \mathrm{Ti}-0.4 \mathrm{Al}-0.1 \mathrm{Si}-0.05 \mathrm{C})$ over a significant area of the lower and, in some cases, the upper waterwalls.

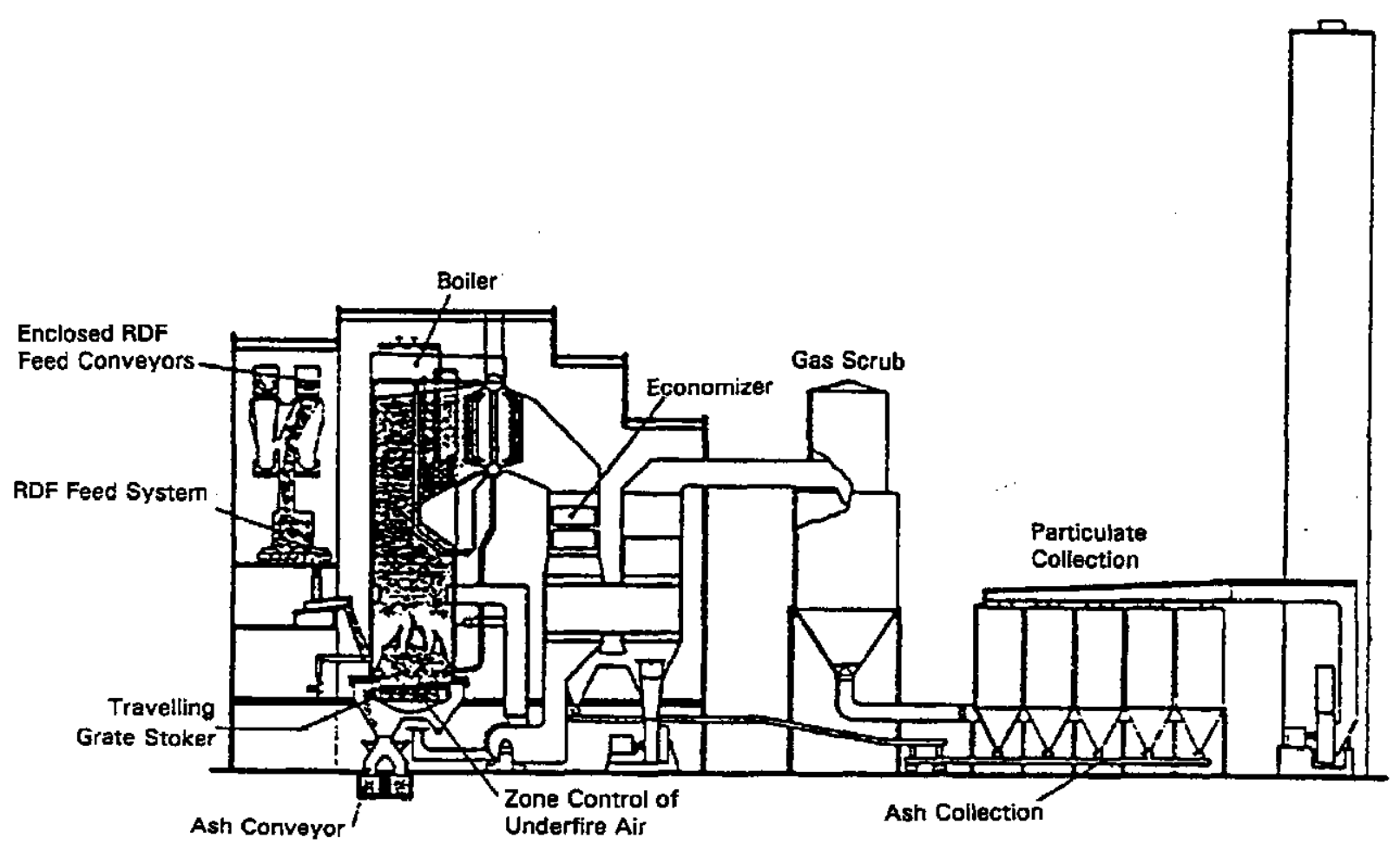

Figure 6.3 Schematic elevation of the RDF boiler design used at Hartford, Connecticut. Used by permission of the Connecticut Resource Recovery Authority.

\subsection{Combustion Zone Problems}

The major factors that contribute to the substantial metal wastage experienced in both waterwalls and convective passes of WTE boilers include (Stanko, 1991): feed stock composition, design features, and operating conđitions such as temperature, velocity, and gas/solids composition. Chlorine-containing species are held to be largely responsible for the rapid wastage, although attack by sulfatic deposits also is possible in the high-temperature regions. 
On bare waterwalls, tube failures typically have occurred just above the stoker, or in the vicinity of over-fire air ducts or ports. In addition, the corrosion effects are exacerbated by erosion from the locally high flue gas or over-fire air velocities. Common characteristics of corroded waterwall tubes are (Reichel, 1989):

(1) the iron oxide formed on the tube is non-adherent, porous, and laminated,

(2) the quantity of corrosion products remaining on the tube wall is only a small fraction of the total corroded metal, and

(3) $\mathrm{FeCl}_{2}$ is observed in the innermost layer of corrosion products in direct contact with the uncorroded metal.

French (1991) categorized the ash deposits on the waterwalls as having two distinct layers: an outer, soft, friable layer containing carbon, sulfur, and chlorine, and an inner, dark or black layer containing much higher levels of carbon and chlorine, as well as $\mathrm{Na}, \mathrm{Zn}$, and $\mathrm{Pb}$. Solution of the inner layer in water usually results in an acid $\mathrm{pH}$, indicating the acidic nature of the chloride deposits. The inner layers are easily scraped off the tubes, indicating a less protective scale than the iron oxide formed under air-oxidizing conditions. The presence of carbon and sulfides within both layers indicates that poor combustion was occurring near the walls, resulting in reducing conditions and possibly an increased heat flux and the presence of aggressive species. Chemical and spectrographic analyses of waterwall deposits led French (1991) to suggest the following scenario::

- strongly reducing conditions exist adjacent to the furnace wall, at least on the micro environment scale,

- $\mathrm{HCl}$ and/or $\mathrm{Cl}_{2}$ migrates to the tube surface and forms an iron chloride as a corrosion product, thus the wastage is a chlorination reaction,

. the presence of $\mathrm{Fe}$, and $\mathrm{Na}, \mathrm{Zn}$, and sometimes $\mathrm{Pb}$ suggest the formation of mixed chlorides and low melting point chlorides, and

the cation mix of the leachable chlorides from the inner layer show mostly $\mathrm{Na}$, with some $\mathrm{Fe}$ and no $\mathrm{Zn}$. Lead oxide is not very soluble in water, so would not show up in this test, whereas $\mathrm{ZnCl}_{2}$ is soluble, and was missing.

The appearance of the corrosion wastage beneath the deposits is of a fairly uniform attack, usually with no evidence of, for instance, deep pitting or circumferential grooving. Maximum wastage 
occurs typically toward the midpoint of the fire-side surface of the tube, which is the hottest portion of the surface.

The available information led to the suggestion (French, 1991) that there are two possible corrosion mechanisms that could account for the rapid wastage of carbon steel waterwall tubes, which are:

(1) Gas-phase chlorination: strongly reducing conditions exist in the flue gas, so that sulfur is present as $\mathrm{H}_{2} \mathrm{~S}$ and iron sulfide scales form rather than iron oxide. These scales are inherently more porous and less protective than oxide scales, and $\mathrm{HCl}$ more easily attacks the sulfides to form iron chlorides as a corrosion product. Reducing conditions are essential for this mechanism to proceed by the formation of iron chlorides.

(2) Liquid ash corrosion: the presence of chlorides in the deposits leads to the formation of low-melting point liquids along the tube surface that may contain $\mathrm{Zn}, \mathrm{Pb}, \mathrm{Fe}$, and $\mathrm{Na}$ chlorides. These liquids would be expected to dissolve any protective iron oxide, leaving bare steel to be corroded by $\mathrm{HCl}$.

Where the main form of corrosion is from gas-phase attack, the generally-accepted threshold temperature below which chlorine-induced corrosion is minimal (Stanko, 1991) is $232^{\circ} \mathrm{C}\left(450^{\circ} \mathrm{F}\right.$ ). Since waterwall tubes typically operate with metal temperatures between 260 and $315^{\circ} \mathrm{C}$ (500 and $600^{\circ} \mathrm{F}$ ), corrosion from gaseous chlorine species is possible in locations exposed to reducing conditions. In the liquid ash-type of attack, the temperature at which accelerated corrosion occurs depends on the melting temperature of the compound, or mixture of compounds, promoting the corrosion. Vapors containing chlorine compounds tend to condense at or near waterwall tube metal surface temperatures. Correlation with temperature of the composition of deposits removed from various locations in a municipal solid waste combustor was found to be consistent with the notion that deposits formed at lower temperatures are richer in the more volatile compounds such as chloride, while deposits formed at high temperatures are proportionally richer in lower vapor pressure compounds such as sulfates and fly ash constituents. The presence of chlorine at the metal surface has been a consistent observation in studies involving corrosion in WTE units. 
Even if prevailing reducing conditions could be changed to oxidizing conditions along the waterwalls above the grate, the formation of liquid chlorides along the surface of the waterwall tubes still would be possible in the presence of the high levels of chlorine typical in these boilers. Dissolution of the protective iron oxide scale by these liquid species would lead to wastage either by chlorination or oxidation, perhaps even in a fully-oxidizing atmosphere. Simply assuring oxidizing conditions along the waterwalls therefore may not be sufficient to prevent wastage. Recent laboratory tests (Paul, 1993) have shown that both carbon steel and Type 304L stainless steel were severely attacked under oxidizing conditions by molten chloride salt mixtures at $316^{\circ} \mathrm{C}\left(600^{\circ} \mathrm{F}\right)$.

As mentioned earlier, the two main approaches for minimizing corrosion of the lower waterwalls are: protection with a layer of refractory, or the use of higher-chromium alloys, where heat transfer must be maintained. The preferred refractory lining is silicon carbide, usually to a thickness of $2.5 \mathrm{~cm}$ ( 1 inch). The lining usually is applied by trowelling, and is anchored to the walls using a highdensity of sleeveless carbon steel pin studs (Strach, 1989, 1993). Calcium-bonded silicon carbide apparently has proved the most durable. Prefired silicon carbide tiles are preferred in Germany, and are increasingly used in the U.S. However, although such linings are effective, refractory maintenance is constant, and there is a loss in overall heat transfer. Certain types of refractory also are prone to slagging (Gursky, 1992), which further reduces heat transfer.

The choice of replacement alloy depends on the circumstance: for new construction bimetallic tubes of ferritic carbon-steel with an outer layer of high-chromium alloy (such as Type 304, 309 or 310 stainless steel) could be considered while, for existing boilers, a weld overlay of Alloy 625 , which has a coefficient of thermal expansion close to that of carbon-steel, has been used with good success. The successful application of weld overlay coatings is dependent on achieving good overall cleanliness of the tube (grit-blast to white metal) at the time that the weld overlay is made, to avoid local debonding and small gaps in the weld coverage that could lead to pinhole attack.

Cast high-alloy blocks or refractory shapes have been used along the grate line for protection. These replaceable liners, bolted to the waterwalls, typically extend up to $4 \mathrm{ft}$. or so above the grate in the charging section, to approximately $1 \mathrm{ft}$. above the grate at the discharge. The alloys used to fabricate cast grate bars and sidewall plates are typically high-Cr steels such as $25 \mathrm{Cr}-12 \mathrm{Ni}, 27 \mathrm{Cr}-8 \mathrm{Ni}$, and $30 \mathrm{Cr}-3 \mathrm{Ni}$. These components are exposed to temperatures that vary between 700 and $1000^{\circ} \mathrm{C}$ (1292 and $1832^{\circ} \mathrm{F}$ ) and to a wide range of corrosive conditions, depending on the composition of the 
waste being burned. The two major modes of failure of such heat resistant castings in waste combustors appear to be (Steinkush, 1989):

(1) cracking, resulting from high-temperature gradients within the castings, and

(2) loss of wall thickness because of high-temperature corrosion.

This survey indicated that attack of the waterwalls has increased in recent years as two-stage combustion has been introduced to reduce $\mathrm{NO}_{x}$ production. These changes have sometimes resulted in the generation of persistent substoichiometric conditions at the waterwalls, which has allowed the reaction of $\mathrm{HCl}$ with the $\mathrm{Fe}_{3} \mathrm{O}_{4}$ scale on the tubes to form $\mathrm{FeCl}_{2}$, with acceleration in the rate of degradation of the tubes. Chlorine is the main corrosive agent in roughly two-thirds of the cases, and sulfur is a main corrosive element in the other cases.

The mixtures of sulfates observed in waterwall ash deposits are typically not expected to be liquid at the operational temperature, and appear not to be harmful in the solid state. Pyrosulfates and alkali iron tri-sulfates, which are expected to form melts in the temperature range of interest, are not usually detected in tube deposits, but may be a factor under some circumstances in WTE boilers.

In summary, the countermeasures that have been credited with a good measure of success in preventing corrosion of the waterwalls in WTE boilers include:

(1) covering with a SiC lining (pre-fired, high-density tiles preferred) applied over studded carbon steel tubes (mass-burn units),

(2) application of a weld overlay coating of a nickel-chromium alloy, such as Alloy 625, with care to avoid dilution of the nickel content of the alloy,

(3) avoiding locally-reducing (substoichiometric) conditions at the waterwalls from incomplete combustion or flame impingement by arranging for the introduction of air along the walls (air blanketing), and by providing a high quality of combustion through:

- redistributing the over-fire air, and

- controlling the furnace combustion level through control of the moisture level of the refuse feed, and the use of variable gas/oil injection. 


\subsection{Convection Zone Problems}

Incidences of high rates of metal loss from superheater tubes have been observed in some boilers after the first 2,000 to 4,000 hours of operation. The tube failures typically occur on the flue gas in-flow side of the final stage superheater, and near the locations of the soot blowers. Maximum tube thinning typically is located on the crown of the tube facing the gas flow. A not unusual scenario for superheater failures starts with the observation of tube thinning on the leading tubes, and may be followed by tube ruptures, with the interval between ruptures decreasing and the number of tubes requiring repair increasing with time.

The upstream side of the corroded tubes typically develop deposit layers of thicknesses ranging from < 1 to $10 \mathrm{~mm}$ ( 39 to $394 \mathrm{mil}$ ), which often have a bow-shaped form on the leading tubes. The deposit layers consist of an external layer of mainly alkali and alkaline-earth sulfates (very low chloride content), a layer of iron oxide scale, and an innermost, often laminated layer richer in chlorides. On shutdown, such deposits are typically very non-adherent and tend to easily break away. Such corrosion has been observed in the absence of a reducing flue gas atmosphere; also, there is often evidence of localized wastage which is attributed to erosive attack. The thickness of the oxide scale formed frequently is less than that calculated from the loss of wall thickness, indicating that periodic scale shedding occurs. The innermost region of the deposit/corrosion product which contains chlorine

often is iron-chloride $\left(\mathrm{FeCl}_{2}\right)$, which forms a thin layer in direct contact with the metal. This layer may be yellow-brown in color and hygroscopic, or dry and honeycombed in structure. The chlorine may be accompanied by $\mathrm{Na}, \mathrm{K}, \mathrm{Zn}$, alkaline earth, or other metallic elements. In some cases, reducing conditions may prevail during operation when difficulties are experienced in maintaining uniform combustion of the fuel or in ensuring that entrained fuel particles have been completely combusted before they enter the convection zones. Then, the corrosion products consist of the iron oxides lower in oxygen than $\mathrm{Fe}_{2} \mathrm{O}_{3}$, and sulfides of $\mathrm{Fe}, \mathrm{Pb}$, and $\mathrm{Zn}$, in addition to $\mathrm{FeCl}_{2}$.

The thickness of the deposits formed usually does not exceed $0.1 \mathrm{~mm}$ ( $4 \mathrm{mil}$ ), and the chemical composition of the deposit can vary over a large range, and can contain complex alkaline and calcium sulfates and chlorides, and $\mathrm{Al}, \mathrm{Pb}, \mathrm{Zn}$, and $\mathrm{Cu}$ as oxide or sulfates. The sequence of events in the corrosion process involving such deposits has been postulated to be as follows (Kautz, 1971; Miller, et al., 1972): potassium (and other alkali and alkaline-earth) chloride and sulfur dioxide in the deposit react with oxygen to produce potassium sulfate and either $\mathrm{HCl}$ or chlorine. The liberated $\mathrm{HCl} / \mathrm{Cl}_{2}$ 
reacts with the underlying alloy to produce ferrous chloride, which can further react with oxygen to form iron oxide and free chlorine, serving to perpetuate the corrosion process. Factors which accelerate the corrosion were thought to be:

tube wall temperatures exceeding $350^{\circ} \mathrm{C}\left(662^{\circ} \mathrm{F}\right)$, and large quantities of vaporized chlorides reaching the tubes.

Remedial measures involve reducing the temperature of the flue gas before entry into the final superheater, and assuring turbulent conditions in the gas stream to maximize the reaction of the alkali chlorides in the gas stream to sulfates before contacting the hot tube surfaces. Plumley (1991) suggested that the formation of clusters of glowing particles in the flue gas could be minimized by introducing turbulent mixing to ensure complete burnout before the particles enter the superheater; stratified gas flow over the tube banks and the ensuing increase in relative velocity triggers local burnout, which can lead to locally reducing conditions. When these changes cannot be accomplished through modification to the operation of the boiler, design changes are required, such as installing a sufficiently large evaporator section before the final superheater. An evaporator tube section with a steam pressure of $4.6 \mathrm{MPa}(650 \mathrm{psig})$ has a saturated steam temperature of $257^{\circ} \mathrm{C}\left(495^{\circ} \mathrm{F}\right)$, and a tube wall temperature of approximately $268^{\circ} \mathrm{C}\left(515^{\circ} \mathrm{F}\right)$, which is at the lower end of temperature zone in which corrosive attack accelerates. This approach has been used in a number of the RDF boilers in the U.S.

Where it is not possible to install new heating surface to act as screen tubes for the existing final superheater, it may be possible in some boilers to reroute the steam/water flow in the superheater section so that the coolest tubes contact the hottest gas. An example of this principle was the conversion of the original final superheater into an evaporator section, and to subdivide the original primary superheater to become the final superheater, as well as the primary superheater, in a German combustor (Schirmer, 1984). This change resulted in a reduction in flue gas temperature from 760 to $600^{\circ} \mathrm{C}\left(1400\right.$ to $\left.1112^{\circ} \mathrm{F}\right)$ as it passed through the "new" evaporator, compared to 760 to $675^{\circ} \mathrm{C}(1400$ to $1247^{\circ} \mathrm{F}$ ) when the evaporator was connected as the final superheater. The tube wall temperature of the new evaporator was 270 to $275^{\circ} \mathrm{C}\left(518\right.$ to $\left.527^{\circ} \mathrm{F}\right)$, compared to 300 to $435^{\circ} \mathrm{C}\left(527\right.$ to $\left.815^{\circ} \mathrm{F}\right)$ as the final superheater; the new final superheater had a wall temperature of 325 to $435^{\circ} \mathrm{C}$ ( 617 to $815^{\circ} \mathrm{F}$ ), while the flue gas temperature at this location was 450 to $600^{\circ} \mathrm{C}\left(842\right.$ to $\left.1112^{\circ} \mathrm{F}\right)$. During 1,200 hours 
of subsequent operation, the rate of tube wall thinning was approximately $100 \mathrm{~nm} / \mathrm{hr}$ ( $34 \mathrm{mil} / \mathrm{yr}$ ), which still is not acceptable.

Another approach is to install tubes of corrosion-resistant alloy in those locations prone to attack. A number of boilers in the U.S. have several rows of superheater tubing made from Alloy 825 (Fe-42Ni-21.5Cr-3Mo-2Cu-0.6Mn-0.8Ti-0.3Si-0.03C) which, in the case of the Saugus, MA plant, have given good service for 10 to 13 years. Alloy 825 tubes also have been installed in the most vulnerable areas of the superheater in several of the higher steam temperature WTE plants in the U.S., including Westchester Co. NY (1984), Baltimore, MD (1984), and Millbury, MA (1987), all of which operate with $6.3 \mathrm{MPa}(900 \mathrm{psig}), 443^{\circ} \mathrm{C}\left(830^{\circ} \mathrm{F}\right)$ steam. No superheater failures have been reported at these sites. Test sections of superheater tubes of other alloys, such as Mannesmann's AC66 (Fe-32Ni$27 \mathrm{Cr}-0.8 \mathrm{Nb}-0.08 \mathrm{C}-0.08 \mathrm{Ce}$ ), are on trial in several boilers.

Corrosion in the convection zone may be aggravated by erosion from soot blowing, particularly when steam is the cleaning medium. Soot blowing is thought to remove the existing scale/deposit, thus stripping the tube of a potential barrier to the corrosive reaction and exposing fresh metal to attack at higher rate. Tubes adjacent to soot blower lanes have been protected by shields, as in coal-fired utility boilers. Half shields, which cover only one face of the tube, have been used as well as full shields which completely encase the tubes. In many cases, these shields have been made from Type 309 stainless steel, but trials have been made with other alloys, such as Alloy 625 and Alloy 825 . The lifetime of such shields is of the order of up to 2 years. Tubular specimens of, for instance, Alloy 625 and Alloy 825, appear to offer significantly longer service life.

In some cases, the superheater tubes have been studded to minimize the loss of protective oxide film due to soot blowing (Nakazato, 1989). Since some of the erosive damage from soot blowing is caused by entrained water droplets from the soot blower itself, improved maintenance of soot blower valves can reduce the tube damage. The use of compressed air-type soot blowers is practical in some applications. Other devices for cleaning tube bundles are in use in some boilers. Low frequency sonic soot blowers have been found to be ineffective on superheaters (Nakazato, 1989), but sonic horns have been used to good effect elsewhere for steam generator banks. Mechanical rapping systems have been found to be very effective in some boilers in Germany (Herrmann, 1988) and in the U.S., especially with superheaters that have vertical tubes. It is claimed that mechanical rapping effectively removes the loose ash deposits without disturbing the protective oxide film on the tubes. 
In summary, the remedial measures credited with reducing corrosion of the superheater and other convection pass tubes in WTE boilers include those that:

1) Minimize particle carryover from the combustion zone.

(2) Reduce the temperature of the flue gas entering the convection tube banks to a maximum of $760^{\circ} \mathrm{C}\left(1400^{\circ} \mathrm{F}\right)$. If this cannot be achieved because of furnace size limitations, the use of several rows of screen tubes (evaporator tubes) ahead of the superheater can be effective.

(3) Reduce the metal/steam temperature of the leading tubes in the first rows that contact the flue gas.

(4) Protect the first 2 to 4 rows of the final superheater, using devices such as metallic shields or ceramic protective tubes, although these require extensive maintenance to maintain attachment and alignment.

(5) Replace the upstream rows of superheater tubes with a more resistant alloy, such as Alloy 825 .

(6) Protect areas where directional changes in the flue gas flow occur, usually by shields or refractory coverings.

(7) Protect tubes adjacent to soot blower lanes predominately using shields.

(8) Replace soot blowers with mechanical rappers or sonic horns.

\subsection{Summary of Main Categories of Boiler Tube Problems}

The purpose of this investigation is the review of information from the WTE industry which has shown that many of the operating WTE plants in the U.S. experience rapid corrosion of the furnace 
walls. The corrosion is mostly by molten chloride-rich salts and is often associated with reducing conditions. Furthermore the study indicated that corrosion of the superheater tubes is mostly by attack

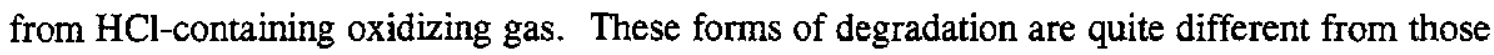
commonly encountered in coal-fired boilers.

The descriptions of corrosion problems experienced, together with the review of the state of understanding of the factors affecting corrosion in these systems, suggests the following categorization of major causes of the modes of boiler tube failures specific to WTE boilers, which are taken from the companion EPRI study (Wright, et al., 1994), in which the causes and remedial measures were examined in greater detail. This categorization of the types of failures is based on location in the boiler, since the failure causes depend on tube metal/fluid temperature, flue gas temperature, velocity, and composition, which change with location.

(1) Waterwall Thinning Along the Grate Line occurs in a band on each sidewall at an elevation extending from the top of the grate to the maximum height attained by the fuel bed. The main evidence of this form of wastage is gouging and general damage along the waterwall in line with the surface of the grate. This form of wastage is caused by the heterogeneous nature of the fuel that results in occasional hard objects that are too large to be properly accommodated on the grate, and are dragged along the wall by the motion of the grate. Wastage results from a combination of mechanical damage from components in the waste stream that are in contact with the wall and are dragged along it, and gaseous corrosion from the proximity of the burning fuel to the wall. The products of combustion can be extremely corrosive in this location, since conditions of incomplete combustion and flame impingement may persist for extended periods, so that the combustion gas is locally substoichiometric, and the possible corrosive species include $\mathrm{HCl}, \mathrm{H}_{2} \mathrm{~S}$, and condensable salts. The combination of mechanical damage, locally high heat flux, and a corrosive environment can result in rates of metal wastage greater than caused by either source acting alone, most probably because any oxide scale formed on the metal is removed before it can provide protection.

(2) Corrosion by Deposits Containing Low-Melting Point Chlorides and Sulfates may be found on the lower waterwalls, upper waterwalls, and sometimes on the leading tubes of the superheater. The area over which this form of attack has been observed may cover a broad band representing several tubes at a location on the waterwall where the metal temperature exceeds the melting 
temperature of the corrosive compounds in question, or may be very localized and affect only a single tube. The root cause of this form of wastage is the deposition on the tubes of mixtures of chlorides that melt at the surface temperatures attained by the tubes. Accelerated thinning of the exposed fireside surfaces of the waterwall tubes is caused by the corrosive action of compounds containing chlorides (and sulfates) of $\mathrm{Na}, \mathrm{K}, \mathrm{Mg}$, and $\mathrm{Ca}$ together with heavy metals such as $\mathrm{Sn}, \mathrm{Zn}$, and $\mathrm{Pb}$. These chlorides are derived from the reaction during combustion of $\mathrm{HCl}$ from $\mathrm{PVC}$ (and $\mathrm{NaCl}$ ), with the oxides of metals volatilized from the refuse, and arrive via condensation from the combustion gases and/or from direct impingement.

(3) Corrosion by Combustion Gases occurs on the waterwalls and leading tubes of the superheater. Tube thinning is observed, typically under porous and/or laminated, voluminous, poorlyadherent corrosion product scales. On the waterwalls, the metal-scale interface will contain $\mathrm{FeCl}_{2}$, but no evidence of alkali metals or $\mathrm{Pb}, \mathrm{Zn}$, or $\mathrm{Sn}$. On the superheater tubes, the metal-scale interface will contain $\mathrm{FeCl}_{2}$ and alkali sulfates. The root cause of this form of wastage is the presence of PVC and $\mathrm{NaCl}$ in the refuse, the persistence of reducing (substoichiometric) conditions at the furnace walls, and high gas and metal temperatures at the superheaters.

This category of boiler tube failure is different from that caused by combustion gas corrosion in coal-fired boilers to the extent that the ambient gas in waste-fired boilers can contain significant levels of $\mathrm{HCl}$ in addition to sulfur-containing species, and the proportion of chlorine- to sulfur-containing species is much higher in waste-fired boiłers.

(4) Erosion-Assisted Corrosion usually is confined to the superheater and steam generator tube banks adjacent to ducting walls; near the rear wall of rear pass; next to gas flow path openings; and close to soot blower lanes. The upstream surfaces of tubes have a polished appearance, especially adjacent to flow passages; damage also appears as flat spots on tubes. These areas are relatively clean, that is, are covered by a dust layer rather than the usual deposit. The eroded areas can be easily distinguished after water-washing, since they corrode to a uniform color. Erosion-assisted corrosion results from two different sources: high local gas velocities resulting from the blocking of flow passages by deposits, and the action of soot blowers. 


\subsection{Best Available Fixes for Types of Boiler Tube Problems Encountered.}

The measures that are currently in use to minimize fireside corrosion problems involve:

Improved combustion: Relocation of overfire air ports in an attempt to control the combustion conditions so that combustion of the fuel is completed in the lower furnace, and gas stream stratification and local substoichiometric conditions in the upper furnace are minimized. Also, attempts are made to ensure that sufficient oxygen is present along the waterwalls to prevent the development of local substoichiometric zones, in an attempt to reduce the likelihood of the development of locally aggressive corrosion conditions underneath any deposits formed in the upper furnace. It is difficult to make a quantitative assessment of the effectiveness of this approach but, since it addresses the nominal root cause of some fireside corrosion problems, it has the potential to prevent their occurrence. However, although this approach is preferred by some manufacturers (DeutscheBabcock/American RefFuel, for instance), tube failures from corrosion caused by persistent substoichiometric conditions continue to occur in their boiler designs. (Kalmanovitch, 1995).

Refractory coating of the waterwalls: The application of protection in the form of a coating of $\mathrm{SiC}$ refractory appears to be effective in preventing further attack of the protected tubes, provided that the coating is properly applied. The use of SiC coatings has been practiced for at least 20 years in Germany, and application in the form of tiles and special shapes attached by studs is currently preferred. In the U.S., SiC coatings are generally applied by trowelling over studs, although tiles are being introduced. As long as the application is sound, trowelled refractory coatings provide good protection, but can represent a significant maintenance problem; also, the thermal conductivity of trowelled coatings may be very low. A common observation is that severe corrosion occurs on the waterwalls just above the refractory layer, at the point where the flue gas first encounters the bare waterwalls. This is presumably a function of the high flue gas temperature (as a result of reduced heat transfer in the refractory-covered lower waterwalls) and the low waterwall temperature (lower than the temperature of the refractory lining), which leads to 
deposition of corrosive species at that location. This corrosion is remedied by extending the refractory, where possible, or installing a weld overlay coating of Alloy 625.

Metallic coating of the waterwalls: A number of sprayed metal coatings have been used in U.S. WTE boilers, with mixed results. In general, such coatings are renewed on an annual basis since they either do not adhere to the tubes, or they corrode and act as sacrificial coatings. In contrast, weld overlay coatings of Alloy 625 have been in service for approximately 10 years, and are credited with drastically reducing waterwall corrosion losses. It is estimated that the corrosion rate of a Alloy 625 weld overlay coating is $<17$ $\mathrm{nm} / \mathrm{h}(<6 \mathrm{mil} / \mathrm{yr})$.

Control of tube surface temperature: Reduction of the temperature of the leading pendant tubes reduces the likelihood of molten phases in deposits. Such reduction may require redesign or repositioning of some of the heat transfer surfaces to ensure that the tubes with the highest metal temperature experience flue gas conditions that are least likely to cause serious corrosion problems. While there are claims that such changes have greatly reduced convection pass tube problems, as recounted in Section 6.3 , continuing corrosion has been reported in superheater sections where such precautions had been taken (Schirmer, 1984).

Use of high-Cr alloy tubes: Alloy 825 tubes have been installed in a number of boilers in the U.S. in the leading rows of tubes in the superheater (or screen) where corrosion is a problem, apparently with successful results; Alloy 825 tubes were in service in one boiler for approximately 14 years before being replaced as part of a redesign of the superheater. Type 304 clad over carbon steel also is in service in this application.

Modification of tube cleaning practices: Exacerbation of corrosion through removal of any protective scale along with the deposits, and the introduction of erosion damage through entraining particles in the soot blower stream can be avoided or minimized by modification of the tube cleaning practices. Mechanical shaking or rapping has been shown capable of efficiently shedding deposits without disrupting any protective oxide 
scale on the tubes. For best results, the tube banks should be designed to withstand the required level of mechanical impact, and vertically-oriented tubes are preferred. One manufacturer has sufficient confidence in this approach that a redesigned superheater with carbon-steel tubes and an improved mechanical rapping system was used to replace a superheater that contained Alloy 825 tubes and an earlier, lower-intensity rapping system. Where soot blowers must be retained, improved maintenance is required to ensure that the desired steam velocity and direction are obtained, and to eliminate the collection of condensate in the steam lines. The tubes adjacent to the soot blower lanes are usually protected by high-alloy (Type 304 or 309 stainless steel) shields, which require frequent inspection and maintenance.

It is interesting to note that co-firing of RDF with coal (at levels of 10 to 20 percent RDF), even at steam conditions that are higher than those used in the state-of-the-art WTE plants, appears to have encountered few corrosion problems. Based on previous research (Krause, 1986), this improvement is thought to be due to the presence of sulfur in the coal, which affects the stability of the aggressive, lowmelting chlorides and effectively eliminates them from the tube deposits. Similariy, blending of the refuse with sewage sludge is known to reduce the corrosion rates in WTE plants (Krause, 1980), presumably through some inhibiting effect of silica.

The most desirable strategy would be to avoid many of the current corrosion-deposition-erosion problems by ensuring that the combustion process was completed and the fly ash solidified before the flue gas encountered any heat transfer surface. Such an approach might imply the use of a well-mixed combustor/reactor, followed by a burn-out chamber in which sufficient cooling of the gas was achieved by heat transfer through, for instance, SiC-lined walls, to lower the flue gas temperature below the dew point of the condensable species responsible for accelerated corrosion, before the flue gas enters the main radiant heat transfer section. This is the approach taken by a number of boiler designers; the fact that some continuing problems are experienced suggests that, if the designs addressed the real root causes, they were compromised in some way; for instance:

the boiler dimensions may have been restricted because of cost, or 
- it may have proven difficult to achieve in practice the degree of control required in the operation of the boiler, or

changes may have been made in fuel or operating practice (the availability of excess air is limited as a result of $\mathrm{NO}_{\mathrm{x}}$ control, for instance) after the design was frozen, or

the heterogeneous nature of the fuel and its wide variation in moisture content causes excursions.

\subsection{Summary of Causes of Metal Wastage and Remedial Measures Practiced.}

It is generally understood that the waterwall and superheater corrosion problems result from the difficulty of maintaining uniform combustion conditions, and the presence of chlorine, alkalis and heavy metals in the fuel. Corrosion occurs following the deposition of low-melting compounds, usually chlorides, or by direct gas-phase attack. In addition, the damage may be initiated or exacerbated by the removal of normally protective oxide scales by mechanical damage (impact, sliding wear, erosion) by the heterogeneous fuel, or from attempts to clean the tubes by, for instance, soot blowing.

The common factors that underly corrosion in WTE boilers of all designs and operating conditions are the deposition of chloride-containing salts which have melting points below the temperatures attained by the surfaces of the heat transfer tubes, and a high concentration of $\mathrm{HCl}$ in the flue gas that traverses the convection bank and can lead to accelerated gas-phase corrosion. Specific salts have melting points in the range 149 to $204^{\circ} \mathrm{C}\left(300\right.$ to $\left.400^{\circ} \mathrm{F}\right)$. The temperature-dependence of the vapor pressures of the condensable salts determines where deposition can occur, and the composition of the depositing species. The aim of protective measures is to prevent molten chlorides from contacting the furnace wall tubes by using a cladding of silicon carbide, or a weld overlay of Alloy 625 (or a combination of silicon carbide on the lower walls with overlay above it) to a height at which the gas has been cooled sufficiently (typically to 649 to $760^{\circ} \mathrm{C} / 1200$ to $1400^{\circ} \mathrm{F}$ ) that the bulk of the condensable chlorides has been deposited. Flue gas temperatures below about $1400^{\circ} \mathrm{F}$ have been found to reduce the rate of corrosion of superheater tubes; the aim is that deposits on the superheaters should be solid (sulfate-rich rather than chloride-rich) hence unlikely to be corrosive, and to present the lowest possible tube metal temperatures to the gas as it enters the superheater bank to reduce the rate of 
gas-phase corrosion (and the rate of molten salt attack in cases where condensable chlorides are carried over).

In general, the older designs of WTE boiler provide insufficient furnace volume to ensure that the combustion process could be reliably completed and the gas cooled below about $1400^{\circ} \mathrm{F}$ before it enters the superheater tube bank. As a result, deposition of low-melting chloride-rich salts is possible on the furnace walls above the silicon carbide cladding, with the potential for accelerated corrosion. In the worst cases, chloride-rich deposits can form on the leading tubes of the superheater bank, leading not only to rapid corrosion especially where such deposits form on the hottest tubes, but also to the build up of flow-blocking deposits that can lead to localized overheating or erosion. Such deposits also lead to the excessive use of soot blowing, which can exacerbate the localized erosion problem.

Where the furnace volume is undersized, one approach to increasing the heat absorption in the furnace is to lower the grate and extend the waterwall downward. This approach also has been used in retrofitting coal-fired stoker boilers for RDF firing. A further possible approach would be to replace the appropriate area of silicon carbide cement-cladding with prefired silicon carbide tiles; depending on its porosity, the thermal conductivity of silicon carbide cement can range to less than $5 \mathrm{Btu} / \mathrm{hrft}^{2} \circ \mathrm{F}$ at $316^{\circ} \mathrm{C}\left(600^{\circ} \mathrm{F}\right)$, for instance, whereas for high-density, prefired tiles the thermal conductivity could range up to $20 \mathrm{Btu} / \mathrm{hrft}^{\circ} \mathrm{F}$. Alternatively, low-thermal conductivity silicon carbide cladding could be replaced by weld overlay of Alloy 625 , which has a thermal conductivity (at $316^{\circ} \mathrm{C} / 600^{\circ} \mathrm{F}$ ) of approximately $8 \mathrm{Btu} / \mathrm{hrft}^{2} \mathrm{~F}$. Obviously, such a change would depend on a careful comparison of the cost of the replacement tiles or weld overlay with the savings from reduced maintenance of the waterwall and superheater tubes, and of the replaced silicon carbide cladding.

Recent WTE boiler designs incorporate increased furnace volumes and a greater distance from the grate to the top of the furnace zone, providing sufficient residence time for combustion to be completed under most operating conditions before the gas exits the furnace. These larger combustion zones allow silicon carbide cladding to be extended to a sufficient height that the gas temperature is cooled to approximately $954^{\circ} \mathrm{C}\left(1750^{\circ} \mathrm{F}\right)$ or less before it encounters bare carbon steel waterwalls. Also, there is sufficient heat transfer area above the silicon carbide cladding to further cool the gas below about $760^{\circ} \mathrm{C}\left(1400^{\circ} \mathrm{F}\right)$ before it exits the furnace zone. Corrosion of the superheater tube banks is minimized by locating them as far as possible from the furnace zone so that there is increased time for condensable chlorides to be deposited out before the gas contacts the superheater tubes. This arrangement is accomplished through the incorporation of multiple convection passes, with the first 
(and second) passes ahead of the superheater bank lined with essentially waterwall tubes. However, even if all the condensable salts are removed from the flue gas, it will still contain gaseous $\mathrm{HCl}$ which can accelerate the normal oxidation rate of carbon steel, so that it is also important to minimize the gas and metal temperatures. The practical approach is to arrange for the steam flow in the superheaters to be counter to the flue gas flow, so that the coolest tubes encounter the hottest gas. Deposits that form on the convective heat transfer surfaces are removed by mechanical rapping, instead of soot blowing. The superheater tubes are oriented vertically, and a robust tube bundle configuration is used to allow high-intensity rapping.

Further increases in boiler steam pressure and final temperature are desirable to increase the cycle efficiency. The records available from WTE units were insufficiently detailed or complete to allow any attempt to correlate corrosion with steam temperature. Because high-temperature corrosion is a thermally-activated process, increased temperatures will undoubtedly increase the potential for accelerated corrosion rates. Increased steam pressure will increase the maximum temperature attained by the waterwall tubes, which will lead to an increase in the corrosion rate even if the deposition of molten chlorides can be prevented by the modifications discussed above. Similarly, increasing the final steam temperature will increase the inherent corrosion rate of the final tubes of the superheater. For the waterwall tubes, reliable information on the temperature-dependence of corrosion of carbon steel and of Alloy 625 is needed to quantify the likely increase in rate of tube metal loss. For highertemperature corrosion-resistant superheater tubes, similar corrosion data are required for the candidate alloys, which include: Alloy 825, Type 304 stainless steel, Sanicro 28, and Alloy 625. A Japanese effort to increase the efficiency of WTE plants includes a significant alloy development effort for superheater tubes. A further consideration is that, if upsets in the combustion process occur, there is the chance that chloride-rich deposits will be formed in the superheater. The increased corrosion rates possible at higher metal temperatures require that some efforts are made to improve control of the combustion process, such as active control of the distribution of secondary air. 


\section{Economic Impact of Boiler Tube Problems in Waste-Fired Boilers}

As of 1993, there were 92 WTE facilities in the U.S. with capacities of 200 tons/day or greater in operation, accounting for approximately 96,200 tons per day of waste, and 24 others in the planning or construction stages, representing approximately 27,000 tons per day of new capacity. The geographic distribution of the operating and planned plants is indicated in Figure 7.1. Of the planned plants for which data were available, 83 percent were mass-burn design (20 plants: 17 waterwall design, 2 rotary, 1 modular), and 17 percent were for burning RDF ( 3 stokers, 1 fluidized bed). Of these plants, some 35 percent were to be owned by municipalities, and 65 by private companies, whereas all were to be operated by private companies. Figure 7.2 shows the distribution of the number of waste-to-energy facilities planned as of 1993. Most of those planned unite are designed or indicated to have steam temperatures between $800-849^{\circ} \mathrm{F}$. A few units are planned to have steam temperatures abot $849^{\circ} \mathrm{F}$.

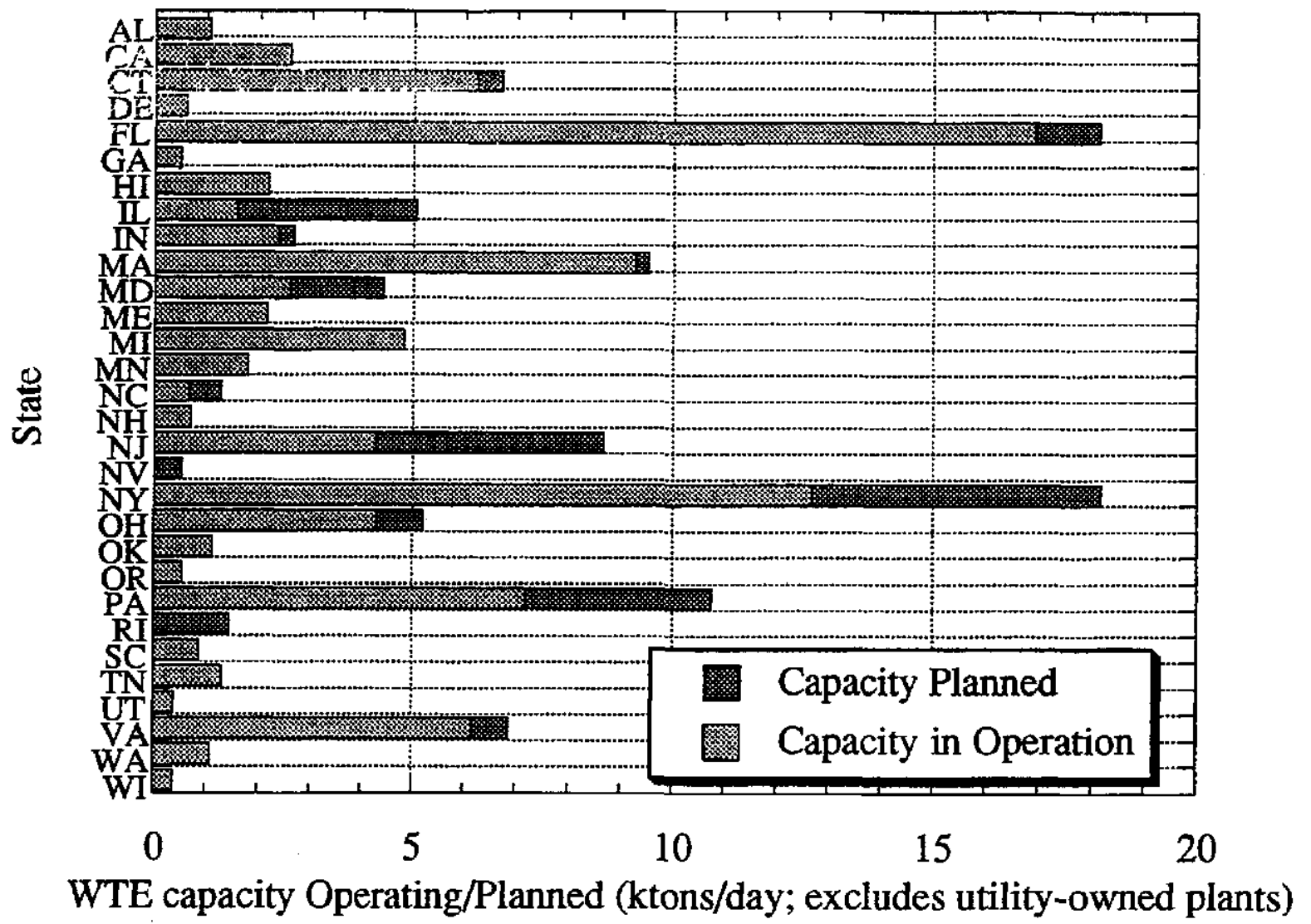

Figure 7.1 Geographical distribution of waste-fired boilers. 


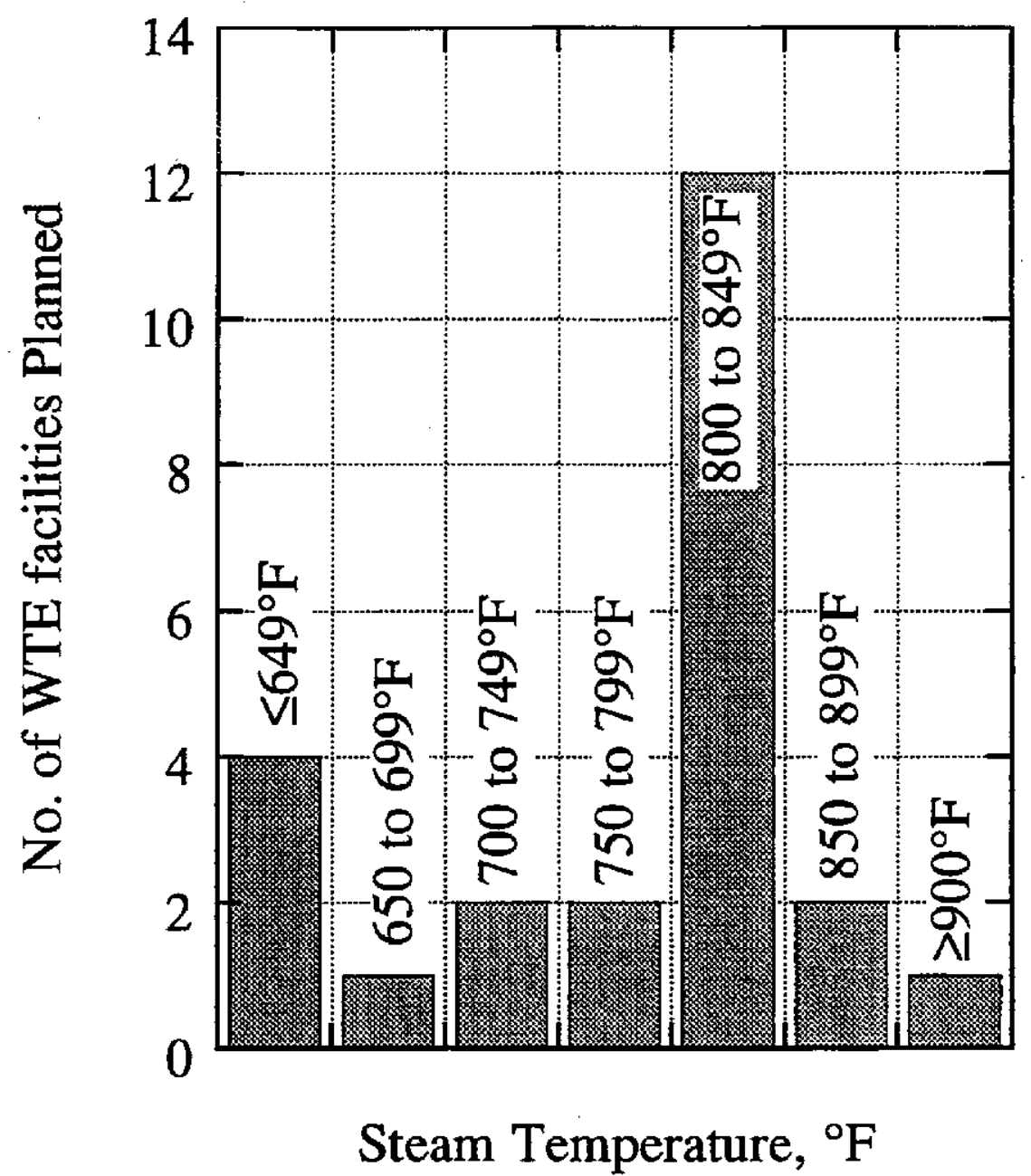

Figure 7.2 Steam temperatures of planned boilers.

Information published by Berenyi and Gould (1993) indicated that the average operating and maintenance cost, based on data provided by 129 WTE facilities, was $\$ 33.58$ per ton of refuse for existing plants and was projected to fall to $\$ 27.41$ for planned facilities. These costs were exclusive of debt servicing, which cost an additional $\$ 26.51$ and $\$ 43.76$ per ton, respectively. The average operating and maintenance costs per ton, excluding debt servicing, were lowest for mass-burning units (\$28.88), and highest for modular, mass buming units (\$39.54); the average cost for RDF units was $\$ 38.60$. However, the capital costs for modular units were far lower than for other mass-burning units, at $\$ 22.98$ compared to $\$ 33.67$ per ton (debt servicing costs); the similar cost for $\mathrm{RDF}$ units was $\$ 17.91$. 
The major source of revenue for WTE plants is the tipping fee charged on the delivery of MSW to a WTE facility, which may vary significantly with plant location. Berenyi and Gould (1993) indicated that the tipping fee for existing facilities averaged $\$ 54.84$ per ton, and ranged from $\$ 49.49$ for RDF units, to $\$ 55.20$ for modular units, to $\$ 57.02$ for mass burning facilities. The tipping fees also varied with region, from $\$ 43.91$ per ton in the south, to $\$ 71.06$ in the northeast; three modular units in the west reported an average tipping fee of $\$ 105.31$.

The average ash residue disposal fee was $\$ 37.54$ per ton; this fee varied with region from $\$ 26.07$ in the south, to $\$ 48.15$ in the northeast, largely as a result of transportation costs.

Due to of the competitive nature of the WTE business, information relating to the economic impact of boiler tube failures was not readily available, except for a few plants. A large fraction of the current mass-burn and RDF-fired boilers for which information was obtained continue to suffer from corrosion of the waterwalls, which can occur at rates up to $580 \mathrm{~nm} / \mathrm{hr}(200 \mathrm{mil} / \mathrm{yr})$, and lead to tube lives as short as 6 months. An estimate of six unplanned outages per boiler per year is probably reasonable. This form of attack can be quite localized, sometimes affecting only one or two tubes in a given area.

Tube failures in superheaters continue to occur from gas phase or deposit-related corrosion. This is the case even in modern MSW combustor designs. Four such failures per boiler per year are not uncommon. Similarly, deposition in, and partial plugging of, convection pass tube banks result in corrosion and/or erosion failures. Attempts to clean these tubes also are implicated in tube failures, even though in boilers that are equipped with soot blowers, measures to protect adjacent tubes usually have been tried.

An estimation of the costs associated with a given forced outage was made, using some simplifying assumptions, which are outlined below. The cost of a forced outage has the following elements:

- The minimum time required to repair a failed tube, provided that the tube location is accessible and the replacement piece is a stock item, is 12 to 16 hours. This time assumes 4 to 6 hours for the boiler to cool down, 4 hours to make the repair, and 4 to 6 hours for hydro-testing the boiler and heat up.

- Cost of repairing the failure $=2$ boilermakers (typically) at $\$ S_{b} / \mathrm{hr}$ each (with overtime) $\mathrm{x} t_{b}$ hours on site per outage + cost of materials. The boilermakers are required to be on-site to make 
preparations, to carry out the repair, and to be available through the hydrotest. It was assumed that the labor necessary for providing access to the failure, and performing the boiler operating functions is provided by the normal operating staff, so that their time is not charged to the outage.

- In the worst-case scenario, a plant must produce power or buy replacement power. The cost of replacement power or steam [calculated as the cost of natural gas required to augment the firing of the remaining boiler(s) to maintain output $=$ steam flow to be replaced $\left(S_{i} \mathrm{lb} / \mathrm{hr}\right) \times$ enthalpy for operating steam temperature $\left(H_{s} \mathrm{Btu} / \mathrm{lb}\right) \mathrm{x}$ cost of natural gas $\left(\$ C_{n g} / \mathrm{MBtu}\right) \mathrm{x}$ duration of outage $\left.\left(t_{o}\right)\right] /[$ utilization efficiency $(e)]$.

Alternatively, if the plant does not have excess capacity and must purchase replacement power, the cost would be:

$M \mathrm{MW} \times t_{o} \mathrm{~h} \times \$ P / \mathrm{MWh}$ (assumed to be the same as the price received by the combustor from the sale of electricity).

Assuming that the plant can continue to accept trash deliveries for the duration of the outage, the estimated cost per outage is given by:

$$
\$\left[2 \cdot S_{b} \cdot t_{b}+\left(S_{i} \cdot H_{s} \cdot t_{o} \cdot C_{n g} \cdot 10^{-6}\right) / e\right]+\text { cost of materials. }
$$

or

$$
\$\left[2 . S_{b} \cdot t_{b}+M \cdot t_{o} \cdot P\right]+\text { cost of materials }
$$

Major differences in cost among outages caused by failures in the furnace area and in the generator bank/superheater sections of a boiler can result from the difficulty of access to the location of the failure, and so will be reflected mainly in the values of $t_{o}$ and $t_{b}$. Waterwall failures typically are more readily accessible than failures in the pendant or convection section tube banks. For a waterwall failure at a hypothetical plant with a capacity of 2250 ton/day ( 3 boilers, each producing $168,000 \mathrm{lb} / \mathrm{hr}$ steam $/ 54 \mathrm{MWe}$ net at $6.3 \mathrm{MPa} / 900 \mathrm{psig}, 454^{\circ} \mathrm{C} / 850^{\circ} \mathrm{F}$ ), and using values of:

$$
T_{f}=\$ 55 / \text { ton }
$$




$$
\begin{aligned}
& F_{i}=31.25 \text { ton } / \mathrm{hr} \\
& t_{o}=12 \mathrm{hr} \text { (considered the minimum time needed to repair a waterwall leak) } \\
& S_{b}=\$ 50 / \mathrm{hr} \\
& t_{b}=16 \mathrm{hr} \\
& S_{i}=168,000 \mathrm{lb} / \mathrm{hr} \\
& H_{s}=1,353 \mathrm{Btu} / \mathrm{bb} \\
& C_{n g}=\$ 2.00 / \mathrm{MBtu} \\
& e=40 \% \\
& M=18 \mathrm{MW} \\
& P=\$ 80 / \mathrm{MWh}
\end{aligned}
$$

the minimum cost per outage is estimated to be $\$ 15,238$ to $\$ 18,880+$ cost of materials. Based on discussions with WTE plant personnel (but undocumented), a reasonable estimate of the number of unplanned outages experienced per boiler per year is 6 to 10 . In the case where the plant has no reserve trash storage capacity, the loss of income from suspension of trash deliveries would be given by: tipping fee $\left(\$ T_{f}\right)$ (ton) $\mathrm{x}$ feed rate to boiler $\left(F_{i}\right.$ ton $\left./ \mathrm{hr}\right) \mathrm{x}$ duration of outage $\left(t_{o} \mathrm{hr}\right)$ and the cost per outage would be increased by $\$ 20,625$.

On the basis of a plant with excess trash storage capacity, the minimum annual cost of forced outages is estimated (for 6 outages/year) to be $\$ 274,284$ to $\$ 339,840+$ cost of materials, or $\$ 0.36$ to $\$ 0.45$ per ton of waste processed (+ cost of materials). Therefore, using this argument, the elimination of 6 unscheduled outages each year (involving either waterwall or convection pass tubing) for each of the 234 boilers at the 92 facilities operating in the U.S. that have waste capacities greater than 200 tons/day, could save a minimum of approximately $\$ 21 \times 10^{6}$ to $\$ 26 \times 10^{6}$ per year, not including the cost of materials.

Based on the assumptions outlined above, the cost of unplanned outages for plants that can continue to accept waste deliveries during an outage amounts to at least 1.1 to 1.3 percent of the average operating and maintenance costs of a WTE plant. If trash deliveries must be stopped during the outage, this cost rises to 2.6 to 2.8 percent of the average operating and maintenance costs. It should also be noted that a claim made for the more modern waste-fired boilers is that unexpected stoppages caused by corrosion failures are rare. Continuous operation of these units can be maintained between scheduled outages; however, operating personnel are under increasing economic pressure to 
increase both throughput and time between scheduled outages. These conditions can result in increased corrosion and forced outages. 


\section{Research Opportunities}

The basic causes of reduction in boiler tube lifetime in waste combustors are well known in general terms: they are the presence of chlorine, alkali and heavy metals in the fuel that combine to produce low-melting, highly-corrosive deposits on the tubes, and the heterogeneous nature of the fuel that makes it difficult to handle and results in hard to control combustion conditions.

One route to minimizing corrosion in WTE units would be to remove the bulk of the chlorineand heavy metal-containing waste products from the fuel stream. The processing used in the production of RDF has the potential to separate out some of these waste products. However, RDF processing is viewed currently as being expensive, and mass-burning of waste is the favored approach. At present, it is considered very unlikely that it will be economically viable to make changes in the content of the waste that could significantly reduce its corrosion potential in WTE units, because of the diversity of the sources of the key corrosive species in the waste. Some changes in the fuel received by WTE boilers could be brought about if, for instance individual combustors refused to accept certain categories of waste, as occurred at the Akron facility where certain industrial solvents were not accepted to avoid explosions (Waste Age, 1984). Benefits from sorting and recycling of plastics to maximize the removal of PVC could remove up to 50 percent of the chlorine from the waste, but it would be impossible to remove the rest, which is present mostly as sodium chloride. Reclamation programs for the removal of metals such as $\mathrm{Sn}, \mathrm{Pb}$, and $\mathrm{Zn}$ could reduce the amount of very lowmelting chlorides formed in the combustor, but it is not known what the lower threshold of these elements should be to significantly decrease the potential for fireside corrosion. Also, implementation of such recycling programs is dependent on the cooperation of the communities concerned, and on the ability of industry to absorb the reclaimed material.

The implementation of engineering solutions to corrosion problems in WTE plants has been successful in that modern plants operate routinely despite the problems. Nevertheless, the same kind of corrosion problems are repeatedly encountered, which suggests that the real causes are not being addressed, and that the solutions applied provide a way of managing the problems. Solutions that address the true causes, and which can be used to devise permanent remedies, require a detailed 
understanding of the processes that occur in the fireside circuit of WTE units. Translating the present understanding of the mechanisms of corrosion in chloride-containing gases and molten salts to operating WTE systems will require a significant effort. There is, for instance, a need for more detailed knowledge of the corrosive conditions and processes involved in specific locations in the WTE system before more durable solutions to the fireside corrosion problems can be devised. These and other needs are addressed in the following sections.

\subsection{Research Opportunities for Industry}

\subsubsection{Improved Documentation}

The generation of a realistic estimate of the extent to which problems with thinning or failure of boiler tubes are reducing the cost effectiveness of the operation of WTE units requires information that often is not published, or is considered confidential. Since there is currently no organization that is charged with advancing the generic technical needs of the WTE industry, there is no centralized or authoritative source of information that could be used by the industry to help itself. One approach to establishing such a resource would be to invite all the major owners and operators of WTE boilers to cooperate in an effort to assemble, as a first step, a record of the number and types of fireside tube

problems that have led to unscheduled stoppages. An independent body such as the ASME might act as a focus for this information, which would be handled in such a way that the source was strictly anonymous.

In the electric power industry, this type of reporting is made annually to the National Electricity Reliability Council (NERC); recently (1988) a more detailed reporting system which involves a categorization of boiler tube failures and permanent solutions based the identification of the root cause, was implemented in a number of U.S. boilers. The result of implementing these procedures is that the availability loss of the participating boilers has dropped from the national average value of 2.6 to 2.7 percent to 1.7 percent (with a best value of 1.4 percent, Dooley, 1991). The two major ways in which this scheme has been effective have been the virtual elimination of repeat failures, since the remedial measures address the root causes of the problems and an increase in the accuracy with which failure types, and causes, have been recognized by maintenance engineers through the use of a working manual of the categorized failure types. The net result has been a more rapid identification of the 
causes of problems, and longer-lasting solutions. Although the causes of the tube problems that currentiy are the most prominent in WTE boilers are different from those in coal-fired boilers, the same type of approach would be expected to have a significant impact on reducing the unexpected failures, hence loss of revenue in WTE units.

One of the first efforts proposed would be the setting up of a recommended standardized method protocol of reporting the types of problems that cause unscheduled outages in WTE boilers. This would be an opportunity for a group to develop reporting methods and root-cause analysis/repair/prevention procedures for WTE boiler tube failures. A model for this approach is contained in the reporting system established for U.S. utility boilers (Lamping and Arrowood, 1985; Dimmer, Lamping and Jonas, 1989). This model has proved to be effective in the understanding of the root cause of failure and development of corrective or preventive programs.

\subsubsection{Control of the Combustion Process}

Some modification of the corrosive environment can be accomplished if reasonable control of the conditions in the combustion zone can be maintained by, for instance, increased turbulence so that the locations of zones where complete and incomplete combustion persist are relatively stable. In such circumstances, the predominant corrosive environment as a function of location in the boiler could be better defined, which would greatly assist effective alloy selection and utilization. Reconfiguration of the combustion zone to increase turbulence can be considered. Some flexibility in the amount and location of overfire air also could assist in improving the uniformity of combustion, and in ensuring that the fireball was contained in the lower regions of the furnace. One approach to providing such flexibility could be through the use of flame monitoring devices inside the furnace zone, with feedback to control the amount and/or location of underfire and overfire air to ensure that combustion was as uniform as possible.

There may be developments that can be transferred from ongoing research, such as that to monitor specific species in the stack gas from the incineration of hazardous waste, and to use a feedback control system to modify the combustion process to maintain the concentration of the given species below set limits (private communication from Dr. C. F. Holt, Midwest Research Institute, 1993). Similarly, it may be possible to analyze the levels of specific components of the fuel in real time to adjust the combustion parameters by, for instance, changing the grate speed or the ratio of 
under-fire to over-fire air. Developments in defense-funded combustion and propulsion programs (see, for instance, Oldenborg, 1989) have resulted in sensors for specific gas-borne species relevant to corrosion reactions. These sensors may have potential in monitoring or controling to the combustion processes in WTE units.

\subsubsection{Definition of Conditions at Tube Surfaces}

There is a need for detailed information on the conditions actually experienced at the tube surface as a function of location in the combustor and of operating conditions. Such information would be useful to the industry in general, and would form the basis for supporting laboratory work. A means of generating this information would be to implement a program at an operating MSW combustor to monitor the conditions experienced by the lower and upper waterwall and superheater tubes while controlled changes were made in the operation of the combustor Of course any modification to the combustors and its operation must be performed under the permit restriction. This activity should preferably involve expertise from specialist organizations and academia that has access to the types of instrumentation best suited to the specific tasks. This approach also is addressed in Section 8.2 .

\subsection{Research Opportunities for Academia}

There are two main routes to reducing the rates of tube metal loss due to corrosion: the first is to modify the corrosive environment, and the second is to use more corrosion-resistant alloys. A factor that is exacerbating the corrosion problem is the trend to increasing outlet steam pressure and temperature of WTE units, which leads to increased tube metal temperatures, and thereby increases the range of salts that will be molten, hence corrosive. Because of the range of corrosive environments possible in waste-fired boilers, which may include oxidizing or reducing gas mixtures with chlorineand sulfur-containing compounds present as gaseous or condensed species, it is unlikely that any single alloy will provide the maximum corrosion resistance under all conditions. The approach to be taken for alloy development should, therefore, be guided by a definition of the types of conditions expected at specific locations, or by specific components, so that the alloy requirements for corrosion resistance in those conditions can be addressed. 


\subsubsection{Definition of the Corrosive Environment}

Definition of the conditions experienced at specific locations in a WTE boiler is not an easy task, and will require a concerted effort involving sampling of the local gaseous/vapor/particulate environment, and of deposits. There are several conventional and experimental techniques available for making the necessary measurements, such as electrochemical probes (see, for instance, Whitlow, et al., 1991), but most of these are research tools, so that their use probably will require cooperation with specialist organizations.

A near-term need is for a means of monitoring to detect high-temperature furnace exit temperatures (or other parameters), to provide a means of alerting the operators to take action to avoid subjecting the convective pass to a corrosive environment.

Measurements to characterize the corrosive environment should be made in units that employ different heat absorption rates in the furnace, and different superheater designs or locations. These differences would allow the relative effects of gas and metal temperature, and of residence time in the combustor on the local corrosive environments to be analyzed. Suggested candidate units are: an RDFfired unit with the superheater located at the furnace nose, and a MSW-fired unit with the superheater located much further away from the furnace.

\subsubsection{Alloy Development}

The major areas for research related to alloy development are concerned with the definition of the alloying requirements for improved corrosion resistance to the specific conditions experienced at the furnace wall and in the convection zone. For example, there is a need to understand the conditions that cause accelerated corrosion immediately above $\mathrm{SiC}$ linings or high-alloy overlays on the upper furnace wall. In addition, research is needed to explore the temperature-dependence of the corrosion behavior of currently-used alloys and corrosion-resistant alternatives so that better informed materials selection in terms of cost effectiveness is possible. Increasing the outiet steam temperature of WTE plants also is the goal of a program being conducted by the New Energy Development Organization (NEDO) in Japan (private communication, 1994); that program is actively developing high alloys for 
use in the final stages of the superheaters. Alloys with improved corrosion resistance could be used to increase the tube lifetimes in current boiler designs, provided they prove cost-effective.

The Japanese (Otsuka, et al., 1993) have suggested that the deposits responsible for much of the high-temperature fireside corrosion in their waste-fired boilers can be classified as either chloriderich, or sulfate-rich. Translation of Japanese data to U.S. WTE units may not be straightforward, since the maximum steam temperature of current Japanese WTE units is significantly lower than for U.S. units (typically less than $300^{\circ} \mathrm{C} / 572^{\circ} \mathrm{F}$ ). It is likely that in U.S. waste-fired boilers, chloride-rich deposits may be representative of the conditions at the lower furnace wall, whereas sulfate-rich deposits may be representative of the upper furnace wall and superheater conditions. The combination and total content of the key corrosive species (chlorine, sulfur, alkali metals, $\mathrm{Sn}, \mathrm{Pb}, \mathrm{Zn}$ ) depend on the fuel, and definition of the appropriate range of components in deposits derived from combustion of U.S. MSW will require care, since sampling of deposits remaining after shut down of the plant can give quite erroneous results. The Japanese work indicated, not surprisingly, that alloy chromium content is important in providing resistance to sulfate-rich deposits; alloys with chromium contents greater than approximately 20 percent gave the lowest corrosion. For chloride-rich deposits, the alloy content of (nickel + cobalt) also was important, with more than 40 percent required for maximum resistance. There also was an indication of a rapid increase in corrosion at temperatures greater than $500^{\circ} \mathrm{C}$ $\left(932^{\circ} \mathrm{F}\right)$, and the suggestion of a "bell-shaped" dependence of corrosion on temperature with a maximum at $550^{\circ} \mathrm{C}\left(1022^{\circ} \mathrm{F}\right)$, but it was not clear if this behavior was connected to the melting point of the deposit constituents. Further work of this type, using deposits, gas mixtures, and temperatures representative of U.S. WTE boiler conditions would be useful in furthering the understanding of the reasons for the good corrosion resistance exhibited by Alloys 625 and 825 , and in defining the ranges of conditions in which good corrosion resistance can be expected. The temperature-dependence of corrosion in WTE conditions also is extremely important, since the ability to operate superheater tubes at temperatures above $482^{\circ} \mathrm{C}\left(900^{\circ} \mathrm{F}\right)$ is key to increasing the efficiency of WTE units. The suggestion of a "bell-shaped" dependence requires further exploration and definition.

The first step in an alloy development program should be laboratory tests to determine trends under conditions that properly simulate the key factors of the deposit and gaseous environments. Alloys or alloy types indicated by these tests to show useful improvements over standard materials should be subjected to field tests in which the actual conditions experienced are known and properly monitored throughout the test exposures. Some of the same techniques used to define the corrosive 
environment in the boilers prior to the laboratory simulation tests should be employed in conjunction with field tests using probes or tube panels, so that the actual conditions experienced during the trials are known. Such trials should involve not only a boiler manufacturer, but also an alloy manufacturer so that reduction of the technology to practice is facilitated.

\subsection{Government Involvement}

One of the main functions that government could undertake to spur the development of techniques to increase heat transfer tube lifetime in WTE units is that of initiating programs that could not be considered by the industry itself. As suggested in Sections 8.1 and 8.2, some of the recommended activities involve collaboration between boiler owners/operators and academia or specialty organizations. The following are areas where a central body or group could facilitate research and assist the WTE industry.

\subsubsection{Industry-Academia Interactions}

Research projects such as that outlined in Sections 8.1 and 8.2 should be supported. An example might involve an industry-academia consortium, in which representatives of the WTE industry have oversight of the efforts. The industry would ensure that the research addressed the issues most

pertinent to its near-term and perceived future needs, and that any simulations of boiler operation were based on realistic parameters. The industrial participation possibly could be through a Technical Steering Committee, which could have the responsibilities of reviewing proposals and overseeing the progress of the selected projects. The same committee also could be charged with setting in motion the actions necessary to define the procedures for implementing an industry-wide failure documentation system (8.1.1).

\subsubsection{Technology Transfer}

Research in programs funded at the U.S. National Laboratories (see for instance, Oldenborg, 1989) has resulted in the development of sensors and control systems for combustion. The application of these technologies to combustion emerging units should be explored. This may be an opportunity to 
involve old military installations. In addition to improving the control of corrosion, the ability to control stack gas emissions may be improved if the combustion process is more uniform.

Studies of this type are unlikely to be given high priority at present by the WTE industry without external support, given the other demands on available funds. The demonstration of the feasibility of a method of improved combustion control could provide direction for future improvements in plant operation and design. 


\section{Acknowledgments}

We wish to express our appreciation to Dr. D. Kalmanovitch, Chairman of the ASME Steering Committee on Deposits in Waste-Fired Boilers, and Mr. R. Art, of ASME, for their help and advice during the course of this project. This project involved innumerable discussions by telephone and in person on-site and at conferences with personnel involved in various capacities in the waste-to energy industry. We wish to express our thanks to all of these persons, and especially to those who supplied information for use in this report. None of these contacts have been named, to protect confidentiality. We also would like to thank members of various ASME committees who supplied information, especially those of the MSW and Corrosion Deposition Committees, for their comments or names of further contacts. In addition, we are grateful to colleagues at Battelle, in particular Richard Barrett, for providing access to their personal files. 


\section{References}

Anon, "New Look at the Waste Stream," Waste Age 19, 44-46 (1988).

R. E. Barrett, H. H. Krause, R. B. Engdahl, and J. H. Oxley, E. E. Hughes and C. R. McGowin, "Technology Status Assessment of Municipal Refuse to Energy Systems," Proc. EPRI 1989 Conf. on Municipal Solid Waste as a Utility Fuel, October 1989.

A. H. Beckman and M. G. Dragovich, "Mass Burning of MSW with Energy Recovery," J. Environmental Engineering, 112 (3), 564-571 (1986).

E. B. Berenyi and R. N. Gould, "1993-4 Resource Recovery Yearbook, Directory and Guide," Government Advisory Associates, Inc., NY (1993).

R. J. Bishop, "The Formation of Alkali-Rich Deposits by a High-Chlorine Coal," J. Institute of Fuel, 41, 51-65 (1968).

R. D. Blakley, "Fireside Tube Corrosion in an Industrial RDF-Fired Boiler-Kodak's Experience," pp 9-19 in Proc. 1990 ASME National Waste Processing Conference, Long Beach, CA (1990).

G. L. Boley, "Combustion Engineering's Experience in Coal-Firing RDF and Coal in Dedicated Combustors," Proc. EPRI 1989 Conf. on Municipal Solid Waste as a Utility Fuel, October 1989.

G. L. Boley, "Start-up and Operations of the Mid-Connecticut Resource Recovery Project," pp. 21-29 in Proc. ASME 1990 National Waste Processing Conference (1990).

R. H. Boll and H. C. Patel, "The Role of Chemical Thermodynamics in Analyzing Gas-Side Problems in Boilers," Trans. ASME, J. Engg. for Power, $\underline{83}, 451-467$ (1961).

R. H. Bourquin, Jr., "Cofiring of RDF at the C. P. Crane Station: 1980 Test Results and Future Plans," pp. 853-860 in Proc. 1983 Natl. Conf. on Environmental Engg, ASCE Specialty Conf., ASCE, NY (1983).

S. Brooks and K. S. Gilroy, (1984), mentioned in Latham, et al (1991).

S. Brooks and D. M. Glover, (1981), mentioned in Latham, et al (1991).

S. Brooks and D. B. Meadowcroft, "The Influence of Chlorine on the Corrosion of Mild and Low Alloy Steels in Substoichiometric Combustion Gases", pp 105-120 in Corrosion Resistant Materials for Coal Conversion Systems, D. B. Meadowcroft and M. I. Manning, ed., Applied Science Publishers, London (1983). 
S. Brooks and D. B. Meadowcroft, "The Role of Chlorine in the Corrosion of Mild and Low Alloy Steels in Low $\mathrm{PO}_{2}$, High $\mathrm{PS}_{2}$ Environments," pp. 515-527 in High-Temperature Corrosion in Energy Systems, M. F. Rothman, ed., Met. Soc. of AIME (1985).

D. E. Burnham, J. S. Gittinger, D. R. Gibbs, and H. E. Johnson, "The Evolution of RDF Boiler Designs Through the State-of-the Art System at Palm Beach," Proc. EPRI 1989 Conf. on Municipal Solid Waste as a Utility Fuel, October 1989.

R. Chapman, G. Titus, and W. Greamer, "The Impact of Air and Fuel Distribution on Low Waterwall Corrosion," pp. 369-372 in Incinerating Municipal and Industrial Waste: Fireside Problems and Prospects for Improvement, R. W. Bryers, ed., Hemisphere Publishing Corp. (1991).

F. Clarke and C. W. Morris, "Combustion Aspects of Furnace Wall Corrosion," pp 47-61 in Corrosion Resistant Materials for Coal Conversion Systems, Applied Science Publishers, London (1983).

A. W. Coates, D. J. A. Dean, and D. Penfold, "Phase Studies on the Systems $\mathrm{Na}_{2} \mathrm{SO}_{4}-\mathrm{SO}_{3}, \mathrm{~K}_{2} \mathrm{SO}_{4^{-}}$ $\mathrm{SO}_{3}$, and $\mathrm{Na}_{2} \mathrm{SO}_{4}-\mathrm{K}_{2} \mathrm{SO}_{4}-\mathrm{SO}_{3}$," J. Inst. Fuel, $41,129-132$ (1968).

S. Collins, "Slay the WTE Plant Dragon: Boiler Tube Wastage," Power, 42-46, Oct. 1992.

R. C. Corey, B. J. Cross, and W. T. Reid, "External Corrosion of Furnace Wall Tubes II: Significance of Sulfate Deposits and Sulfur Trioxide in Corrosion Mechanisms," Trans. Met., 67, 289302 (1945).

R. C. Corey, H. A. Grabowski, and B. J. Cross, "External Corrosion of Furnace Wall Tubes III: Further Data on Sulfate Deposits and the Significance of Iron Sulfide Deposits," Trans. Am. Soc. Mech. Eng., 71, 951-963 (1949).

A. J. B. Cutler, W. D. Halstead, J. W. Laxton, and E. G. Stevens, "The Role of Chloride in the Corrosion Caused by Flue Gases and Their Deposits," Trans. ASME, J. Eng. for Power, 307-312, July 1971.

P. L. Daniel and R. A. Rapp, "Halogen Corrosion of Metals", chapter in "Advances in Corrosion Science and Technology, Vol. 5," M. G. Fontana and R. M. Staehle, eds., Plenum Press (1976).

P. L. Daniel, J. D. Blue, and J. L. Barna, "Furnace-Wall Corrosion in Refuse-Fired Boilers," pp 221228 in Proc. of the 1986 National Waste Processing Conference, Denver, Colorado, Amer. Soc. Mech. Eng., June 1986.

P. L. Daniel, "Corrosive Species in RDF-Fired Boilers," Paper No. 1 in Corrosion-Erosion-Wear of Materials at Elevated Temperatures, A. V. Levy, ed., NACE (1991).

M. Davies, R. C. Hurst, and P. Hancock, Trans AIME (1972). ???

C. F. Davis, "Annual Snapshot of Six Large Scale RDF Projects," pp. 75-88 in Proc. 15th Biennial Conf., 1992 National Waste Processing Conf., ASME (1992). 
D. M. DeVincentis, S. P. Goff, J. W. Slusser, Z. Zurecki, and J. T. Rooney, "Solving Fireside Corrosion in MSW Incinerators with Thermal Spray Coatings," NACE Paper 93-198 (1993).

J. P. Dimmer, G. A. Lamping, and O. Jonas, "Boiler Tube Failure: Correction, Prevention, and Control,” EPRI Report No. GS-6467 (1989).

E. S. Domalski, A. E. Ledford, Jr., S. S. Bruce, and K. L. Churney, "The Chlorine Content of Municipal Solid Waste from Baltimore County, Maryland and Brooklyn, New York," pp 435-448 in Proc. of the 1986 National Waste Processing Conference, ASME, New York, NY, June 1986.

R. B. Dooley, "Boiler Tube Failures—A Perspective and a Vision," presented at the EPRI International Boiler Tube Failure Conference, La Jolla, CA (1991).

R. B. Engdahl, "Utilizing Wastes: Fact or Fancy?" Solid and Liquid Waste Utilization in Community Energy Planning, State of the Art Report: Integrating Community Energy Systems Planning, Battelle, Dec. 1977.

EPA Report No. EPA/530-R-92-019 (NTIS No. PB92-207 166) "Characterization of Municipal Solid Waste in the United States: 1992 Update," July 1992.

B. Ettehadieh and S. Y. Lee, "Incineration of Low-Quality MSW in the Rotary Water-Cooled O'Conner Combustor," pp. 193-201 in Proc. Natl. Waste Processing Conf., ASME (1990).

D. E. Fiscus, R. D. Peterson, J. C. Glaub, A. W. Joensen, C. V. Pearson, and C. R. McGowin, "Electric Utility Operating Problems in Cofiring RDF," presented at ASM/IEEE/ASCE Joint Power Generation Conf., Indianapolis, IN (1983).

E. Follett and M. J. Fritsch, "Two Years of RDF Firing in Converted Stoker Boilers: Part 1: MSF Processing; Part 2: RDF Firing," Proc. EPRI 1989 Conf. on Municipal Solid Waste as a Utility Fuel. October 1989.

Franklin Associates, Ltd., "Characterization of Municipal Solid Waste in the U.S., 1960-2000", 1988.

D. N. French, "Waterwall Corrosion in RDF-Fired Boilers," pp 359-368 in Incinerating Municipal and Industrial Waste: Fireside Problems and Prospects for Improvement, R. W. Bryers, Ed., Hemisphere Publishing Corp. (1991).

P. Ganesan and G. D. Smith, "Laboratory and Field Experience with the Use of Nickel-Containing Alloys for High-Temperature Applications in Waste Incinerators," pp. 167-179 in ASM Conf. Proc. High-Temperature Materials, P. Ganesan and R. A. Bradley, eds., Oct. 1987.

G. Garing, "Six Years Experience in Producing RDF and Coal-Firing the RDF in a Pulverized Coal Boiler," Proc. EPRI 1989 Conference on Municipal Solid Waste as a Utility Fuel, October 1989.

M. Geyelin, “Incinerator's Flaws Cost $\$ 8$ Million Last Year, St. Petersburg, FL Times, pp. 1-3, Feb. 13, 1985. 
W. H. Gibb, "The Nature of Chlorine in Coal and Its Behavior During Combustion," pp 25-45 in Corrosion Resistant Materials for Coal Conversion Systems, Edited by D. B. Meadowcroft and M. I. Manning, Applied Science Publishers, London (1983).

D. R. Gibbs, J. D. Blue, and M. P. Hepp, "Design and Operating Experience with High-Temperature and High-Pressure Refuse-Fired Boilers," pp. 93-99 in Proc. 1988 National Waste Processing Conf., Philadelphia, PA, May 1988.

S. Gursky, "Improvements in Refractories in W-T-E," Solid Waste and Power, May-June 1992.

B. J. Hamette and C. P. Natarajan, "MSW Boilers: A Review of Two System Designs," Solid Waste and Power, III (2), (1989).

P. Hancock, R. C. Hurst, and A. R. Sollars, "Influence of Chloride Contamination of the Atmosphere on the Mechanism of Oxidation of Iron," pp. 415-418 in Proc. Int. Symp. on Metallurgical

Chemistry_-Applications in Ferrous Metallurgy, Iron and Steel Institute, London (1972).

J. A. Harris, W. G. Lipscomb, and G. D. Smith, "Field Experience of High Nickel Containing Alloys in Waste Incinerators," NACE Paper No. 87-402 (1987).

M. P. Hepp and J. F. Wood, "Considerations in the Design of High-Temperature and Pressure RefuseFired Power Boilers," pp. 113-118 in Proc. 1986 Natl. Waste processing Conf. (12th Biennial), ASME (1986); also Discussion Volume, pp. 23-26.

M. P. Hepp and J. M. O'Sullivan, "Improving Efficiency of Energy Production from Wastes," Solid Waste and Power, pp. 42-47, Jan/Feb 1992.

R. H. Herrmann and J. R. Berry, "The Impact of Recycling and Pre-Combustion Processing of Municipal Solid Waste on Fuel Properties and Steam Generation," pp. 9-15 in Refuse-Derived Fuel (RDF)_-uality, Standards, and Processing, C. Saltiel, ed., ASME FACT-Vol. 13 (1991).

W. Herrmann, "Comparison of Effectiveness of the Various In-Service Cleaning Methods for Heating Surfaces With Respect to Refuse Incineration Steam Generators," EVT Report No. 98/88 (1988).

T. P. Hoare, in "Role of Chlorine in Flue Gas Deposits," Proc. CEGB Conf., London, 26-27 Nov. 1969.

E. H. Hohman and M. W. McNerney, "The SEMASS Project: Shred and Burn," Proc. EPRI 1989 Conf. on Municipal Solid Waste as a Utility Fuel, October 1989.

M. K. Hossain, Corr. Sci., 21, (12), 843-861 (1981).

E. E. Hughes, “An Overview of EPRI Research on W-T-E,” Proc. 1989 Conf. on MSW as a Utility Fuel, EPRI GS-6994 (1991). 
R. C. Hurst, J. B. Johnson, M. Davies, and P. Hancock, "Sulphate and Chloride Attack of NickelBased Alloys and Mild Steels," pp. 143-157 in Deposition and Corrosion in Gas Turbines, A. B. Hart and A. J. B. Cutler, eds., John Wiley \& Sons, New York (1973).

P. J. Jackson, "The Physicochemical Behavior of Alkali-Metal Compounds in Fireside Boiler Deposits," pp. 484-495 in Mechanisms of Corrosion by Fuel Impurities, Butterworths, London (1963).

P. J. Jackson and H. C. Duffin, "Laboratory Studies of the Deposition of Alkali-Metal Slats from Flue Gas," pp. 427-442 in Mechanisms of Corrosion by Fuel Impurities, Butterworths, London (1963).

P. L. Jacobus, "Coal-Firing RDF with Pulverized Coal: Ten Years Experience in Madison," Proc. EPRI 1989 Conf. on Municipal Solid Waste as a Utility Fuel, October 1989.

G. M. Johnson, et al., Combustion and Flame, 15, 211-214 (1970).

M. F. Jantzef, "Bresco, 3 Years Later," Waste Age, 19 (10), 117-120 (1988).

D. P. Kalmanovitch, personal communication, 1995.

K. M. Kautz, "The Causes of Boiler Metal Wastage in the Stadtwerke Dusseldorf Incineration Plant," pp 437-444 in Deposits and Corrosion Due to Impurities in Combustion Gases, Hemisphere Publishing Corp., Washington, D.C. (1977).

H. H. Krause, P. W. Cover, W. E. Berry, and R. A. Olexsey, "Corrosion and Deposits from Combustion of Solid Waste. Part 7 - Co-incineration of Refuse and Sewage Sludge," Trans. ASME, J. Engg for Power,102, 698-705 (1980).

H. H. Krause, "Dewpoint Corrosion by Inorganic Acids,", pp. 14/1-14/9 in Solving Corrosion Problems in Air Pollution Control Equipment, NACE., Orlando, FL, December 1984.

H. H. Krause, "High Temperature Corrosion Problems in Waste Incineration Systems," J. Matls. for Energy Systems, $\underline{7}$ (4), 322-332 (1986).

H. H. Krause and J. T. Stropki, "Corrosion of Boiler Tube Alloys in Co-Firing of Refuse Derived Fuel and Pulverized Coal," NACE Paper No. 89-553 (1989).

O. Kubaschewski and B.E. Hopkins, "Oxidation of Metals and Alloys," pp. 211, Academic Press, Inc., New York (1953).

G. A. Lamping, and R. M. Arrowood, Jr., "Manual for Investigation and Correction of Boiler Tube Failures," EPRI Report No. CS-3945 (1985).

E. P. Latham, D. B. Meadowcroft, and L. Pinder, "The Effects of Coal Chlorine on Fireside Corrosion", pp 225-24 in Chlorine in Coal, Stringer, J. and D. D. Banerjee, eds., Elsvier, Amsterdam (1991). 
C. W. Loveland, III, "Operating a Water-Wall Combustor: Problems, Approaches, and Solutions," pp 23-27 in Workshop Proceedings: Energy from Municipal Waste Research: Technical Review, Report No. ANL/CNSV-TM-144, Conf-840223, Sep. 1983.

J. Makansi, "Key Modifications Bolster Performance of RDF Plant," Power, 128 (10), 91-94 (1984).

J. Makansi, "Tires-to-Energy Plant Takes Highroad in Managing Discharges," Power, 136 (4), 152156 (1992).

A. S. Mal'tseva, Yu. E. Frolov, and A. I. Rozlovskii, "Establishment of Deacon Equilibrium in a Flame," Fizika Goreniya i Vzryva, 9 (5), 80-83 (1983).

M. G. Matuny and P. Adkin, “W-T-E Plant Combines Recycling with Mass-Burning,” Power, 136 (4), 144 (1992).

M. J. McNallan and W. W. Liang, "The Influence of Oxygen and Chlorine Potentials on the HighTemperature Corrosion Behavior of Materials," pp. 457-466 in High-Temperature Corrosion in Energy Systems, M. F. Rothman, ed., Met. Soc. of AIME (1985).P. D. Miller, H. H. Krause, J. Zupan, and W. K. Boyd, "Corrosive Effects of Various Salt Mixtures Under Combustion Gas Atmospheres," Corrosion, 28 (6), 222-225 (1972).

P. D. Miller, et al., "Corrosion Studies in Municipal Incinerators," Battelle Report to U.S. Environmental Protection Agency, SW-72-3-3 (1972).

D. F. Moats, J. Mathews, and K. C. O'Brien, "A Performance Update for the Columbus Project," pp. 181-190 in Proc. 1988 National Waste Processing Conf., ASME (1988).

T. J. Morello, "Fireside Corrosion at Occidentals Energy from Waste Plant," pp. 313-320 in Incinerating Municipal and Industrial Waste: Fireside Problems and Prospects for Improvement, R. W. Bryers, ed., Hemisphere Publishing Corp. (1991).

R. Musolino, "SiC Hydraulic-Setting Gunning Mix Used for Refuse-Fired Steam Generating Facility," Industrial Heating, 54 (11), 40-41 (1987).

K. Nakazato, "Summary of Experience With Fireside Problems While Firing Refuse in Japan," Presented at the Engineering Foundation Int. Conf. on Fireside Problems While Burning Municipal and Industrial Waste, Palm Beach Coast, FL (1989).

R. Nicoletti, "Refuse-Derived Fuel Coal-Firing Test Program, Data Evaluation Report," Proc. EPRI 1989 Conf. on Municipal Solid Waste as a Utility Fuel, October 1989.

J. P. O'Conner, "RDF Plant: Centerpiece in an Integrated Waste System," Solid Waste and Power, VI (4), 38-45 (1992).

R. C. Oldenborg, "Opticai Detection of Corrosive Compounds," Pp. 87-99 in Proc. Advanced Research and Technology Development: Direct Utilization, Instrumentation, and Diagnostics 
Contractors Review Meeting, D. W. Gelling and P. M. Goldberg, eds., Report No. DOE/METC$89 / 6108$ (1989).

N. Otsuka, A. Natori, T. Kudo, and T. Imoto, Sumitomo Metals, "High Temperature Corrosion of Austenitic Stainless Steels and Ni-Base Alloys in Simulated Waste Incinerator Environments," NACE Paper No. 93-289 (1993).

L. D. Paul and P. L. Daniel, "Corrosion Mechanisms in Oxidizing, Reducing, and Alternating Combustion Gases in Refuse-Fired Boiler Environments," NACE Paper No. 93-216 (1993).

R. J. Petersdorf, S. M. Sansone, A. L. Plumley, W. R. Roczniak, and C. R. McGowin, "Co-Firing Coal and RDF in a Utility Steam Generator: Operational Experience and Corrosion Probe Evaluation," presented at Am. Power Conf. (1980).

A. L. Plumley, "Present Status and Research Needs in Energy Recovery from Wastes," pp. 84-95 in Proc. 1976 ASME Conf, on Present Status and Research Needs in Energy Recovery from Wastes, ASME (!977).

A. L. Plumley and W. R. Roczniak, "Corrosion Probe Evaluation of Boiler Tube Materials During Cofiring of Prepared Refuse and Coal," Section 7 in EPRI WS-79-225 Seminar Proceedings: Municipal Solid Waste as a Utility Fuel (1980).

A. L. Plumley and W. R. Roczniak, "Cofiring of Refuse-Derived Fuel and Coal at Oak Creek. Volume 1: Boiler Corrosion Evaluation," EPRI CS-1983 (1981).

A. L. Plumley, G. Kerber, and W. Herrmann, "Gas Side Corrosion and Fouling in Refuse-Fired Steam Generators Demonstrated by the Wurzburg CHP Station," pp. 25-46 in Incinerating Municipal and Industrial Waste: Fireside Problems and Prospects for Improvement, R. W. Bryers, ed., Hemisphere Publishing Corp. (1991).

A. L. Plumley, W. R. Roczniak, and E. C. Lewis, "Waterwall and Superheater Performance in a RDF Resource Recovery Steam Generator," pp. 373-404 in Incinerating Municipal and Industrial Waste: Fireside Problems and Prospects for Improvement, R. W. Bryers, ed., Hemisphere Publishing Corp. (1991).

A. L. Plumley, W. R. Roczniak, and J. A. Bacchi, “Update on Materials Performance in RDF-Fired Steam Generators," NACE Paper No. 93-220 (1993).

R. Plur, "Experiences and Improvements to Minimize Fireside Corrosion and Flue Gas Side Deposits on Heat Transfer Surfaces Made in Operating the Gemeinschafts-mull-Verbrennungsanlage Niederrhein GmbH," pp. 47-70 in Incinerating Municipal and Industrial Waste: Fireside Problems and Prospects for Improvement, R. W. Bryers, ed., Hemisphere Publishing Corp. (1991).

H. H. Reichel and U. Schirmer, "Waste Incineration Plants in the FRG: Construction, Materials, Investigation of Causes of Corrosion," Werkstoffe u. Korrosion, 40, 35-141 (1989). 
M. Reisch, "Plastics, Synthetic Fibers Output Increases", Chem. and Eng. News, p. 13, April 12, 1993.

M. Reisch, "Polymer Production," Chem. and Eng. News, p. 22, April 131992.

R. S. Rochford, and S. J. Witkowski, "Superheater Tube Corrosion on MSW-Fired Boilers at Nashville," pp. 96-119 in Proc. 1976 ASME Conf. on Present Status and Research Needs in Energy Recovery from Wastes, ASME (!977).

T. K. Ross, "The Distribution of Sulfur in Corrosion Products Formed by Sulfur Dioxide on Mild Steel," Corrosion Science, $\underline{5}, 327-330$ (1965).

U. Schirmer, E. A. Baumgarte, and M. Schroeder, "The New Bielefeld-Herford Refuse Incinerator Plant-An Unexpected Cause of Corrosion," VGB Kraftswerkstechnik, 64 (9), (1984).

J. E. Scheatzle and W.C. Hanson, "The Design and Start-Up of Elk River's Conversion to RDF Firing," Proc. EPRI 1989 Conf. on Municipal Solid Waste as a Utility Fuel, October 1989.

W. G. Schuetzenduebel, I. E. Johnson, C. W. Clemens, and H. Thielsch, “Accelerated Tube Metal Wastage in MSW-Fired Furnaces," NACE Paper No. 91-244 (1991).

D. J. Smith, “Can Recycling Save Waste-to-Energy?” Power Engineering, 92 (9), 21-27 (1988).

G. D. Smith and W. G. Lipscomb, "Field and Laboratory Performance of Alloys 825 and 625 in Waste Incineration Environments," NACE Paper No. 89-201 (9189).

I. Stambler, "With Landfills Closing, Waste-to-Energy Heats Up," Cogeneration, 9 (6), $41-47$ (1993).

G. J. Stanko, J. L. Blough, E. D. Montrone, and P. Adkin, “MSW Corrosion: Materials and Design Solution," pp. 261-278 in Incinerating Municipal and Industrial Waste: Fireside Problems and Prospects for Improvement, R. W. Bryers, ed., Hemisphere Publishing Corp. (1991).

T. P. Steinbeck, "Managing Tube Metal Wastage in RDF-Fired Boilers at Elk River Station," pp. 6168 in Proc. 15th Biennial Conf., 1992 National Waste Processing Conf., ASME (1992).

L. Strach, "Operating Experience of Refractory Linings in Mass-Burn Fired waterwall Boilers," NACE Paper No. 89-203 (1989).

L. Strach and D. T. Wasyluk, "Experience with Silicon Carbide Tiles in Mass-Fired Refuse Boilers," NACE Paper No. 93-219 (1993).

W. Steinkusch, "High-Temperature Failures of Heat-Resistant Steel Castings in Waste Incinerators," Werkstoffe und Korrosion, 40, 160-162 (1989).

K. H. Thoemen, "Contribution to the Control of Corrosion Problems of Incinerators with Water-Wall Steam Generators", pp 310-318 in Proc. 1972 National Incinerator Conference, New York, NY (1972). 
K. H. Thoemen, "Review of 4-yr Operation with an Incinerator-Boiler of the Second Generation", pp 171-181 in Proc. 1976 Conf. on Present Status and Research Needs in Energy Recovery from Wastes, R. A. Matula, ed., ASME, New York, NY (1976).

R. P. Tracy and D. A. Perry, "Fireside Corrosion in Energy From Waste Boilers," NACE Paper No. 91-243 (1991).

W. D. Turner, "Mass Burn Technologies--Technical Considerations," Workshop Proceedings: Energy from Municipal Waste Research: Technical Review, Report No. ANL/CNSV-TM-144, Conf-840223, Sep. 1984.

M. C. Turner, G. C. Wilson, and D. F. Robinson, "First Year of Operation at the SEMASS WTE Facility," ASME 1990 Natl. Waste Processing Conf. (1990).

M. Valenti, “Today's Trash, Tomorrow's Fuel,” Mechanical Engineering, pp. 64-67, Jan. 1993.

D. A. Vaughan, H. H. Krause and W. K. Boyd, Battelle Report to U.S. Environmental Protection Agency, June 1974.

D. A. Vaughan, H. H. Krause, and W. K. Boyd, "Corrosion Mechanisms in Municipal Incinerators Versus Refuse Composition," pp. 182-209 in Present Status and Research Needs in Energy Recovery from Wastes: Proc. 1976 Conf., R. A. Matula, ed., ASME, New York, NY (1977).

D. A. Vaughan, H. H. Krause, and W. K. Boyd, "Handling and Co-Firing of Shredded Refuse and Coal in a Spreader-Stoker Boiler," pp. 61-72 in Proc. 1978 Natl. Waste Processing Conf., Chicago, Il (1978).

C. O. Velzy, "Corrosion Experiences in Incineration," NACE Paper No. 74-133 (1974).

C. O. Velzy, "30 Years of Refuse-Fired Boiler Experience," presented at Engineering Foundation Conf. on Unit Operations in Resource Recovery, Jul. 17, 1978. Also, in Resource Recovery and Conservation, April 1979.

T. H. White, "Wheelabrator's Mass Burn Experience," Proc. EPRI 1989 Conf. on Municipal Solid Waste as a Utility Fuel, October 1989.

G. A. Whitlow, "Rotary Combustor and Boiler Tubes After Long-Term Service--A Materials Evaluation," Topical Report on Municipal Solid Waste Subscale Rotary Combustor Problem, Report No. DOE/CE/30839-T1, DE88 015586, Nov. 1986.

G. A. Whitlow, P. G. Gallagher, and S. Y. Lee, "Combustor and Superheater Materials Performance in a Municipal Solid Waste Incinerator," NACE Paper No. 89-204 (1989).

I. G. Wright, H. H. Krause, and V. Nagarajan, "Boiler Tube Failure in MSW/RDF Incineration/CoFiring," Final Report on EPRI Research Project No. 3295-07, (1994). 
W. M. Zill, and P. J. Meehan, "Rebuilding the RDF-Fired Steam Generators at Metro Dade Co., FL," pp. 69-73 in Proc. 15th Biennial Conf., 1992 National Waste Processing Conf., ASME (1992). 


\section{Appendix A}

Questionnaire Used in Assembling Information for Individual Waste-to-Energy Units and Summary of Data Obtained 


\section{Municipal Solid Waste/Refuse-Derived Fuel Boiler Tube Failure Survey}

\section{Site Description}
(a) Name of the facility
(b) Name of contact person(s)
(c) Location of the facility
(d) Owner
(e) Who operates the facility?
(f) Start-up date
(g) Number of units
(h) Manufacturer of:

(i) Grate

-type

-location of air zones

-air preheat temperature

(ii) Boiler

$$
\begin{aligned}
& \text {-location of superheater } \\
& \text {-location/type of screen tubes }
\end{aligned}
$$

(iii) Refuse handling equipment

(iv) Ash handling equipment 


\section{Fuel and Fuel Processing}

(a) Source of fuel (city, county)

(b) Fuel storage capacity

(c) Fuel combustion capacity - design/actual

(d) Fuel calorific value-as collected

-as burned

(e) Chemical analysis of fuel

$$
\begin{aligned}
& \text {-moisture content } \\
& \text {-ash content } \\
& \text {-plastics content (PVC, other) } \\
& \text {-seasonal variation }
\end{aligned}
$$

(f) Others-any major changes in fuel/fuel source?

-when did such changes in fuel occur?

(g) What size is the fuel?

(h) What sorting is done?

$$
\begin{aligned}
& \text {-shredding } \\
& \text {-magnetic separation } \\
& \text { - trommels } \\
& \text {-other }
\end{aligned}
$$

(i) What materials are recovered?

(j) Other fuels - coal

$$
\begin{aligned}
& \text { - wood waste } \\
& \text { - tires } \\
& \text { - others } \\
& \text { —what proportion? } \\
& \text { —co-fired? }
\end{aligned}
$$




\section{Plant Operating Specifications}

(a) Plant output

\begin{tabular}{lll}
$\mathrm{MW}_{1} \mathrm{lb} / \mathrm{h}$ process steam. & Customer: \\
\hline $\mathrm{lb} / \mathrm{h}$ district heating steam. & Customer: \\
$\ldots$ other & Customer:
\end{tabular}

(b) Operating parameters:

(i) Boiler operations

$\begin{array}{ll}\text { — steam temperature } & { }^{\circ} \mathrm{F} \\ \text { - steam pressure } & \mathrm{psig} \\ \text { — steam } & \mathrm{lb} / \mathrm{h}\end{array}$

— gas temperature at furnace exit______ ${ }^{\circ} \mathrm{F}$

— gas temperature at superheater entry____ ${ }^{\circ} \mathrm{F}$

_XS air level___ _ \% undergrate

\%overfire

(ii) Operating schedule:

h/day; days/year

(iii) Load factor

(iv) System availability

(v) Longest run/unit

(c) Inspection and maintenance schedule

-what are biggest maintenance problems?

(d) Process control

(i) How do you clean tubes?

-how often?

- what devices are used?

- how do you decide when to clean? 
(ii) Start-up \& shut-down procedure:

- auxiliary fuel

— unit kept warm on shut down

— nitrogen blanket

(e) Materials of construction \& any changes:

(i) Grate

-Initial materials?

-Changes?

(ii) Furnace

— Waterwall tubing alloy?

- How much of the wall is protected with

- weld overlay

- refractory

- What overlay is being used?

-Thickness?

-What refractories are being used?

- Any problems with either?

(iii) Superheater

- Tube materials

- Protection used-shields (what type, what alloy?)

-other

(f) Any design modifications? 


\section{Boiler Tube Failures (BTF)}

(a) How many BTFs per year, or after how many hours of operation

(b) Where do BTFs occur?

-Location in lower furnace wall

-Location on upper furnace wall

-Location on screen tubes

-Location in superheater

-Other locations

(c) Are BTFs Categorized According to EPRI Guidelines? - (Y) or (N)

(d) What is known about BTF Causes?

(i) Failure analysis

- Is analysis done?

-Who does analysis?

-Are reports available?

(ii) Causes of furnace wall problems

- overheating

- flame impingement

- high $\mathrm{CO}$

- poor combustion

- slagging/channelling

(iii) Causes of superheater problems

- overheating

- deposits - - - solid, liquid?

- channelling

- sootblowing

- erosion

- other

(iv) Were any analyses made of:

- fuel 


$$
\begin{aligned}
& \text { - deposits } \\
& \text { - gas }
\end{aligned}
$$

(e) How is economic impact of outage assessed?

-cost of replacement power

cost associated with loss of revenue

-landfill costs 


\section{BTF Remedies Applied}

(a) Was remedy based on known root cause?

(b) Unit de-rated, or combustion/air distribution modified? How?

(c) Modified cleaning procedures? Schedule?

(d) Protection added? — overlay

- shields

- coatings

- other

(e) Design changes needed? - screen tubes

- other

(f) New tube materials used?

(g) Have repeat BTF's occurred in the same locations?

(h) Have you run any material trials - (Y) or (N)

If $(\mathrm{Y})$ :- Do trials involve replacement tubes or probe data?

-- Any data on - - - IN 825, IN 625, IN 671, HR 160

-. Others?

_Any data on coatings?

-Who is running/ran the trials? 


\section{Emissions Controls}

What equipment/procedures are used to meet emissions control requirements?
(a) Opacity
-limits?
-equipment
-problems

(b) Particulate control

$$
\begin{aligned}
& \text {-limits? } \\
& \text {-equipment } \\
& \text {-problems }
\end{aligned}
$$

(c) $\mathrm{NO}_{\mathrm{x}}$ control

-limits?

-equipment

-problems

(d) $\mathrm{SO}_{2}$ control

-limits?

-equipment

-problems

(e) Halide control

-limits?

-equipment

-problems

(f) Dioxins/Furans control-limits?

$$
\begin{aligned}
& \text {-equipment } \\
& \text {-problems }
\end{aligned}
$$

\section{-Others}

-Any special problems? 
Table A-1. Summary of Data From Questionnaires

\begin{tabular}{|c|c|c|c|c|c|c|c|}
\hline \multirow[t]{2}{*}{ Unit No } & \multirow{2}{*}{ Problems Reported } & \multicolumn{3}{|c|}{ Preventative/Corrective Actions Taken } & \multirow[b]{2}{*}{ Design Changes } & \multicolumn{2}{|c|}{ Wastage Rate (mII $y$ ) } \\
\hline & & Grate & $\underline{w w}$ & SH & & $\underline{\underline{W W}}$ & \\
\hline \multirow{2}{*}{\multicolumn{8}{|c|}{$\begin{array}{l}\text { Mass-Burn-Grate-Type Firing } \\
\text { Steam temperature > } 800^{\circ} \mathrm{F}\end{array}$}} \\
\hline & & & & & & & \\
\hline 1 & no accelerated corrosion or erosion of waterwalls or superheater & & modified reftactory & 825 tubing & targer furnace; increased SH tube spacing & & \\
\hline 2 & reffactory spalling; Al on grate; superheater erosion & frequent repairs & replace refractory & 825 tubing; limited soot blowing & & & \\
\hline 3 & corrosion of upper waterwalls & & 625 overlay & & & $\geq 150$ & \\
\hline 4 & wear/corrosion of grate; waterwall corrosion; fouling//erosion/corrosion & & added refractory & 825 tubing & added screen tubes; improved air distribution; & & $>650$ \\
\hline & of superheater tubes; flame impingement into superheater & & & & modular SH; rapping; combustion control & & \\
\hline 5 & grate burnout; slagging of refractory; corrosion of waterwalls & adjusted air distribution & combustion control & & added filters to protect preheater & & \\
\hline \multirow{2}{*}{\multicolumn{8}{|c|}{ Steam temperature $\geq 750^{\circ} \mathrm{F} \leq 800^{\circ} \mathrm{F}$}} \\
\hline & corrosion of upper waterwalls, resulting trom slagging of OFA nozzles & & 625 overlay above refractory & & & $\approx 100$ & \\
\hline 7 & corrosion of waterwalls; corrosion/erosion of superheater & & 625 overlay & $\begin{array}{l}825 \text { tubing; shields of } 304,310, \\
625,825\end{array}$ & modified over-fire air & $=400$ & $\approx 200(\approx 500$ \\
\hline 8 & waterwall corrosion beneath refractory & & Sic+625 overlay & (203, toss tubing & & - & - \\
\hline 9 & waterwall failures by corrosion/erosion in $\approx 1 \mathrm{yr}$; & & 625 overlay; modified OFA distribution & & & $\approx 120$ & \\
\hline 10 & waterwall refractory loss; superheater corrosion & & modified refractory & 825 tubing & installed wall soot blowers & & \\
\hline 11 & reducing conditions/corrosion of WW; deposit-related corrosion of SH & & replaced with same, extended refractorn & ythicker, upgrade & frequent rapping of superheaters & 30.50 & $40-60$ \\
\hline 12 & waterwall corrosion above refractory & & SiC +625 overlay & No & revised air distribution in upper furnace & $>150$ & $=$ \\
\hline \multicolumn{8}{|c|}{ Steam temperature $<750^{\circ} \mathrm{F}$} \\
\hline \multirow{2}{*}{13} & waterwall corrosion-water treatment, waterwall corrosion above & replace same; CrNi alloy & added SiC; thicker tubes; 625 added & added OFA: 825 tubing & & $>150$ to 28 & $>50(\mathrm{SB})$ \\
\hline & refractory; SH corrosion, high gas temperatures; Al probs on grate & & above refractory & & & & \\
\hline \multirow[t]{2}{*}{14} & superheater erosion-corrosion (due to soottlowers) & & & upgraded materials; reduced & & & $>360$ \\
\hline & Cl corrosion of upper waterwalls, erosion of SH (due to soot blowers) & & extended refractory & $\begin{array}{l}\text { soot blowing frequency } \\
\text { reduced SB frequency }\end{array}$ & & $\approx 50$ & \\
\hline \multirow[t]{2}{*}{16} & Cl corrosion of screen tubes and convection bank; erosion/corrosion & & & composite 304/SA 192 tubes & Improved rapping system & & $\approx 100$ \\
\hline & of convection bank & & & & & & \\
\hline \multirow{2}{*}{\multicolumn{8}{|c|}{ Mass-Burn-Rotary Combustors }} \\
\hline \multirow{2}{*}{\multicolumn{2}{|c|}{$\begin{array}{l}\text { Steam temperature }>800^{\circ} F \\
17 \text { watewall corrosion; molten salt corrosion of superheater }\end{array}$}} & & & & & & \\
\hline & & & & & & $>350$ & $60-270$ \\
\hline \multicolumn{2}{|c|}{ Steam temperature $\geq 750^{\circ} \mathrm{F} \leq 800^{\circ} \mathrm{F}$} & & & & & & \\
\hline \multirow[t]{3}{*}{18} & repeated superheater soot blower-related erosion & & 625 overlay; SiC & added 309 shields & & & nurnerous \\
\hline & & & & & & & BTFs \\
\hline & emperature < $750^{\circ} \mathrm{F}$ & & & & & & \\
\hline $\begin{array}{l}\text { Steam temperature }<755^{\circ} \mathrm{F} \\
19\end{array}$ & soot blower erosion of upper waterwalls and superheater; WW corrosion & & 625 overlay & shields & & 30 & \\
\hline 20 & corrosionflame impingement of WW: SB erosion/corrosion of SH & & castings; 625 overlay & upgraded matls & redesigned superheaters & $\approx 160$ & $\leq 55$ \\
\hline 21 & soot blower erosion of superheaters & & 625 overlay; $\mathrm{SiC}$ & 253MA shields & increased superheater tube spacing & & 5 ET $=5 / y r$ \\
\hline & & & & & & & \\
\hline
\end{tabular}


Table A-1. Summary of Data From Questionnaires

\begin{tabular}{|c|c|c|c|c|c|c|c|}
\hline \multirow[t]{2}{*}{ Unitito } & \multirow[t]{2}{*}{ Problems Reported } & \multicolumn{3}{|c|}{ Preventative/Corrective Actions Taken } & \multirow[b]{2}{*}{ Design Changes } & \multicolumn{2}{|c|}{ Wastage Rate (mil//yr) } \\
\hline & & Grate & $\underline{\underline{w w}}$ & $\underline{\text { SH}}$ & & $\underline{\text { ww }}$ & SWH \\
\hline$\frac{\text { Mass-bu }}{22}$ & $\begin{array}{l}\text { ri-Modular Combustors } \\
\text { corrosion of lower waterwall above refractor. flame impingement on }\end{array}$ & & & thicker twbes. unarade to T2? & modified air distribution & & \\
\hline & upper waterwall; superheater corrosion & & increase neignt or rerraclory & thicker tubes; upgrade to 122 & modified alr distribution & & \\
\hline RDF-Fire & d Units with Suspension or Grate Burning & & & & & & \\
\hline Steam te & mperature $>800^{\circ} \mathrm{F}$ & & & & & & \\
\hline$\frac{23}{24}$ & $\begin{array}{l}\text { erosion/corrosion of superheater } \\
\text { corrosion of unoer waterwall and sunetheater }\end{array}$ & & 625 overlay & shields; overlay & & & $\leq 125$ \\
\hline 25 & upper waterwall corrosion-reducing conditions & & $\begin{array}{l}625 \text { overlay } \\
625\end{array}$ & $\begin{array}{l}\text { shields } \\
\text { shields } 309 \text { overlav chromizina }\end{array}$ & modified over-fire air & $>50$ & \\
\hline & & & & & & $\approx<0$ & \\
\hline Steam te & mperature $\geq 750^{\circ} \mathrm{F} \leq 800^{\circ} \mathrm{F}$ & & & & & & \\
\hline 26 & erosion/corrosion at lower furnace arch & & 625 overlay; refractory added & & & $\leq 125$ & \\
\hline$\frac{27}{28}$ & $\begin{array}{l}\text { Al on grat; ; corrosion of waterwalls } \\
\text { corrosion of WW (overheating): SH erosion:SH erosion/corrosion (SB) }\end{array}$ & design modifications & 825-clad tubes; 625 overlay & & ${ }^{2}$ & & \\
\hline 29 & waterwall corrosion (reducing atmosphere); slagging of waterwalls & & 625 overlay & Sos snielas & larger fumace; added superheater screen tubes & $\approx 80$ & $\approx 50$ \\
\hline Steam te & mperature $\leq 750^{\circ} \mathrm{F}$ & & & & & & \\
\hline 30 & waterwall corrosion; grate probs; fouling of SH; SB erosion of SH & med decign medured & & & & & \\
\hline & & $\begin{array}{l}\text { mod. design; reduced } \\
\text { A intake }\end{array}$ & thicker tubes; metal spray & shields & & $\leq 300$ & \\
\hline 31 & wastage of lower waterwalls; corrosion of superheater (overheating) & & thicker tubes; 625 overlay & 825 tubing & installed Sic, then replaced with 625 ; & $=125$ & $\approx 00$ \\
\hline 32 & overheating (int deoosits) +corrosion of lower WW carrosion of SH & & 625 goverlay & 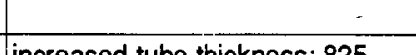 & reduced soot blowing frequency & nom & 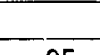 \\
\hline & & & & tubes; cast shields & added over-fire air levels & 80 & ב950 \\
\hline Utility Bc & ilers Burning Some Waste & & & & & & \\
\hline 33 & corrosion of lower waterwalls (reducing atmosphere); corrosion of & & 625 overlay & shields; possibly upgrade to SS & & $=150$ & $\leq 60$ \\
\hline
\end{tabular}




\section{Appendix B}

Listing of Waste-to-Energy Units

in Operation and Planned in the United States 
Table B-1. Listing of Waste-Fired Boilers Operating in the U. S.

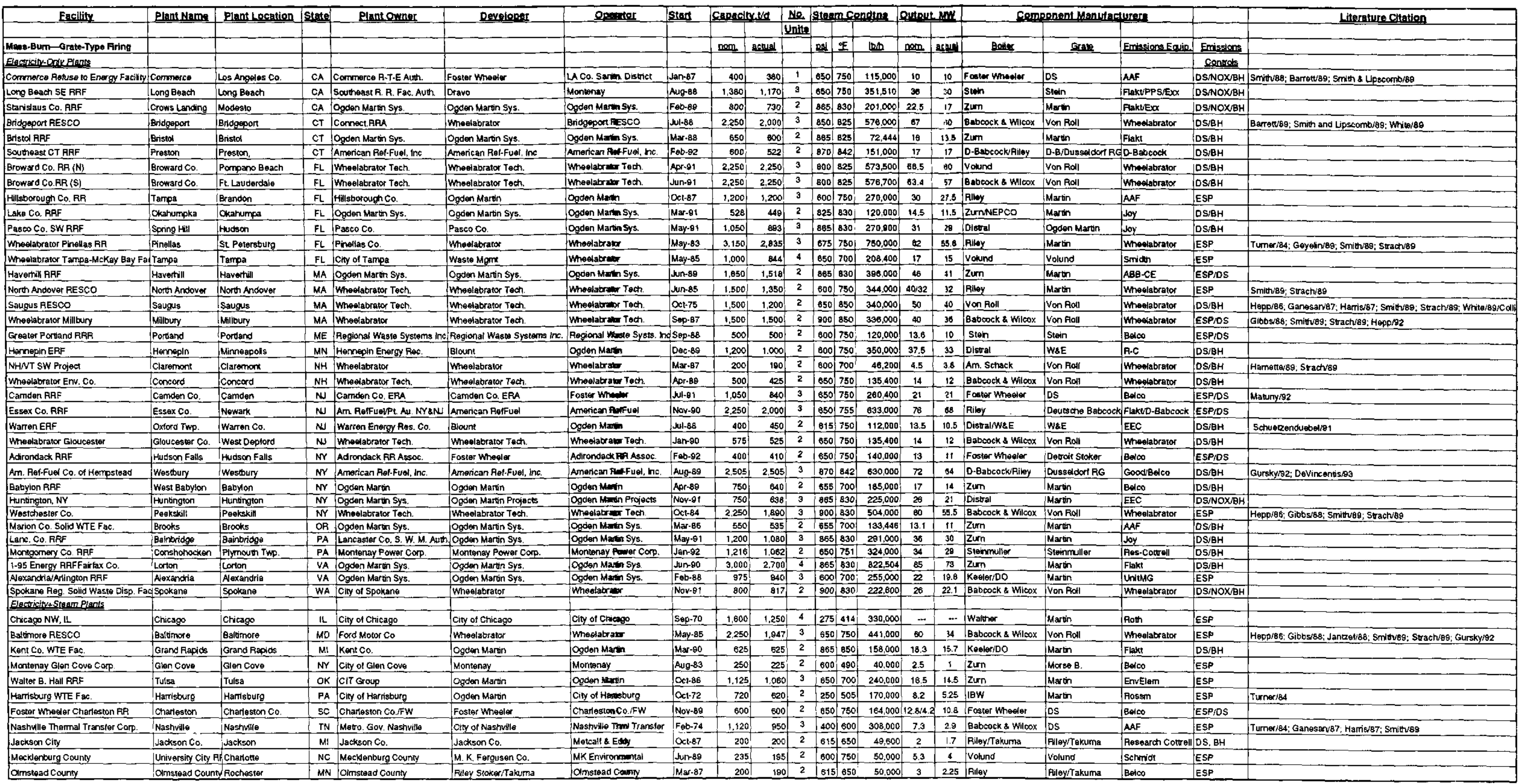


Table B-1. Listing of Waste-Fired Boilers Operating in the U. S.

\begin{tabular}{|c|c|c|c|c|c|c|c|c|c|c|c|c|c|c|c|c|c|c|c|}
\hline Eacilitix & Deaniname & PlantLecation $\mathrm{S}$ & sitere & Plant owner & Developer & Qpegation & stan & capacitust & 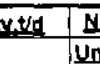 & (2) & 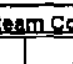 & nenting & & & & Denent mancitact & twrene & & Litereture citation. \\
\hline & & & & & & & & $\operatorname{sem} 2$. & acual t & & d I I E & 15e & m & ane & goves & Sicate & Emiscons Eavide & 2 Entrians & \\
\hline 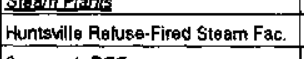 & thansalile & tunsesille & AL_t & Huntsoville S.W.W.iisp. Auth. & Opdon Marin & ogdon Marain & (201.99 & 800 & .896 & & $500] 470$ & 172,000: & & & & | Merang & ARB.CE. & DStert & \\
\hline 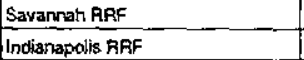 & 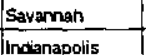 & $\begin{array}{lll}\text { Savananah } \\
\text { nidanaposis }\end{array}$ & $\frac{G A}{\text { in }}$ & Kay-Seghaers. inc. & 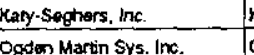 & 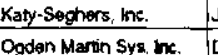 & 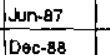 & $\frac{5002}{2032}-$ & -4807 & & 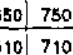 & \begin{tabular}{|l|l|}
120.000 \\
500000
\end{tabular} & $\div$ & $\frac{07}{0-1}$ & $\frac{D i m}{20 m}$ & Stopheras & EEC & $\frac{\mathrm{ESP}}{\mathrm{ESPOP}}$ & Becckmaver 7 \\
\hline Bens Avercue incinerata $x$ & 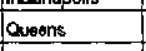 & New Yoork & $\mathrm{NY}-\mathrm{S}$ & Cing of New Yook & cily of New York & ciny of Now Yark & San-64. & 1.000 & & & & 31.250 & 0 & th & 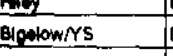 & & & & \\
\hline $\begin{array}{l}\text { Davis co WTTE Fac. } \\
\text { Hetsono falts }\end{array}$ & Laxon - & Layron - & $\frac{u \pi f}{\Delta \alpha}$ & Dans Co. SWM z ER Dist & 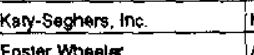 & 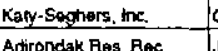 & $\frac{\operatorname{coc}-88}{109-92}$ & $-4000-$ & 3500 & & 200350 & 110.000 & 0 & 07 & & Soppers & EEC & ESPDOS & Becthmanizy \\
\hline Husanpion Fits & 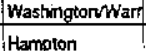 & 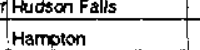 & $\frac{N_{1}}{v_{A}}$ & 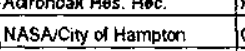 & 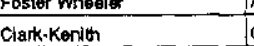 & 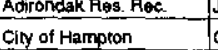 & 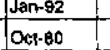 & 4000 & & & & & & 11 & Foleres whodeder & & & & \\
\hline - & & & & & & & & & & & & & & & & & & & 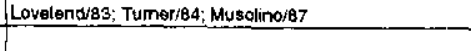 \\
\hline 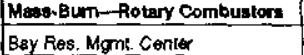 & Dam & penomaiv & Fot & Ford & 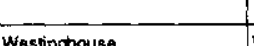 & Wassinghouse & 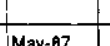 & & & & & & & & & & & & \\
\hline Duchess Co. RRF & Paighteopsis & 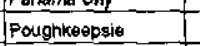 & $\mathrm{Nr}$ & Duchass $C_{0}$. Ras . Aec. $A_{8}$ & Wossingtouse & $\begin{array}{l}\text { Westinghouse } \\
\text { Westions }\end{array}$ & octses & 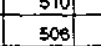 & 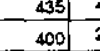 & & 225.7500 & \begin{tabular}{|l|l|}
68.000 \\
$110.000 \mid$ \\
\end{tabular} & $-\frac{12}{8}$ & $\frac{106}{22}$ & 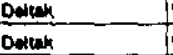 & 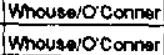 & 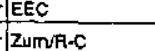 & ESP & 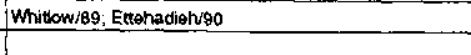 \\
\hline MacArthur WTE Fac. & sisp & SIIP & wit & 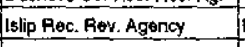 & Montenary & Menonay & $x_{n+1}-89$ & 518 & & & & 166,000 & 10.5 & 8 & & 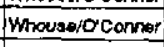 & & & \\
\hline Mompogomery Co. (N) RA & Dayan & Dayron & $\frac{O H}{O H}$ & Mombogmern Co. & Montgamery $\mathrm{co}$. & Monponamer co. & sep-88 & $300_{-}$ & 255 & & & 72,000 & 6 & 57 & comoustoren Enege. & Monitgamary $\mathrm{C}_{0}$ & unimg & Esp & \\
\hline 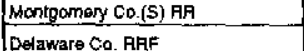 & Daron. & & OM & 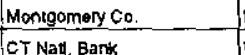 & Monigomery co. & Montyomery co. & 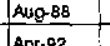 & 2000 - & & & & & 18.6 & $1: 7$ & Combutanon Erege & Montiomerey co. & & & \\
\hline 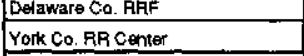 & 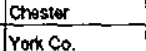 & 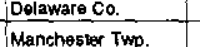 & $\frac{P A}{F A}$ & 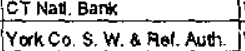 & 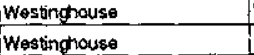 & 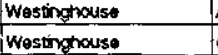 & Apres 82 & . 2.689 & $\frac{2,2055}{1,100}$ & & 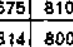 & 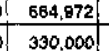 & $\frac{90}{35}$ & $\frac{73}{302}$ & & 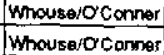 & floy & DSSBH & Whitwerag \\
\hline Fos. Auth. in Sumprer co. & Gilation & Summerco. & $\mathrm{TN}$ & 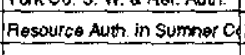 & Ressource Aut.sumner Co. & Rassource Aut, Summor of & $\begin{array}{ll}0.000 .81 \\
0.01\end{array}$ & 2005 & $=150$ & & 2255510 & 5 & 0.5 & 0.4 & ocomperikgoaler & whioconner & PPC & ESP & 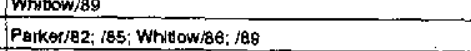 \\
\hline Mass.Bum-Modular Combustor & & & & & & & & & & & & & & & & & & & \\
\hline Tuscalooss EFf & Tuscalosasa & Tusealoosa & AL & Tuscalosas S. W. Disp. Autr & consumat & Tuscaioost S. W. Desp. Af & afsob:-84 & 3600 & 2000 & & 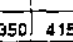 & 55,$900 ;$ & 0 & 0 & consumat & Consumant & $P$ PPC & ESP & \\
\hline 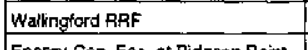 & Wealingtord- & Watingtoro & ct & Wallingtod A RA A AssoC & CT RR AUTh & Wallifinglord AR Assoce & Apr:so & 420 & 300 & & 8507.750 & 105,000 & & 23 & & Enercon & Frocel & OS.POH & \\
\hline 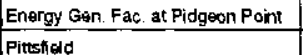 & & Nowcaste & DE & & 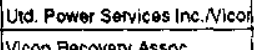 & 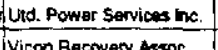 & 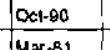 & 8000 & 546 & & & 152,000 & 13.3 & 10.5 & Am. Schack & & & ESP & Harmentosis? \\
\hline 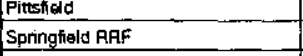 & 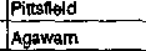 & 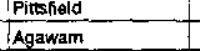 & $\frac{M A}{M A}$ & 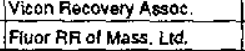 & 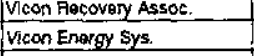 & 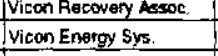 & 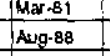 & \begin{tabular}{rl|}
$\frac{240}{3600}$ \\
\end{tabular} & $\begin{array}{l}-315 \\
-315 \\
-315\end{array}$ & $\frac{2}{3}$ & 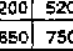 & $\frac{52,0.00}{85.500}$ & $=$ & $\frac{71}{7.4}$ & 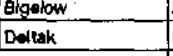 & $\begin{array}{l}\text { Enarcicon } \\
\text { Enercon }\end{array}$ & $\begin{array}{l}\text { Uuda.McGiil } \\
\text { Flast }\end{array}$ & ESS, WS & \\
\hline 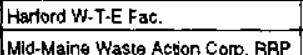 & $\begin{array}{l}\text { Edogenood } \\
\text { Auvum }\end{array}$ & Aberddeen Prov. Gds. & $\frac{M D}{M E}$ & 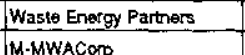 & N.E. Mo Solld Wasto Auth. & Consumat & 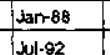 & $\frac{360}{200}$ & & & & & & 0 & Abco & Consumat & PPC & $\frac{\mathrm{Esp}}{\mathrm{Seg}}$ & \\
\hline 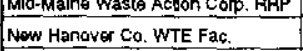 & 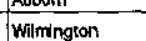 & 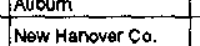 & & 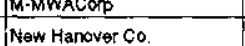 & 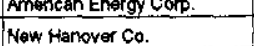 & 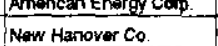 & 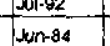 & & & & & & & $\frac{3.3}{4}$ & The Schatrick & 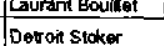 & & & \\
\hline Long Bosect & Long Beach & Leng Beat & $\frac{N}{N r}$ & & Mononany & Montenay & Fob:8B & 2000 & & & $750-480$ & 88,000 & 4.5 & & 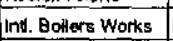 & Barse Bullgor & Baco & IESP & \\
\hline contida Couny & oneida County. & Roment & we & & & oneidathantimer SWA & talan-8s & 2000 & & & $250-425$ & & 2.2 & 1.2 & & & tura. Megill & ESP & \\
\hline 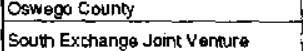 & fowego Coung & Voveney & 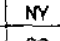 & Poswego Couny & Consumat _... & oswegog Couny & Fob-86 & 200 & 180 & & $265+400$ & 550.000 & 4 & 1 & & Consunat. & Prodopleabs & ESEP & \\
\hline & & & & souttiand Exthangeg inc. & & Souttland Exchanges hinc. & :00r:85 & 270]. & $-200 \mid$ & & $150+296 \mathrm{C}$ & of 45,000 & & & Nuerson & & & ESPP & \\
\hline RaF-Fred Ur & rar & & & & & & & & & & & & & & & & & & \\
\hline 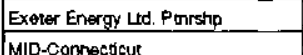 & Exot: & 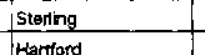 & $\frac{C T}{c T}$ & 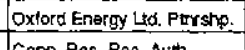 & 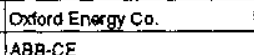 & CMS Gon. & on:91 & 3001 & 2255 & & 0009.936 & 240,0000 & 30 & 28 & & Lambion Stokerer & GEESINAateo & BHWSNO & Makansilo2 \\
\hline 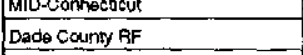 & thatcica & thatrour & $\frac{C T}{F L}$ & & Mag-cen & 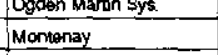 & 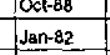 & $\begin{array}{l}2.000 \\
3.000\end{array}$ & $\begin{array}{ll}2.2000 \\
3.000 \\
\end{array}$ & $\frac{4}{4-15}$ & & 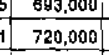 & $\frac{80}{7}$ & $\frac{68.5}{62}$ & & $\begin{array}{l}\text { Contbuston Engeg } \\
\text { Zum }\end{array}$ & & $\begin{array}{l}\text { DSFH } \\
\text { ESP }\end{array}$ & 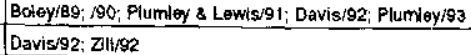 \\
\hline & Wost Palm B & WWoss Pam & $\mathrm{FL}$ & S. W. Auth of Palm Baadic & Babcocks. & aatcook \& Wicox & Now-89 & 2,000 & 2,000 & $2+2$ & & of 5220.000 & 80 & 49 & 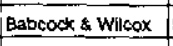 & os _ _ & JoYWE & Espos & 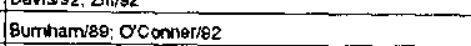 \\
\hline HFower & Eva a Beasth. & Honolidu & HII & & $A B B \cdot C \cdot C E$ & osoden Matrin Syz & & 2,$160 ;$ & 1.7.70 & $2=1$ & 9000) 35. & 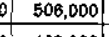 & & 48 & Comboustion Engge. & Combussion Engga & $A B B \cdot C E$ & & \\
\hline Lamrence BDF F Fac. & Havethilin. & 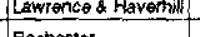 & $M A$ & 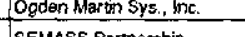 & 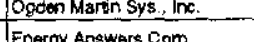 & 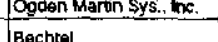 & Sopp.84 & 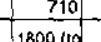 & -450 & $\frac{1}{2}=5$ & 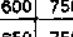 & 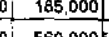 & 21 & $\frac{-17}{45}$ & Babcocos \& Witcox & $\frac{D S}{w}$ & odco & ESPP & \\
\hline & 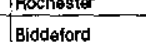 & Fichestester & MA & & 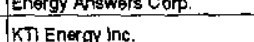 & $\frac{186}{167}$ & & (10000 & & & & 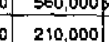 & & & & Hitey & & & \\
\hline & Orimingon- & & ME & & & $G E C$ & 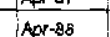 & 7500 & 2500 & & & of 2550.000 & $\frac{25.3}{253}>0>0$ & 21 & & Ficioy & & 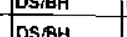 & \\
\hline 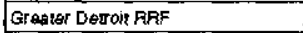 & Derevoin & & $\overline{\mathrm{M} 1}$ & & R.R. R.Auth. & ABB-CE & Mar-68 & 4.000 & 1.600 & & & 5) 8380.000 & & & & cambussio & & SPR & \\
\hline (odake Af & 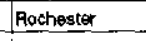 & Frochoseler & st & Easman Ko & Easmman Koodak & Easmman Kotate & $\tan 70$ & $150 \%$ & 119 & & $400055=1.50$ & of 150.0000 & & $=$ & combus & Conbustion Engg, & imeolalabr & ESP & \\
\hline & & & $-\frac{N Y}{v y}$ & & ocectionatal cham, corp. & Pocidertal cham & aec:60 & 2,000 & $\ldots$ & 2 & 600.70 & of & & & & & & & \\
\hline & & & & & & & & & & & & & & & & & & & \\
\hline
\end{tabular}


Table B-1. Listing of Waste-Fired Boilers Operating in the U. S.

\begin{tabular}{|c|c|c|c|c|c|c|c|c|c|c|c|c|c|c|c|c|c|c|c|}
\hline Eacillty & Elant Name & \begin{tabular}{|l|} 
PlantLocalion \\
\end{tabular} & & Plant owner & Devaloper & operater & Sent & Gaperelit & xite & & itemengen & zattare fs & putponte & & Somp & penent Manuthact & tyeren & & Lhernure cilation \\
\hline & & & & & & & & 100 . & 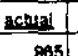 & & & 些 & nom. & . & & Selate & Emissions Equio & Emssions & \\
\hline 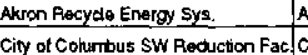 & Acon & Acon & $\frac{O H}{O S+C}$ & $\begin{array}{lll}\text { cily of Acron } \\
\text { ciry of columbus }\end{array}$ & 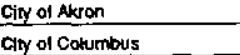 & 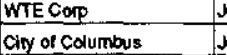 & 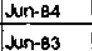 & $\frac{1.100 \mid}{2.000}$ & $-\frac{8053}{1.900}$ & & & & -4 & $\frac{18}{x+8}$ & 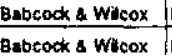 & & & & 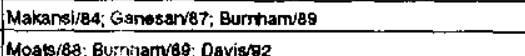 \\
\hline SEEP & 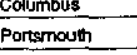 & 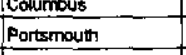 & 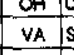 & 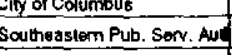 & & Sountreastem Pub. Serv. As & 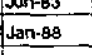 & $2 \frac{2,000}{2,000}$ & $\begin{array}{lll}-1.8045 \\
-1.845\end{array}$ & $\div$ & & 375,000 & (40 & 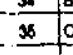 & 年 & Combuston Enoge. & Generaral Electric & SSPEAMDS & 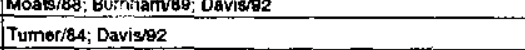 \\
\hline 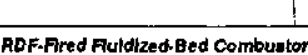 & & & & & & & & & & & & & & & & & & & \\
\hline W. Lake Supprior Sanki Dist. - & Dolut & w. Laks Supr Snon. of & 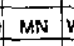 & W. Laka Sipporior Sanit DIs & Consoer Toumsendibaloil Fa & W. Laka Supetror Saniti: D. & Mar-81 & 4000 & 3000 & 2 & & 38.000 & $=$ & $=10$ & Dollak - & Copoland & Emroal. & ws & \\
\hline Tracoma & Stroam Plantert2 & Tacooma__. & WA 7 & Tacoma Fut. Uabl. - - - & & Tacoma pub vol _. & A $\mathrm{N}: 29$ & $300]$ & 2000 & 2 & & 528.000 & 50 & 4 E & 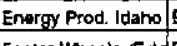 & Enorgy Prod idarange & & & 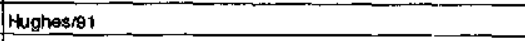 \\
\hline Lac Coose $C$ C. & French sistand & Lacrosse- & 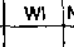 & Northern States Power_ & Northen States Power. & Northem Sates Powar & Apr-88. & 400 & 225 & & 450,7500 & 300,000 & 30 & .285 & 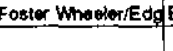 & & compow & GBM & 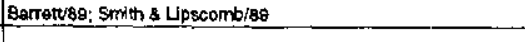 \\
\hline 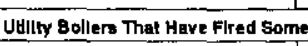 & E. Watate & & & & & & & & & & & & & & & & & & \\
\hline (a)incoeration & & & & & & & & & & & & & & & & & & & \\
\hline Cily of Lakeland & Mennosines & LLakoland. & $\mathrm{FL}=\mathrm{S}$ & Ciry of Lakeland & Givinot Latalland & Cliy of Lakeland & sop:-32 & 300 & -275 & & & 3.300 .000 & -364 & 305 & 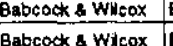 & 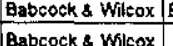 & Babcocok \& Wilc & XESPNS & 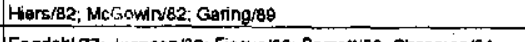 \\
\hline 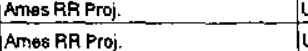 & Unitus & Anmos & $\frac{\mathrm{AA} C \mathrm{C}}{\mathrm{AA} d \mathrm{C}}$ & & 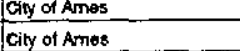 & 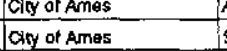 & $\frac{100679}{50075}$ & 2009) & . $-\frac{.744}{174}$ & & & & $\frac{-65}{35}$ & & 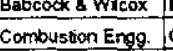 & 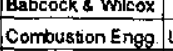 & & EEPPBH & 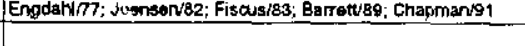 \\
\hline 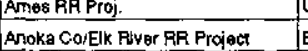 & 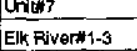 & Ames & $\frac{A 4}{M N}$ & 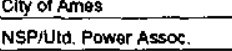 & 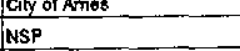 & 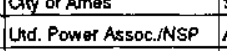 & 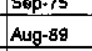 & $\frac{2.500}{1.500}$ & $\frac{1.164}{1.500}$ & 3 & & & $\frac{35}{33}$ & $-\frac{6}{-1}$ & 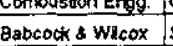 & 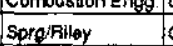 & GERAes-Cortoll & & 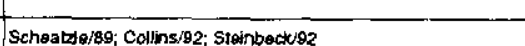 \\
\hline Markato RAF - & 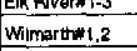 & Markato & $\mathrm{MN}$ & N. States Power & N. Slates Powar- & N. Sates Power & Alug:87. & & & 2 & & & -11 & -4 & & & & & 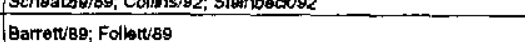 \\
\hline 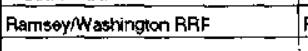 & Red Wing _ & Nempor & MN I & NSPPRPAd Wing__ & N. Salates Power & NN. SEtes Power- & 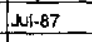 & 1.200 & 1.150 & & 6507725 & 24,000 & 24 & $22-5$ & FWAstw & Dercolis Scoker & Bolco. & ESP & 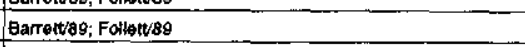 \\
\hline & & & & & & & & & & & & & & - & & & & & \\
\hline 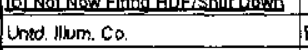 & 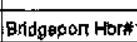 & Brososeorn & CT & & & $-{ }_{-1}$ & Nov-79 & & & 1 & & & 80 & & Baw orclionere & & & & Mocomintr82: Fiscus/83 \\
\hline Corm. Ed. Co. & Crawtircter.8 & chicago & $\pi$ & & & & & & & 2 & & & & & Combussoon Enges. & & & & McGounnazaz: Fiscoss:83; Tumeri/84 \\
\hline Baltamore Gas s Eloct. CO. & Crenantat & Bationore & MO & Balifmere $G \& \mathrm{E}$ & & & Feb-8.4. & 1.2000 & -000 & & 4755 : 1050 & $1,032.000$ & 2007 & 188 & Bew cycosono & & General Eloctric & BH... & 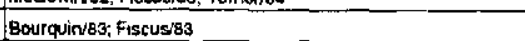 \\
\hline Whion Elest co. & Meramecti, 1,2 & St. Laus & mo- & & & $\ldots$ & Aer:7210 & thov7.75 & & + & & & 125 & -1 & Combustion Engeg. & & & & 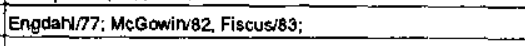 \\
\hline Alande Electic Co. & B.LEnglanditit & Beossays Point. & N & Atantic Electric & & & & & - & 4 & 16001005 & & $\frac{129}{1025}$ & it & 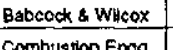 & & & & Ncobobtitige \\
\hline Hochesster Gas \& Elec. & 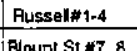 & Rochesster & $\frac{N}{N}$ & Madion Gas A Elactic & & & Sop:-8110 & & & $-\frac{4}{2}$ & & & $\left\{-\frac{2275}{55}\right\}$ & - & Combuston Engeg. & Combersonenont & APQDCE & Tyerisod & 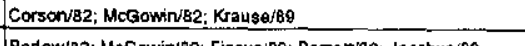 \\
\hline 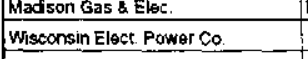 & 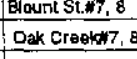 & Mativanonos & $\begin{array}{ll}\frac{w}{w} \\
\mathrm{w}\end{array}$ & Madison Gas _ E Elactic & $\ldots \ldots$ & $-\ldots$ & 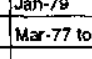 & Aunge0 & 200 & 2 & & s & \begin{tabular}{|l|l|}
35 \\
310 \\
\end{tabular} & 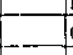 & 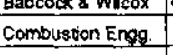 & . & 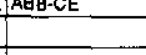 & CYCLESP & 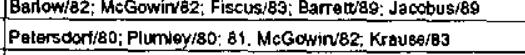 \\
\hline & & & & & & & & & te & & & - & & -7 & & & & & \\
\hline 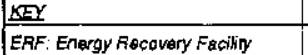 & & & & & & & -5 & - & 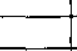 & & & & - & - & & & & 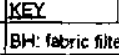 & \\
\hline AF: Recovery Faccily & & & & & & & & & & & & & & & & & & crca: ardone & \\
\hline Fif: Aessurres Recovery. & & & & & - & & & - & - & - & & - & - & - & & & & os:dysecon & \\
\hline 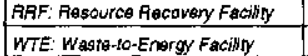 & & & -1 & & & & - & - & 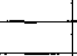 & - & & & 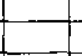 & $\square$ & & & & 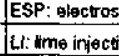 & stiac prociphatar \\
\hline & & & & & & & & & & & & & & - & & & & Nox: NOX Con & \\
\hline & & & & & & & & & & & & & & & & & & ws: we & \\
\hline
\end{tabular}


Table B-2. Summary of Waste-to-Energy Units Planned in the U. S.

\begin{tabular}{|c|c|c|c|c|c|c|c|c|c|c|c|c|c|c|c|c|c|}
\hline \multirow[t]{2}{*}{ Project } & \multirow[t]{2}{*}{ Location } & \multirow[t]{2}{*}{ Stata } & \multirow[t]{2}{*}{ Start } & \multirow[t]{2}{*}{ Owner } & \multirow[t]{2}{*}{ Operator } & \multicolumn{3}{|c|}{ Steam Condts } & \multirow[t]{2}{*}{ Cappedity } & \multirow{2}{*}{$\begin{array}{l}\text { Dlan! } \\
\text { Produst }\end{array}$} & \multirow{2}{*}{ No } & \multicolumn{2}{|c|}{ Output. MW } & \multirow{2}{*}{$\frac{\text { Emlsgions }}{\text { control }}$} & \multicolumn{3}{|c|}{ Component Manufacturers } \\
\hline & & & & & & & & & & & & & & & Boiler & Grate & Emissions \\
\hline & & & & & & psi & 오 & 占佔 & yd & & & $\underline{\text { srons }}$ & №⿱ & & & & Conirols \\
\hline \multicolumn{18}{|l|}{ EBCUnits } \\
\hline Robbins RRF & Robbins & II & Dec-95 & Reading Energy Co.IFW & Foster Wheeler & 900 & 835 & 460,000 & 1,600 & Elece. & 2 & 54 & 41 & DSNOXBH/FBOI & Foster Wheeler & Foster Wheeler & $T B D$ \\
\hline Moapa Energy Project & Moapa & NV & Juil-95 & Moapa Energy Utd. Ptnrshp & CMS Generation & 950 & 905 & 450,000 & 540 & Elec. & 2 & 56 & 53 & WSINOX/BH & Babcock \& Wilcox & FBC & TBO \\
\hline KEY & & & & & & & & & & & & & & KEY & & & \\
\hline RF: Recovery Facility & & & & & & & & & & & & & & BH: fabric fitter & & NOX: NOx control & \\
\hline \multicolumn{2}{|c|}{ RRF: Resource Recovery Facility } & & & & & & & & & & & & & crc: cyclone & & WS: wet scrubber & \\
\hline & & & & & & & & & & & & & & DS: dy scrubber & & TBD: to be determir & \\
\hline & & & & & & & & & & & & & & ESP: olectrostatic & ic precipitator & Hg: mercury control & \\
\hline & & & & & & & & & & & & & & L: lime injection & & & \\
\hline & & & & & & & & & & & & & & & & & \\
\hline
\end{tabular}


Table C-1. Summary of Waste-to-Energy Units Planned in the U.S.

\begin{tabular}{|c|c|c|c|c|c|c|c|c|c|c|c|c|c|c|c|c|c|}
\hline \multirow[t]{2}{*}{ Prolect } & \multirow[t]{2}{*}{ Location } & \multirow[t]{2}{*}{ State } & \multirow[t]{2}{*}{ Start } & \multirow[t]{2}{*}{ Owner } & \multirow[t]{2}{*}{ Operator } & \multicolumn{3}{|c|}{ Steam condts } & \multirow{3}{*}{ Capactity } & \multirow{2}{*}{\begin{tabular}{|l|} 
Plant \\
Producs \\
\end{tabular}} & \multirow{2}{*}{\begin{tabular}{|l} 
Ne. \\
Units \\
\end{tabular}} & \multicolumn{2}{|c|}{ Output, MW } & \multirow{2}{*}{$\begin{array}{c}\text { Emissions } \\
\text { control } \\
\end{array}$} & \multicolumn{3}{|c|}{ Component Manufacturers } \\
\hline & & & & & & & & & & & & & & & Boiler & Grate & Emissions \\
\hline & & & & & & 2si & 으 & $\underline{\underline{b} / \mathrm{h}}$ & & & & gross & Net & & & & Controls \\
\hline \multicolumn{18}{|c|}{ Mass-Burn-Grate-Type Firlng } \\
\hline Lisbon & Lisbon & CT & Mar-95 & TBD & Wheelabrator & 900 & 8301 & 135,400 & 500 & Elec. & 2 & 15 & 13 & DSINOXBH & B \&W/Riley & Von Roll: & TBD \\
\hline Lee Co. Solid WTE & Fort Myers & FL & Jan-95 & Le日 Co. & Ogden Martin & 850 & $825: 3$ & 337,500 & 1,200 & Elec. & 2 & 39 & 33.5 & DSINOXBBH & Distral & Martin & $A B B$ \\
\hline East Bridgewater RRF & East Bridgewater & MA & Jan-95 & American RefFuel, Inc. & American Reffuel, inc. & 855 & 842 & 400,000 & 1,500 & Elec. & 2 & 50 & 40 & DS/NOXBBH & TBD & Deutsche Babcock & $T B D$ \\
\hline Montachusett Regional RF & Shirley & MA & Dec-95 & ITIRU & TRU & 900 & 712 & 70,000 & 243 & Elec. & 2 & 7 & 5.8 & DS/NOX/BH/Hg & TBD & TIRU. S.A. & TBD \\
\hline Montgomery co. RRF & Dickerson & MD & Dec-95 & N. E. Maryland W. Disp. Autti & Ogden Martin & 865 & $830 \mathrm{~s}$ & 512,000 & 1,800 & Elec. & 3 & 83.6 & 69 & $\mathrm{DS} / \mathrm{NO} / \mathrm{BH} / \mathrm{Hg}$ & TBD & Martin & TED \\
\hline Arrowood RRF & Mecklenburg co. & NC & \begin{tabular}{|l|} 
Jan-96 \\
\end{tabular} & Mecklenburg Co. & Wheelabrator & 675 & 750 & 150,000 & 600 & Elec. & 2 & 16 & 12.5 & DS/NOX/BH & Babcock \& Wilcox & Von Roll & Wheelabrator \\
\hline Mercer Co. RRF & Hamilton Twnshe & NJ & Jan-96 & Mercer Co. Improv, Auth. & Ogden Martin Sys. & 865 & 825 & 480,000 & 1,450 & Elec. & 2 & 52 & 47 & DS/NOX/BH/Hg & TBD & Martin & TBD \\
\hline Hudson $\mathrm{Co}$. & Kearny & No & $\operatorname{Jan}-96$ & Ogden Martin Sys. & Ogdan Martin Sys. & 865 & 8304 & 410,000 & 1,500 & Elec. & 2 & 45 & 38.3 & DS/NOX/BH/Hg & TBD & Martin & TBD \\
\hline Union co. & Rahway & $\mathrm{NJ}$ & Feb-94 & Union Ca. Util. Auth. & ogden Martin & 865 & 8303 & 360,000 & 1,440 & Elec. & 3 & 44 & 39 & DS/NOXBBH/Hg & Distral & Martin & Res-Cottrell \\
\hline Brooklyn Navy Yard RRF & Brooklyn & NY & Jan-99 & Wheelabrator Env. & Wheelabrator Env. & 465 & 4756 & 650,000 & 3,000 & stoam & 4 & 0 & 0 & DSINOX/BH/Hg & Babcock \& Wilcox & Von Roll & Wheelabrator \\
\hline Green Island & Green Island & NY & Jun-96 & American Reffuet & American Reffuel, inc. & 855 & 8424 & 400,000 & 1,500 & Elec. & 2 & 50 & 40 & DS/NOX/BH & TBO & Deulsche Babcock & TBD \\
\hline Onondaga co. & Onondaga & NY & Sep-95 & Ogden Martin Sys. & Ogden Martin Sys. & 865 & 83013 & 311,646 & 990 & Elec. & 3 & 39 & 30 & DS/NOX/BH/Hg & TBD & Martin & Env. Elements \\
\hline Glendon RR Proj. & Glendon & PA & Jan-96 & Energetics-Glendon Inc. & Delmarva Operat Serv. & 750 & 7501 & 130,000 & 500 & Elec. & 2 & 14 & 12.5 & $D S / N O \times / B H / H g$ & FileyTak & Riley/Tak & $T B D$ \\
\hline West Pottsgrove R/RRF & Stowe & $P A$ & oct-95 & Whoelabrator Pottsgrove & Wheelabrator Pottsgrove & 900 & 850 & 336,000 & 1.500 & Elec. & 2 & 45 & 40 & DS/NOX/BH/Hg & Babcock \& Wilcox & Von Roll & Wheelabrator \\
\hline Wheelabrator-Falls ERF & Morrisville & $P A$ & May-94 & Wheelabrator-Falls & Wheelabrator-Falls & 900 & 8503 & 380,000 & 1,600 & Elec. & 2 & 50 & 45 & DS/NOX/BH/Hg & Babcock \& Wilcox & Von Roll & Wheelabrator \\
\hline Quonset Point RRF & N. Kingston & RI & Jan-96 & RI Solid Waste Mngt. Corp. & Ogden Martin & 650 & 6301 & 182,000 & 710 & Elec/St & 2 & 21 & 18 & $D S / B H$ & Distral & W\&E & TBD \\
\hline \multicolumn{2}{|c|}{ Johnston RRF (Central Ldfill) Johnston } & $\mathrm{Rl}$ & Jan-96 & RI Solid Waste Mngt. Corp. & Ogden Martin & 850 & 825 & 150,000 & 750 & Elec. & 2 & 21 & 17 & DSINOXIBH & TBD & Martin & TBD \\
\hline & & & & & & & & & & & - & & & & & & \\
\hline \multicolumn{18}{|c|}{ Mass-Burn-Modular Combustor } \\
\hline \multirow[t]{2}{*}{ Sangamon $\mathrm{Co}}$. & |liliopolis & IL & Jan-96 & Kirkby-Cotfman Inc. & Kirkby-Coffman Inc. & 600 & 575 & 90,000 & 450 & Elec. & 3 & 8 & 6 & DSINOX/BH & TBD & L. Bouillet & L. Bovillet \\
\hline & & & & & & & & & & & & & & & & & \\
\hline \multicolumn{18}{|c|}{ Mass-Burn-Rotary Combustors } \\
\hline Monroe Co. & Bloomington & IN & Jan-96 & Westinghouse & Westinghouse & 425 & 625 & 160,000 & 300 & Elec/St & 2 & 10.5 & 8.9 & DS/BH & TBD & Whouse/O'Conner & TRD \\
\hline \multirow{2}{*}{ Montgomery co. South } & Dayton & $\mathrm{OH}$ & $\operatorname{Jan}-96$ & Montgomery Co. & Montgomery $\mathrm{Ca}$. & 500 & $650]$ & 240,000 & 900 & Elec. & 3 & 18.6 & 17.7 & ESPIDS & Comb. Engg. & Montenay $\mathrm{Co}_{0}$ & Utd. McGill \\
\hline & & & & & & & & & & & & & & & & & \\
\hline \multicolumn{18}{|c|}{ RDF-Fired Units with Suspension or Grate Burning } \\
\hline W. Suburban R\&EC & Summit & IL & Jan-96 & W. Sub. R/EC inc. & Kirby-Coffman Inc. & 850 & 825 & 393,000 & 1,400 & Elec. & 1 & 45 & 36 & DSINOX/BH & TBD & TBD & Flakt \\
\hline Petersburg (Utd. Bio-Fuel) & Petersburg & $v_{A}$ & Jan-96 & United Bio Fuel Indust. & United Bio Fuel Indust. & 750 & 700 & 250,000 & 700 & Elec. & -1 & 12 & 9 & ESPPB & Abco & Consumat & $T B D$ \\
\hline & & & & & & & & & & & & & & & & & \\
\hline & & & & & & & & & & & & & & & & & \\
\hline
\end{tabular}




\section{REPORT DOCUMENTATION PAGE}

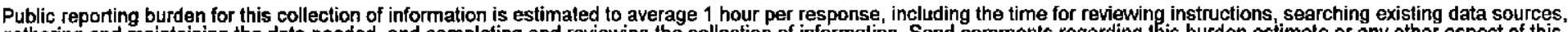

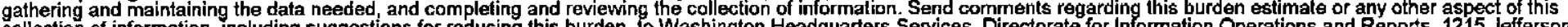

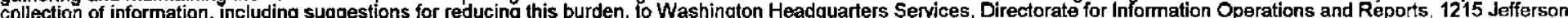
Davis Highway, Suite 1204, Arlington, $Y A$ 22202-4302, and to the Office of Management and Budget, Paperwork Reduction Project (0704-0188), Washington, $D C$ 20503.

\begin{tabular}{|l|c|l}
\hline $\begin{array}{l}\text { 1. AGENCY USE ONLY (Leave } \\
\text { blank) }\end{array}$ & $\begin{array}{c}\text { 2. REPORT DATE } \\
\text { April } 1994\end{array}$ & $\begin{array}{l}\text { 3. REPORT TYPE AND DATES COVERED } \\
\text { Final subcontract report } \\
\text { Technical Report }\end{array}$ \\
\hline
\end{tabular}

4. TITLE AND SUBTITLE

Assessment of factors affecting boiler tube lifetime in waste-fired generators: New opportunities for research and technology development

5. FUNDING NUMBERS

6. AUTHOR(S)

lan G. Wright and H.H. Krause

7. PERFORMING ORGANIZATION NAME(S) AND ADDRESS(ES)

Battelle Laboratory ORGANIZATION REPORT

505 King Street

Columbus, Ohio 43201

WM51.1010

9. SPONSORING/MONITORING AGENCY NAME(S) AND ADDRESS(ES)

10.

Natonal Renewable Energy Laboratory

SPONSORING/MONITORING

1617 Cole Boulevard

Golden, Colorado 80401

AGENCY REPORT NUMBER

NREL/TP $-430-21480$

\section{SUPPLEMENTARY NOTES}

NREL Technical monitor. Philip Shepherd (303) 275-2929

\section{2a. DISTRIBUTION/AVAILABILITY STATEMENT}

National Technical Information Service

U.S. Department of Commerce

5285 Port Royal Road

Springfield, VA 22161 12b. DISTRIBUTION CODE

UC. Category: 1414

13. ABSTRACT (Maximum 200 words)

This study assessed corrosion and erosion of metal boiler tubes in waste-fired steam generators, and identified research and technology development that could best improve boiler tube performance. Corrosion is caused by deposits that contain alkali, chlorine, and heavy metals, and by the heterogeneous nature of the fuel that may result in incomplete combustion, high CO levels or high heat flux from flame impingement. More efficient plants must operate at higher temperatures than 400 degrees $C$, previously considered the highest temperature at which corrosion could be controlled. Avoiding corrosion in the furnace zone requires that combusion be completed in the lower furnace. The cost of furnace downtime to repair manageable corrosion is estimated to be at least $1.1 \%$ of operating maintenance costs.

14. SUBJECT TERMS

waste-fired steam generators, boiler tube lifetime, metal corrosion in waste-fired generators

15. NUMBER OF PAGES

16. PRICE CODE

19. SECURITY

CLASSIFICATION

OF ABSTRACT
20. LIMITATION OF ABSTRACT

\section{SECURITY LASSIFICATION \\ OF REPORT}

\author{
18. SECURITY \\ OF THIS PAGE
}

Standard Form 298 (Rev. 2-89) Prescribed by ANSI Std. Z39-18 